University of Wollongong

Research Online

Faculty of Engineering and Information

Faculty of Engineering and Information

Sciences - Papers: Part B

Sciences

2019

Improved Performance of Ballasted Tracks at Transition Zones: A Review of Experimental and Modelling Approaches

Buddhima Indraratna

University of Wollongong, indra@uow.edu.au

Muhammad Babar Sajjad

University of Wollongong, mbs661@uowmail.edu.au

Ngoc Trung Ngo

University of Wollongong, trung@uow.edu.au

A Correia

University of Minho

Richard B. Kelly

SMEC-Member of the Surbana Jurong Group

Follow this and additional works at: https://ro.uow.edu.au/eispapers1

Part of the Engineering Commons, and the Science and Technology Studies Commons

Research Online is the open access institutional repository for the University of Wollongong. For further information contact the UOW Library: research-pubs@uow.edu.au 


\title{
Improved Performance of Ballasted Tracks at Transition Zones: A Review of Experimental and Modelling Approaches
}

\begin{abstract}
Track transitionssuch as bridge approaches, road crossings and shifts from slab track to ballasted track are common locations wheretrack degradation accelerates due to dynamic and high impact forces; as a consequence there is higher differential settlement. Thesetypes of discontinuities cause an abrupt change in the structural responseof the track due mainly tovariations in stiffness and track damping. Track transitionzones are prone to an accelerated deterioration of track material and geometrythat leads to increased maintenance costs. Track deteriorationalso leads to vehicle degradation due to enhanced acceleration, low frequency oscillation, and high frequency vibrations. While ballastdeterioration is amajor factor affecting thestability and longevity of rail tracks, the cost of tackling transitionrelatedproblems that detract from passenger comfort is also high.A good transition zone lessens the impact of dynamic load of moving trains by minimising theabrupt variations in track stiffnessand ensuring asmooth and gradual change from a less stiff (ballasted track)to a stiff (slabtrack) structure. This paper presents a critical review of various problems associated with transition zones and the measures adopted to mitigate them; it also includes critical review of research work carried out using large-scale laboratory testing, mathematical and computational modelling and field measurements on track transition zones.
\end{abstract}

\section{Keywords}

ballasted, tracks, transition, review, experimental, zones:, modelling, approaches, improved, performance

\section{Disciplines}

Engineering | Science and Technology Studies

\section{Publication Details}

Indraratna, B., Sajjad, M., Ngo, T., Correia, A. Gomes. \& Kelly, R. (2019). Improved Performance of Ballasted Tracks at Transition Zones: A Review of Experimental and Modelling Approaches. Transportation Geotechnics, 21 100260-1-100260-25. 
Authors: Buddhima Indraratna ${ }^{1}$, Muhammad Babar Sajjad ${ }^{2}$, Trung Ngo $^{3}$, António Gomes Correia ${ }^{4}$,

Richard Kelly ${ }^{5}$

${ }^{I}$ Distinguished Professor in Civil Engineering, Research director: Centre for Geomechanics and Railway Engineering, ARC Training Centre for Advanced Technologies in Rail Track Infrastructure (ITTC-Rail), Faculty of Engineering and Information Sciences, University of Wollongong Australia, Wollongong, NSW 2522. Email: indra@uow.edu.au (corresponding author)

${ }^{2}$ PhD candidate: ARC Training Centre for Advanced Technologies in Rail Track Infrastructure (ITTC-Rail), University of Wollongong Australia, Wollongong, NSW 2522. Email: mbs661@uowmail.edu.au

${ }^{3}$ Research Fellow: ARC Training Centre for Advanced Technologies in Rail Track Infrastructure (ITTC-Rail), University of Wollongong Australia, Wollongong, NSW 2522. Email: trung@uow.edu.au

${ }^{4}$ Professor in Civil Engineering, ISISE, Vice-Dean: School of Engineering, University of Minho. Email: agc@civil.uminho.pt

${ }^{5}$ Chief Technical Principal at SMEC (Member of the Surbana Jurong Group): Email: DrRichard.Kelly@ smec.com

Abstract: Track transitions such as bridge approaches, road crossings and shifts from slab track to ballasted track are common locations where track degradation accelerates due to dynamic and high impact forces; as a consequence there is higher differential settlement. These types of discontinuities cause an abrupt change in the structural response of the track due mainly to variations in stiffness and track damping. Track transition zones are prone to an accelerated deterioration of track material and geometry that leads to increased maintenance costs. Track deterioration also leads to vehicle degradation due to enhanced acceleration, low frequency oscillation, and high frequency vibrations. While ballast deterioration is a major factor affecting the stability and longevity of rail tracks, the cost of tackling transition related problems that detract from passenger comfort is also high. A good transition zone lessens the impact of dynamic load of moving trains by minimising the abrupt variations in track stiffness and ensuring a smooth and gradual change from a less stiff (ballasted track) to a stiff (slab track) structure. This paper presents a critical review of various problems associated with transition zones and the measures adopted to mitigate them; it also includes critical review of research work carried out using large-scale laboratory testing, mathematical and computational modelling and field measurements on track transition zones.

Keywords: Transition zone, Ballasted track, Bridge deck, Transportation geotechnics, Modelling 


\section{Introduction}

Track or railway transitions are locations along the track characterized by the presence of an abrupt variation of their stiffness, such as rail tracks change from a stiff structure (slab track) to soft structure (ballasted track) or vice versa. They occur when a conventional track changes to slab track to cross a roadway, a waterway (canal, river, etc.), or valleys through bridges, culverts or level crossings. Such transitions can be due to a sudden change in track substructural components (as in the case of slab track to ballast track transitions, bridge approaches, etc.), track superstructural components (as at special trackwork, level crossings, tie types, etc.) or both [96]. Figure 1 provides some examples of track transitions as a result of sudden change in substructural components. Figure 1a shows two rail track transitions indicating a ballast track to slab track and a slab track to ballast track on both sides of Berry Bridge crossing Tannery road in NSW, Australia. In contrast, Figure 1b illustrates a ballast track to slab track transition with an obvious alignment error that is often a problem associated with such transitions. Figure 2 provides some examples of track transitions as a result of sudden change in the superstructural components. Figure 2a shows a single level crossing on a conventional track at Unanderra, NSW, Australia, whereas, Figure 2b illustrates several other types of such transitions that can generate extreme dynamic loadings attributed to associated gaps and discontinuities causing variations on the rail running surface [96].

Transitions create a sudden change in the structural properties of tracks due to variations in track stiffness, track damping and subgrade reactions. This abrupt change leads to differential settlements and increased dynamic loading that accelerates track degradation through the successive deterioration of track geometry and materials $[9,10,24,31,60,95,128]$. The sudden change in structural properties at track transition can have an adverse effect on the rail deflections, dynamic loads and track acceleration due to the moving wheel loads. This effect can be seen in Figure 3 that has been reproduced from the modelling data given in references [34] and [186]. Figure 3 illustrates how these values vary suddenly in a short length at the junction point of a ballasted and slab track, while loads move from the ballast track to the slab track. It has been suggested that such abrupt variation in track acceleration causes oscillations or vibrations that further cause destructive effects [186].If there is no proper intervention the wear and tear of track and vehicle components will increase as ride quality for all types of rail traffic will decrease, and this includes accelerated ballast degradation (breakage). The consequences will affect railway operations through restrictions in train speed, delays in train schedules, further passenger discomfort and higher maintenance costs $[10,31,56,95,97,127,137$, $159,188,194]$.

The cost of tackling problems associated with track transitions to maintain the smooth operation of 
railways is often very high [64, 137, 139], for instance the annual maintenance costs for track transitions is approximately 200 million dollars in the USA and 110 million dollars in Europe [64, 139, 162]. According to Nicks [120], US\$26 million per year is spent just repairing bridge related transitions, while in Spain; a major portion of their overall investment goes to track maintenance and infrastructure materials [137]. Previous studies also show that the cost of maintaining track transitions (at track discontinuities) is much higher (up to eight times) than normal conventional track [58, 79, $84,95,133,137,166,167]$.

Transition zones are provided at track junctions to alleviate the problems associated with structural discontinuities [56, 79, 133, 137, 194] and to mitigate the dynamic effect of moving loads through smooth and gradual stiffness transitions [4]. With the increasing demand for long and heavy haul trains to travel at fast speeds, crossing bridge decks, concrete culverts or tunnels with stiff foundations towards softer soils or very soft estuarine plains, the precise and economic design of transition zones is a challenge for designers and practising engineers.

This article reviews various aspects of railway transition zones by first defining a track transition and its importance with respect to the structural integrity of track catering for passenger and heavy haul trains (in introduction). Second, reviewing the various problems associated with track transition to identify their causes and consequences on railway operations, and third, investigating the multiple measures taken to minimise and mitigate these problems with reference to their limitations and effectiveness. The design and modelling of tracks at transition zones, including large-scale laboratory testing and prototype experiments, mathematical and computational modelling and field measurements is also discussed, and detailed comparisons of computational modelling and field measurements are also provided in tabular forms. The paper concludes with future research recommendations for improved track design.

\section{Problems of track transitions}

Major problems associated with railway transitions include (i) differential settlement, (ii) enhanced dynamic load, and (iii) accelerated track deterioration; these problems are summarised as follows.

Differential settlement (also referred to as geometric irregularity) is the result of uneven deformation on both sides of track transitions where sections of ballasted tracks undergo more settlement than the stiff side, such as a slab track on a bridge, which is normally designed for minimal settlement [48, 79, 137]. Field investigations mostly show the maximum deformations at any specific point under repeated train loading. This maximum deformation includes the elastic component (i.e. fully recoverable upon unloading)) as well as plastic deformations which remain irrecoverable and continue to accumulate over successive load applications. Usually this occurs within a very short time (e.g. in 120ms), where the deformation attains its maximum value and returns to the residual 
value [119]. Furthermore, the smaller values of differential settlement suggest the structural behaviour to be elastic, whereas the large differential settlements indicate plastic track response especially that of the substructural components [137]. It is also noted that some research based on computational modelling addresses the occurrence of transient deformations where the materials considered in the analysis are assumed fully elastic (i.e. small strain behaviour).

A detailed comparison of the differential settlement of various rail transitions is given in Figure 4. Figure $4 \mathrm{a}$ shows a sudden increase in vertical displacement [56, 57, 138, 189] when a slab track 111 changes to a ballast track, giving rise to differential settlement at this location. Figure $4 \mathrm{~b}$ compares 112 the field measurements of two studies [43, 97, 174] for vertical displacements on each side of a bridge 113 where the sudden variation in values is obvious. Figure $4 \mathrm{c}$ shows the increasing trend of rail 114 displacement along the approach zones towards bridges at three different sites that could be due to 115 hanging sleepers [172]. Figure 4d compares the vertical displacement at concrete culverts [25, 133] 116 where approach slabs have been provided on each side. In this specific Figure 4, the part (a) indicates 117 the elastic settlements that have been obtained by load application for a shorter duration, whereas (b), 118 (c) and (d) include the plastic deformations as well.

119 Differential settlement also leads to the development of dips, bumps and undulations near the junction 120 of tracks at transition zones, which is another source of passenger discomfort and increasing 121 maintenance costs [43, 45, 62, 84, 120]. Fara [43] calls the development of dips and bumps, "Jump 122 and Bump" and reports they can occur at both sides of a bridge at track transitions, as shown in Figure 123 5. While dips and bumps in railway and highway bridge approaches have been seen by various researchers $[16,100,120,187]$, in the USA, more than $50 \%$ of all bridge transitions face dip/bump problems, with average bumps being $33 \mathrm{~mm}$ high and $5.2 \mathrm{~m}$ long [120].

The amplification of dynamic loads at track transitions due to abrupt changes in the structural properties of tracks is another major problem associated with rail transitions. Sudden variations in stiffness and differential movement at track junctions often increase the dynamic force at track transition under vehicle loading [26, 50, 106, 123, 194]. Mishra et al. [106] measured wheel loads using strain gauges at two bridge approaches and found an increase of up to $100 \%$ or more in the dynamic force on top of sleepers at bridge approaches compared to ballasted tracks. They recorded both the plastic and elastic deformations of every individual substructural layer through multi-depth deflectometer systems, but they considered only the effect of elastic (transient) response for obtaining the wheel load. This could be due to poor sleeper support at the bridge approach section, which affects the dynamic response of train suspension [106]. Lei and Mao [91] showed that differential settlement at track transitions leads to higher dynamic forces at the wheel-rail interface than sudden changes in track stiffness; the results found in $[8,50,102]$ are similar. A detailed comparison of modelling result of enhanced dynamic loads in terms of wheel-rail interaction forces for various track transitions [92, 
120, 175, 189] is given in Figure 6; here the very high contact forces at the wheel rail interfaces within the transition zone area are a clear indication of enhanced load impact at the transition.

141 The differential settlement and dynamic load at a transition zone are directly connected, and any 142 increase in dynamic load would results in a corresponding increase in differential settlement, a 143 process that seems to be exacerbated when moving trains with increased axle loads and faster speeds 144 are involved $[8,45,46,50,62,64,92,103,139,194]$. The cycle of track transition problems and its 145 main components is drawn in Figure 7 (inspired by Paixão [122]). This figure illustrates the inter146 dependency of enhanced dynamic load and differential settlement and their relationship to track 147 degradation. If these problems are not addressed properly, they can lead to enhanced track 148 deterioration and increased maintenance costs [95, 107, 137]. Figure 7 also shows the various causes 149 of these problems and the probable consequences of not intervening properly; further details of these 150 causes and consequences are discussed in subsequent sections.

151 It is known that rail tracks deteriorate faster at transition zones than normal ballasted tracks [30, 95], 152 and this deterioration is triggered by the uneven settlement at rail transition zones which also increases 153 the track degradation process. Track degradation includes rail corrugation and wear, track level 154 irregularities, cracking sleepers, loosening ballast and rail fastenings, and hanging sleepers $[8,9,30$, $15589,91,110,128,173,189]$. Moreover, the ballast breakage and particle migration adjacent to the 156 sleeper may also lead to hanging or swinging sleepers due to increasing dynamic loads and differential 157 settlement at transitions [5, 25, 31, 48, 58, 64, 92, 95, 106, 120, 123, 133, 154, 162, 194]. According 158 to Pita et al. [127], track deterioration is mainly influenced by the performance of its components at 159 track transitions subjected to higher dynamic loads and the frequent movement of high-speed trains. 160 Track degradation also leads to vehicle degradation due to enhanced acceleration, low frequency 161 oscillation, and high frequency vibrations $[9,30,41,93,102,190]$.

\section{Major causes of track transition problems}

163 Uneven stiffness and damping between two different subgrade materials, the variation of moisture 164 and geotechnical causes are the primary sources of track degradation at any transition zone [79, 84, $16595,120]$. Gallage et al. [48] divided the causes of transition related problems into two categories: (i) 166 primary causes such as variations in stiffness and damping, geotechnical issues, subgrade failure, 167 excessive plastic deformation, progressive shear failure, soil water response, and wetting and 168 shrinking cycles, and (ii) secondary causes such as train loads and speed, traffic conditions, embankment heights and types of bridge abutments.

171 The abrupt variations in stiffness at track transition are the major reasons for track problems [22, 23, $17245,62,79,84,92,98,103,107,113]$. Figure 8 shows a typical example of variations in track stiffness 
where the total track stiffness $k_{o}$ (ballast track) suddenly changes to $k_{n}$ (slab track on a bridge deck); these sudden variations cause differential settlement and expedite track degradation [10, 31]. High values of track stiffness can also cause hanging sleepers as sleeper-ballast contact decreases and the gap between ballast and sleepers increases [25]. A detailed comparison of variations in track stiffness/modulus at various sites is given in Figure 9. Figure 9a shows the sudden variations in track modulus on both sides of the bridge [133], whereas Figure 9b shows how the track modulus/stiffness increases when a track changes from being less stiff to stiffer [54, 120, 166]. Note that stiff tracks such as bridges have higher modulus values than tracks that are not as stiff.

Stiffer tracks can reduce track settlement and increase longevity but they are vulnerable to track deterioration because the stiffness increases the contact forces between wheel and rail and at sleeperballast interfaces that could increase dynamic pressures acting on track substructure [10, 24, 98]. Track stiffness is defined as the load needed to produce a unit deflection in track and is denoted by $k$, $(\mathrm{kN} / \mathrm{mm})$; it can be static (remains constant) or dynamic (depending on the load and excitation frequency) [131, 137]. Track modulus is sometimes used instead of track stiffness because it can be defined as the load to produce a unit deflection per unit length of rail [133]. The value of track stiffness depends on the type of material and height of track embankments [51]. Figure 10 shows the track stiffness at various locations on a west coast line in Sweden; note that the track on a pile-deck bridge is almost twice as stiff as the normal track. The influence that sub-ground (formation soils) has on track stiffness is also evident, hence the rapid change in stiffness for various types of track [30].

Ballast degradation at track transitions is one of the main causes of progressive track deterioration [72, 79, 95]. This degradation occurs as ballast deforms due to volumetric compaction (ballast compaction and particle breakage) and frictional sliding (lateral movement of ballast particles under sleepers) mechanisms $[25,29,70,78,140,144,158,164,174]$. There is always more ballast degradation on the ballasted track side due to ballast fouling (contamination by fines), plastic deformation, chemical actions, and variations in moisture and temperature [22, 66, 154, 175, 194]. However, no such degradation occurs on a slab track [4]. Because of this, the subsequent differential settlement does increase the dynamic loads and ballast stresses at transition zones [107, 137]. These sudden variations of induced stresses on ballast aggregates continually increases the rate of ballast degradation. A comparison of the various ballast pressure/stresses for different track transitions [120, 171, 174] is given in Figure 11. This figure shows that the amplitude of ballast stresses suddenly changes at the bridge abutments on both sides, thus indicating the abrupt variation in measured stresses at these locations where the stiffness is greater.

Since the settlement of the capping and subgrade layers is mostly permanent (i.e. plastic deformation) it does contribute to problems such as hanging sleepers at transition zones because the vertical movement of ballast particles that leads to differential settlement and enhanced dynamic loads [85, 
107, 109, 137, 162]. Impeded track drainage and poor compaction of low quality backfill materials, as well as limited accessibility beside these structures, can also accelerate subgrade settlement [95,

$210120,130,137]$. A detailed study on the settlement of subgrade under heavy axle loads can be found 211 in [94].

212 Sudden variations in track damping characteristics plays an important role in the development of 213 differential settlements at track transitions [107] and also defines dynamic interaction at the wheel214 track interface [24, 40], which is why damping of track components at transition zones influences the 215 vehicle-track-subgrade dynamic response and helps to reduce track vibrations [90, 149]. Track 216 damping helps to dissipate the energy produced by large dynamic loads from fast moving vehicles, 217 whereas a sudden change from a highly damped track (track on an embankment) to a low damped 218 track (slab track on a bridge deck) can cause damage from wheel impact (due to surface deterioration) 219 or wheel bounce (due to variations in stiffness) phenomena. The energy imparted onto embankment tracks can be dissipated through its structural components and the subgrade and surrounding ground, and while the ballast layer in a ballasted-deck bridge track will dissipate some of the energy and most of it will still reach the bridge structures [139].

\section{Mitigation measures to track transition problems}

A good transition zone must be able to minimise the impact of dynamic loads applied by moving trains. Different approaches for providing a smooth and gradual transition have been proposed and implemented through laboratory experiments, model testing, field investigations and mathematical and numerical modelling; they are reviewed and discussed in the following sections.

Transition wedges are widely used to smooth the tracks at transition areas; these wedge shaped backfills are combinations of cement bond granular materials (CBM), unbound granular material (UGM), graded gravels with some percentage of cement, simple graded gravels, and well graded coarse grained soils $[25,44,59,79,95,125,126]$. When this system is used at bridge approaches, there is an immediate improvement in the dynamic response of the overall track system under moving train loads [147]. This technique focuses mainly on selecting materials with a variety of characteristics (type, modulus, stiffness, cementation, among others) for the transition wedge and its geometry (thickness, slope, layer distribution, among others) so there is a gradual transition from soft to stiff material in the transition zones. Recommendations for such selections based on variations from soft to stiff, and even from sleeper to sleeper, can be found in [50]. At present there is no universal standard for the design of a transition wedge, so different countries choose their own set of parameters. A comparison of various transition wedges, including their material configurations and geometric shapes that are used in different countries, is described in [44]. 
track stiffness at transition zones; in this approach the length, width and height of sleepers gradually

243 increase, while the spacing between them gradually decreases when track structures proceed from 244 being less stiff to more stiff $[112,113,133]$. Larger sleepers have proven to be good at mitigating 245 ballast settlement and contact pressure between ballast and sleepers [113, 147], but not as good at 246 reducing the dynamic load factor [120]. Unlike maintaining the uniformity and compaction of ballast, 247 this approach to mitigation does not help to increase track stiffness, but it may reduce vertical 248 displacement and induced stresses by distributing train loads over wider areas [137].

249 Sleepers made from composite, plastic, or rubber materials can be used at the transition zone [113, $250133,139]$. Rubber sleepers that can adjust the sleeper/ballast stiffness are better at reducing the ballast 251 vibration of high speed railway lines [113]. Frame sleepers, where every two sleepers are connected 252 by additional supports to distribute the load over a wider area can also be used in the transition zone 253 [3]. Nicks [120] studied the effect that three different sleepers (wooden, concrete and plastic) had on 254 the dynamic response of bridge approaches in dip and bump cases and found that wooden sleepers 255 will help to mitigate the bumps and dips better than the other materials.

Rail pads have recently been used to reduce the vibration and noise from impact loads under train movements and improve the damping properties of track substructure [30, 133, 152]. According to Namura and Suzuki [113], installing softer rail pads on the stiffer side of track transitions makes the rider smoother; studies into the use of soft pads on the stiff side of transitions can be found in [56,

260 166] and studies on the use of rubber pads that are as stiff as the bridge approaches is given in [83]. 261 Note that thermoplastic elastomer rail pads/seat plates that are used in railway maintenance works are temperature dependent, so this property must be considered in design practice [20]. The temperaturedependency of static stiffness of various types of rail pads can be found in [176], where a nonlinear variation of static stiffness of rail pads was observed with temperature ranging from $-40^{\circ} \mathrm{C}$ to $70^{\circ} \mathrm{C}$.

Under sleeper pads (USPs) are increasingly being used to mitigate the problems associated with transition zones because they actually reduce ballast degradation, enabling the stiffness on the stiffer side (concrete deck) to match the softer (ballasted track) side, and minimise the dynamic load impact $[2,30,76,112,115,120,152,166]$. However, placing USPs on ballasted track at bridge approaches may not be that effective in reducing the stiffness variation, as it makes the softer side of the bridge transition even softer [120]; however, it can reduce the ballast stresses significantly due to the increase in sleeper-ballast contacts leading to reduced ballast degradation [115]. The use of resilient material mats (rubber mats) under slab track has proven to reduce track vibration [52]. A summary of the various effects of under sleeper pads can be found in $[102,178]$, and a detailed investigation for their effectiveness through laboratory experiments and numerical simulations can be found in $[80,115]$. 
section of the transition zone will help to distribute the dynamic loads evenly $[34,56,84,113,133]$; one example of this is where guard rails are extended from the bridge abutments to the bridge approaches [133]. This technique helps to improve the bending stiffness of the track and reduce ballast stresses by distributing the load to the sleepers [147]. According to Shahraki et al. [147], auxiliary rails improve the dynamic response of track by providing a smooth transition over the sudden changes in stiffness. In some cases, auxiliary rails may not be as good at reducing the dynamic response compared to some other mitigation approaches, so proper consideration should be given to its benefitcost ratio before making a final selection $[133,148]$. However, two extra rails along the transition zone are the optimum number of rails needed to decrease rail deflections [56].

In some cases, concrete confinement walls (wing walls) are installed along the approaches to reduce ballast loosening [133, 177]; these walls increase the lateral confinement on ballast and thus reduce the problems associated with track deformation; these walls also confine the subgrade layers and further decrease track settlement [177]. However, there may be a large increase in track modulus due to increased confinement and associated ballast breakage and this must be considered during design [137]. Apart from wing walls, Nicks [120] installed steel bars of varying lengths between sleepers into the subgrade to increase the confinement and strength of ballast; this approach is much better at reducing subgrade stress and the track deflection, and ultimately mitigating the development of dips.

While increasing the thickness of ballast and sub-ballast (capping) at transition zones will enhance track performance, it might also cause excessive track settlement $[90,94,95]$. However, if there are bumps in the track, increasing the thickness of ballast at the bridge approaches is the best approach because the extra depth helps to attenuate stress and reduce the deviatoric stresses applied on the substructural layers [120, 141]. Moreover, increasing the ballast thickness also increases the track modulus; Selig and Li [143] report an increase in the track modulus from $24 \mathrm{MPa}$ to $34 \mathrm{MPa}$ after increasing the ballast from $0.3 \mathrm{~m}$ to $1.07 \mathrm{~m}$ thick.

The use of resin and polyurethane compound to glue ballast aggregates to reduce track settlement [55, 82, 113, 180-183] has been tested. In fact according to Kennedy et al. [82], an almost 99\% reduction in permanent settlement can be achieved with polymer treated tracks because a ballast track performs almost the same as a slab track. Similarly, reinforcing ballast with 3D polyurethane and 3D polymer not only improves the efficiency and safety of a railway track, it also helps to reduce the cost of track maintenance [180, 181]. However, Stanislav et al. [153] while investigating the effectiveness of expanding polyurethane resin at bridge transition zone, found no improvement in track dynamic performance. While there is no convincing evidence to indicate the life-span of this polymeric material and its resistance to harsh track environments including UV damage, this method also raises the question about the benefits of highly angular ballast particles (i.e. intrinsic friction in the microscale) that may be subdued by bonding of particles. 
Approach slabs (submerged approach structure) are often used on both sides of buried structures such

312 as viaducts, culverts or bridges to reduce the high impact loads associated with sudden changes in 313 track stiffness [19, 26, 114, 139, 165, 167]. It is a common practice in European railways to have 314 concrete slab transitions (both horizontal and inclined) between a ballasted track and a concrete 315 culvert to provide a smooth transition [25]. However, the recent research by Coelho et al. [26] shows 316 that track on an approach slab has about four and eight times higher vertical displacements than on 317 an embankment or culvert, respectively. It is reported that these higher displacements could be due 318 to hanging sleepers on the approach slab and the tracks rocking under train movement due to a 319 pivoting action around the edges of the stiff culverts, all of which leads to high impact loading.

320 Placing a layer of hot mix asphalt (HMA) under ballast to improve its performance is another proven 321 mitigation technique for transition zones [86, 95, 133, 155, 177]. When an HMA layer is placed under 322 ballast and protected from the effects of climate it can increase the life of the track substructure and 323 enhance track performance by reducing stress at the ballast/capping interface and reduce the 324 maintenance cycles [135]. Moreover, since HMA is impervious, it prevents water from seeping into 325 the underlying subgrade layer [95], so the drainage capacity of tracks increases. An HMA layer may 326 also help to strengthen the substructure layer by improving its load bearing capacity and further 327 reducing the stresses acting on the subgrade [142].

328 Improving the load bearing capacity of track embankments with soil treatment such as grouting, 329 dynamic compaction, soil cement, geosynthetics, geocells, cement gravels, etc., has been widely 330 adopted [95, 130, 137, 153]. Using geocells (honeycomb structure) within the sub-ballast (capping) 331 layer will help to improve track performance by increasing the stiffness of infilled aggregates [94]. A 332 variety of mitigation techniques commonly used at transition zones, especially bridge approaches, to 333 improve the embankment soil can be found in [79, 129, 130, 153]; they can be divided into three 334 categories: (i) Mechanical (excavation and replacement, preloading and surcharge, dynamic 335 compaction), (ii) Hydraulic (sand drains, prefabricated drains, surcharge loading), and (iii) 336 Reinforcement (columns, stone and lime columns, geo-piers, concrete injected columns, deep soil 337 mixing columns, deep foundations, in-situ: compacted piles, continuous flight auger cast piles, driven 338 piles: timber and concrete piles, geosynthetics, geotextiles / geogrids, geocells).

339 Improving the foundation of track embankments using piles made from reinforced concrete, steel, 340 gravel, timber, sand column, and stone column, etc., can be very helpful in mitigating transition zone 341 problems by increasing track stiffness and reducing settlement on the softer side of the transition [88, $342137,146,168,179]$. However, this solution may not be cost effective because it depends mainly on 343 the length of the piles and the material used [133]. The effectiveness of piles at a transition zone can 344 be enhanced by arranging them in a proper pattern, and by varying their lengths depending on whether 345 the structures are soft or stiff, as shown in [86]; the length of any transition zone can be optimised 
by these arrangements.

347 Other mitigation measures may include lightweight fills [101, 130, 146], precast prestressed crossings 348 (PPC) [113], increasing the length of the stiffness transition zone [137] and improving the treatment 349 of subbase materials [139]. The use of lightweight fills (expanded polystyrene, geofoam lightweight 350 concrete or aggregate, among others) at transition zones (i.e. bridge approaches) reduces the dead 351 weight (self-weight load) of embankments, which further increases their stability and reduces track settlement $[101,130,146]$. Although this approach has been widely used for the approaches to highway bridges, it can also be used for railways provided that the selected material is suitable (i.e. high stiffness, strength, compressibility, etc.) [130]. Similarly, precast prestressed crossings (PPC), which are approximately $1 \mathrm{~m}$ long concrete blocks with larger sleepers or rubber sleepers at each ends towards the ballast track, have also been used for level crossings [113].

For a smooth and gradual transition, more than one mitigation approach can be used to improve track performance [137]. For example, the cost of maintenance has been reduced considerably using sleepers of varying lengths, and transition slabs [133]. A combination of auxiliary rail, pads with varying stiffness, and geo-grids have been used by Kang et al. [81], and no abnormal response was observed. Similarly, longer rubber sleepers result in a larger base plane which, through the fastening system, also helps to avoid loose sleepers; this has proven to be the best countermeasure against differential settlement used by Namura and Suzuki [113].

Some countermeasures are better at fulfilling the desired function while others are either partly effective or completely unsuccessful; for example, according to Read and Li [133], pads under rails and slab is the best way to reduce structural stiffness, whereas Seara and Correia [142] and Read and $\mathrm{Li}$ [133] indicate that longer sleepers with a reduced spacing in the transition zones do not increase structural stiffness. However, a Hot Mix Asphalt (HMA) layer definitely improves the load-bearing capacity and reduces the stress in subgrade [142], but it does not improve the behaviour of ballast on rigid pavements [83, 133].

\section{Research into track transition zones}

Along with the ever-increasing demand for high-speed passenger and heavy haul freight trains goes the increasing need to design transition zones that deliver smooth and gradual changes of track stiffness at track junctions. In this regard, rail tracks have undergone dynamic analysis to better understand the response of track at transition zones under moving loads, as well as the associated track problems and possible countermeasures. This dynamic analysis of railway track transition zones sets out to understand how traffic loads affect track components in terms of stresses, strains and deformation using established theories on the interaction between vehicle components and the track. These models are powerful enough to predict the performance of track structure as well as making 
designs safe and economical [156].

381 According to Esveld [39], dynamic analysis is the interaction between an applied load and the

382 structure where the structural components react according to their inherent frequencies (governed by 383 mass elastic properties) to the applied load and large amplifications occur when the frequencies of 384 these structural components become equal to their natural frequencies. With transition zones, the 385 properties of components such as track damping and stiffness, rail modulus and inertia, train loads, 386 etc., will vary in time and space, whereas the effect of train load on track components depends on the 387 type (static, dynamic, cyclic, etc.), and velocity in which it is being applied. Other factors that must 388 also be considered in track dynamic analysis are the mass (providing resistance to geometric changes 389 under applied loading), inertia (proving resistance against velocity), damping (energy absorption) 390 characteristics, stiffness (providing resistance to deflection), and the mechanical and geometric 391 properties of track components [156].

392 A concise review of ongoing research into the dynamic analysis of tracks at transition zones via 393 laboratory experiments, mathematical and computational modelling, and field investigations is 394 presented and discussed in the following sections.

\subsection{Laboratory testing and prototype modelling}

396 A number of laboratory experiments on rail track and track components to investigate the properties 397 and performance of different materials/components under various situations have been carried out 398 worldwide, and an extensive number of outcomes in the field of railway engineering have been 399 published by various researchers $[35-37,63,69,73,75,80,99,116,118]$.

400 However, very little work has been carried out in laboratories to model transition zones due to 401 limitations of size and composition. Momoya et al. [111] performed some laboratory experiments on 402 railway track transitions between ballasted embankments and the concrete box culverts. This model 403 was a $1 / 5^{\text {th }}$ scale model of a transition onto which a moving load was applied onto rail sleepers by 404 electric-hydraulic actuators to simulate an actual load from a 10-car train with four axles each. The 405 four models tested were (a) without any buffering, (b) with an approach block, (c) with an approach 406 slab, and (d) with a resilient mat. Results were based on track settlement, the hanging sleeper 407 phenomenon, deformation of the ballast layer, and the relationship between the mobilised friction 408 angle and ballast settlement. The conclusion of this extensive laboratory study was that the 409 countermeasures are expected to reduce any large local settlement and an approach block will reduce 410 settlement by almost one half.

411 Likewise, Namura and Suzuki [113] performed the cyclic loading tests on a $1 / 5^{\text {th }}$ scale model to 412 evaluate the effectiveness of precast prestressed crossing (PPC). The model represents the transition 
413 between ballast track (consisting of sleeper, ballast and subgrade) and the slab track (consisting of 414 concrete block and subgrade). Train loading was simulated by movement loading device with 15 415 actuators (nine on ballasted track and six on PPC) considering the loading pattern of single wheel 416 load running cyclically at a speed of $1.2 \mathrm{~m} / \mathrm{s}$. Track dynamic analysis was carried out to investigate 417 the effect of rail fastening system on the reaction forces and vertical displacements. With no rail 418 fastening system, loose sleepers were observed on the ballasted track side soon after track 419 maintenance by tamping (i.e. after 1000 passes of movement loading), however, no such loose 420 sleepers were occurred even after 20000 passes of movement loading in case of rail fastening 421 provision. It was concluded that the rail fastening system provides a better alignment to longitudinal irregularities, which minimises the disturbance of ballast components caused by tamping work.

\subsection{Mathematical modelling approach}

There have been a number of researchers used the theory of beams on elastic foundations (BOEF) to model railway tracks and transitions $[28,33,47,81,145,185]$. This theory is based mainly on EulerBernoulli beam (rail of infinite length) or Timoshenko beam resting on a Winkler foundation. The mathematical framework for the motion of a track built on a viscoelastic foundation using this theory can be found in [28]. Previous studies [34, 56, 95, 107, 126, 165] used the Euler-Bernoulli to model a transition zone, while some researchers used a Timoshenko beam to consider transverse shear deformation and beam vibration theory [4, 59, 113]. However, after comparing these two conventional approaches for various cases, Czyczula et al. [28] concluded that if either monotonic or moving loads are considered, the results through the Timoshenko beam are almost the same as the Euler- Bernoulli beam. A detailed comparison of deflection of rail beams predicted by different theories subjected to varying train speeds can be found in [28].

The use of BOEF theory to analyses the dynamic response of railway substructure has several limitations. First, a foundation with distributed Winkler springs for soil reactions only gives approximate results if the speed of a moving load (train speed) is less than the critical velocity [166]; second, a Winkler springs foundation assumes there is no deformation of the adjacent soil elements, which does not always represent an actual rail track embankment [169]; third, granular materials (ballast, sub-ballast) under track substructure do not exhibit tension, whereas springs have some tension [169]; fourth, this approach does not consider the interaction between train and track while representing the train loading by a constant moving load [166, 169]. Moreover, the load-deformation response of track is frequently been assumed to be linear [120], whereas a highly non-linear response of ballasted tracks under dynamic loading often occurs, especially in stage-1 (rapid) settlement [29, $65,66,70,140]$.

In spite of lacking of a comprehensive model to predict the actual response of rail track while 
considering the complex nature of track substructure [156], the BOEF model has been used extensively in practice, albeit using an analytical approach to solve the dynamic response of tracks at transition zones is limited because the problem of sudden changes in track stiffness is complex. Walker and Indraratna [169] recently used a semi-analytical approach to solve the moving loads at transition zones; this model considers a Euler-Bernoulli beam (pinned) of finite length on viscoelastic foundations and the approach considers the spatial variation of rail characteristics (i.e. damping, mass, bending stiffness and cross-sectional area) as well as track stiffness and damping. The governing equation for a moving load used in this study is given as:

$$
\frac{E I \partial^{4} w}{\partial x^{4}}+\frac{\rho A \partial^{2} w}{\partial t^{2}}+c \frac{\partial w}{\partial t}+k w=-F \delta(x-v t)
$$

where, $E=$ modulus of elasticity $\left(\mathrm{N} / \mathrm{m}^{2}\right), I=$ second moment of area $\left(\mathrm{m}^{4}\right), \rho=$ rail density $\left(\mathrm{kg} / \mathrm{m}^{3}\right), A$ $=$ cross sectional area $\left(\mathrm{m}^{2}\right), k=$ track stiffness $(\mathrm{kN} / \mathrm{m}), c=$ damping $\left(\mathrm{Ns} / \mathrm{m}^{2}\right), w=$ track deflection $(\mathrm{mm}), F=$ dynamic load $(\mathrm{kN}), v=$ train speed $(\mathrm{m} / \mathrm{s})$ and $\delta=$ Dirac-delta function

Equation 1 is solved for normalised track displacement $(w)$, using the semi-analytical spectral Galerkin method that assumes ' $n$ ' terms truncated series. A general transition from soft (low stiffness value, $k_{1}$ ) to stiff track (higher stiffness value, $k_{2}$ ) over a given transition length $\left(L_{t}\right)$ is investigated under single and multiple moving loads. The differential settlements are simulated by comparing the deflections on each side of the transition. The deflection amplification factor $\left(D A F_{w r t 1}\right)$, is calculated using Eq.2, which considers various speed ratios $\left(\alpha=v / v_{c r}\right)$, damping ratios $\left(\beta=c / c_{c r}\right)$, and stiffness ratios $\left(k_{1} / k_{2}\right)$; these ratios can be determined as:

$$
\begin{aligned}
D A F_{w r t 1} & =\left(\frac{k_{1}}{k_{2}}\right)^{3 / 4} \times D A F_{2} \\
\frac{\alpha_{2}}{\alpha_{1}} & =\left(\frac{k_{1}}{k_{2}}\right)^{1 / 4} \\
\frac{\beta_{2}}{\beta_{1}} & =\left(\frac{k_{1}}{k_{2}}\right)^{1 / 2}
\end{aligned}
$$

To find an optimum length for a transition zone, Walker and Indraratna [169] examined the beam deflection of various transition length ratios with a characteristic length $\left(L_{c}\right)$, as described in Eq.5; they concluded that the minimum transition length should be 8-10 times of system's characteristic length $\left(L_{c}\right)$ to avoid stiffness transition deflection spikes. One of the main outcomes of this study is how valid the conventional theory of BOEF is for long transitions with gradual changes in stiffness; the conclusion is that the dynamic response of transition zones can be described adequately with this theory. Furthermore, the presented model is validated by comparing the results of maximum 
displacement at the transition zone with field data, as shown in Figure 12; this took place using a case study by simulating the actual variations, further details can be found in [169]. This figure shows that as the distance from the abutment increases, track stiffness decreases and peak displacement increases. This figure also indicates the abrupt variation in track stiffness and displacement at the junction between the bridge approach and the abutment.

$$
L_{c}=\sqrt[1 / 4]{\frac{4 E I}{k}}
$$

Mass spring-dashpot models have been used in previous studies to model a multilayer track system [11, 32, 56, 149]. Sometimes these models are simplified by using over-all track stiffness and damping values by combining the values of all structural components and layers, as suggested in [10]. To understand the nature of the transition between a ballast track and a slab track, a simplified mass spring-dashpot model can be developed, as shown in Figure 13. In this model, the total stiffness of the track is represented by the "spring" with spring constants $k_{b}$ and $k_{s}$ for ballast track and slab track respectively, while damping of the track structure is represented as dashpots. However, to study the effect of every individual track supporting layer, full layered models can be used because they simulate all the supporting layers and also incorporate the additional elements for USPs, elastic and soft pads, geogrid, geotextile, and polystyrene, among others [39, 42, 90, 126, 139].

Varandas [166] presented a linear mathematical model for the response analysis of inhomogeneous foundation using the two-layer mass spring-dashpot system shown in Figure 14. In this model two Euler-Bernoulli beams, one for the rail and another for the concrete slab are linked together by viscoelastic elements to represent rail pads of fill material. The whole system is supported by soil represented by a visco-elastic foundation. The stiffness of the upper and lower visco-elastic elements is assumed to change abruptly at the $x=0$ section from $K_{11}$ and $K_{21}$ to $K_{12}$ and $K_{22}$ respectively. The vertical displacements are defined as $U_{i j}(x, t)$, as mentioned in Figure 14, and are calculated using the dynamic equilibrium equations for forced vibration of beams by considering the load is acting on the left side. The governing equations for the model are given in Appendix A. This mathematical model considers an inhomogeneous foundation so it can be applied to rail transitions for a dynamic response analyse under train moving loads; it can also be utilised for the design of transition zones but it would require extensive calculations that may not be solved analytically.

\subsection{Computational modelling approach}

The numerical modelling approach is increasingly being used to simulate rail using fully calibrated numerical models of track transitions under various loading and boundary conditions [12, 56, 184]. Various countermeasures have been modelled and analysed using FEM (finite element method) or 
DEM (discrete element method). In addition to the extensive use of FEM in rail track modelling

510 (Table 1), the DEM has also been increasingly used to study the micromechanical behaviour of 511 railway ballast because it can capture the discrete nature of particulate materials [14, 132, 161]. 512 Furthermore, it is capable of examining the mechanical behaviour of granular assembly of arbitrarily 513 shaped discrete particles under quasi-static and dynamic conditions [61, 105, 117, 192]. A 514 comparison of several numerical and analytical models used to evaluate the dynamic response of 515 railway tracks under moving train loads can be seen in $[64,156]$. Numerical modelling through proper 516 calibration and field validation is an appropriate tool to predict the dynamic response of any transition 517 zone with various design options, remedial measures, train speeds and loads. A detailed comparison 518 of several computational models of transition zones is given in Table 1.

519 One of the benefits of computational modelling is that a single model can be utilised to work out 520 multiple design options for a specific transition. For example, Sañudo et al. [136] placed sleepers at 521 six different locations using 2D FEM modelling and investigated the dynamic response of track in 522 each case to optimise the overall design. Likewise, in [174], a 3D FE model is used to analyse the 523 dynamic response of track transitions by considering the differential settlement, stiffness variation, 524 vehicle dynamics and hanging sleepers. Similarly using a 3D FE model, various subgrade fillings 525 have been investigated to explore the economic filling materials for a high-speed railway transition 526 zone [59].

527 Another use of numerical modelling is to investigate the effect that complex site situations can have 528 on the dynamic response of track. These situations may include large-scale excavation close to a track 529 transition, variations in the moisture of track substructure, and ballast fouling, among others [116, $530150,175]$. Likewise, numerical modelling can be used to investigate the dynamic response of track 531 at various levels and locations of track components at any time. Mishra et al. [107] observed 532 deformation at various levels using a 3D FE model to fully calibrate it with field values measured 533 with multi-depth deflectometers.

534 The type of model and the modelling software/program influences how reliable and accurate is the 535 dynamic response analysis of transition zones. Various selection parameters include, (i) the type of 536 analysis required (static or dynamic), (ii) the inclusion of non-linearity and plasticity of material, (iii) 537 the calculation time, and (iv) the expected outcomes. Previous studies show the use of two types of 538 finite element programs: (i) vehicle modelling packages, and (ii) track modelling packages. The 539 vehicle modelling software packages concentrate more on vehicle dynamics while over simplifying 540 the modelling of ballast and subgrade materials, whereas track modelling software packages mostly 541 deal with a substructure model that over simplifies the vehicle model [120]. At transition zones, even 542 though the main variation is in the structural properties of track, utilising the model while considering 543 the vehicle and track responses would enable a better understanding of the dynamic response of track 
under moving loads.

545 Likewise, selecting a vehicle model which considers various suspended, semi-suspended, and non546 suspended loads can also help to obtain a true dynamic response of track structure. Hunt and Winkler 547 [62] used four vehicle models with, (i) axle load only, (ii) axle and bogie, (iii) axle, bogie, and vehicle 548 body, and (iv) two axles and bogies with the same static axle loads and found similar settlement 549 results from every model; they then conclude there is no effect on the settlement growth rate, even 550 for closely spaced axles. Paixão et al. [125] found a similar track response for a train with different 551 cars in terms of the wheel/rail interaction and vertical displacements; they conclude that a 2-car model 552 can be just as practical as a full train model, and therefore very useful at reducing the calculation time. 553 However, a simplified (one-bogie) vehicle model is not always appropriate for considering responses 554 such as the pitching motion of a vehicle [4].

555 The choice of models depends on the complexity of the analysis and the required precision. 2D 556 models are incapable of modelling the train load distribution in a longitudinal direction, so 2D plane 557 strain model with continuous support has been considered for a transversal track profile instead of real field conditions with the discrete support of rails by sleepers. However, a 3D model can overcome these limitations [147], which is why Galvín et al. [53] suggested using 3D models that include track non-linearity to obtain an accurate response of track transitions under moving loads.

Paixão et al. [125] used a 2D numerical model to examine how backfill settlement affects train and track interaction by measuring the wheel-rail contact force in the transition zone. They used four scenarios of maximum backfill settlement, $1 \mathrm{~mm}, 5 \mathrm{~mm}, 10 \mathrm{~mm}$ and $15 \mathrm{~mm}$, and found large interacting forces in each case due to the negativity of existing settlement (hanging sleeper phenomenon). Similar results can also be found in various other studies [102, 191, 193].

566 Numerical modelling can be utilised to investigate the response of track due to various train speeds and loads. Coelho et al. [25] concluded that train speeds up to a certain limit $(160 \mathrm{~km} / \mathrm{h}$ for that specific case) had limited impact on the track but as the speed became critical $(180 \mathrm{~km} / \mathrm{h})$ the response of track became higher due to resonance. Likewise, in more recent research, Labrado Palomo et al. [86] investigated the effect of train speeds on four different kinds of approaches at embankmentbridge transition using a 3D finite element model. The characteristic parameters of ballast, sub-ballast and soil were optimised through model calibration with field results, and then the model was successfully validated. It is found that the peak and average particle velocities for vehicle speeds of $100 \mathrm{~km} / \mathrm{h}$ are higher than at $160 \mathrm{~km} / \mathrm{h}$ and $220 \mathrm{~km} / \mathrm{h}$, possibly due to a match between train speed and the critical speed of the entire system. However, Heydari-Noghabi et al. [56] found an increasing trend of track displacements for various sections of track as the train speed and loads increase, as shown in Figure 15. Note here that as the train speed (Figure 15a) and loads (Figure 15b) increase, 
track displacement also increases. Moreover, ballasted track has a higher displacement than a slab track. Figure 15 also shows that the auxiliary rails help to smooth the differential settlement at the transition zone.

Numerical modelling can also analyse how the direction of train movement will affect the dynamic response of track in terms of enhanced train-track interactions at transition zones. Many authors believe that trains passing through a transition zone from soft to stiff medium such as embankment to bridge are the worst-case scenarios $[113,125,174]$. This could be due to trains moving from a deformable structure to a non-deformable structure (i.e. concrete bridge) which enhances the impact load. However, Chen [22] found more settlement when moving from a stiff to soft transition zone because the boundary conditions for his model could be case specific. Despite this, some authors suggest that the effect of train direction on the dynamic behaviour of track is minor, which is the case when the quality of tracks is high and there are no sharp variations in the track support conditions [4, $5,124]$

A 3D finite element model has been used by $\mathrm{Hu}$ et al. [59] to evaluate how effective different filling materials are for a wedge-shaped backfill at a tunnel-culvert transition zone. Three different materials are used; (i) graded gravel with 5\% cement, (ii) graded gravel with no cement ( $c=160 \mathrm{kPa}, \phi=39.5$ ), and (iii) well graded coarse grained soil with less than $30 \%$ of fine grained soil ( $c=200 \mathrm{kPa}, \phi=41.8$ ); their properties were calculated through laboratory (for new materials) and field testings (for in-situ material). In every case, maximum deflection occurs under maximum allowed values, however lower wheel loads are used in this study.

In [7-9] the train and track interaction has been investigated by applying a 3D finite element model to the track transition mechanism. This model incorporates variations in stiffness and considers the non-linear behaviour of ballast and subgrade. The conclusion is that simple variations in stiffness at track transitions is not the primary cause of transition problems, it is the soft subgrade, voids, and other faults at transition zones that increase the interaction forces as train speeds increase that cause passenger discomfort. It is therefore suggested that difference in deflection at the junction of two different tracks over a 4-10 m long transition will lead to a smooth transition.

To study the dynamic response of bump at bridge approaches, a detailed investigation using a 3D finite element model that incorporates train and track structure/substructure is given in [120]. The response of this track is observed by varying the sizes of the bumps and dips, the thickness of the ballast, the sleeper material, train speed direction, and the type of abutment and length of the sleepers. It is found that the enhanced load impact and ballast/subgrade pressure due to variations in the track modulus cause dips and bumps to develop; this further increases the dynamic response of track at bridge transitions. 
613 A number of field investigations have been carried out to evaluate the effectiveness of the approaches 614 used to control differential settlement at the transition zones; these studies took place mainly in the 615 USA, Europe, Japan, and China. Various instruments are used to measure/investigate the response of 616 rail track at transition zones in real time scenarios, they include multi-depth deflectometers (MDD), 617 uniaxial and triaxial accelerometers, strain gauges, pressure cells, settlement pegs, video gauge 618 systems, position sensitive devices, geophones, inclinometers, linear variable displacement 619 transducers (LVDTs), among others [15, 26, 71, 126, 153, 155, 174]. Furthermore, the structural 620 health monitoring of rail tracks and transition zones is being carried out with the help of convetional 621 data measuring coaches and advanced techniques including digital image correlation (DIC) device 622 and satellite synthetic aperture radar (InSAR) system which is developed by Wang et al. [170].

623 Stone blowing is a process of adjusting the track geometry by adding the crushed rock to ballast 624 surface under the lifted sleeper. It is a relatively new method involving less damage to sleepers as 625 compared to the tamping process where adjustment is achieved by ballast rearrangement to fill the 626 voids under the lifted sleeper [153]. The effectiveness of stone blowing instead of tamping was 627 investigated by Boler et al. [15] where comparison was made by analysing the performance of track 628 before and after stone blowing; the data shows that stone blowing led to an almost $60 \%$ reduction in 629 transient peak displacement, and moreover, the vertical acceleration and gaps at the sleeper-ballast 630 interface also decreased due to stone blowing. The results obtained by vertical space curves through 631 track geometry car measurements also indicate the increased effectiveness and longevity of this 632 remedial measure.

633 Paixão et al. [126] concluded that Under Sleeper Pads, (USPs) at the transition zones are effective 634 based on the passage of 40 different types of trains passing the fully instrumented zone. It is noted 635 that USPs will reduce the track stiffness values by a considerable amount. Fortunato et al. [44] used 636 a wedge shaped approach at the transition zone and concluded that a gradual transition of vertical 637 stiffness can be achieved with this approach, however, passenger trains at higher speeds cause more 638 acceleration at sleepers than heavy freight at lower speeds. They also presented the various 639 characteristics of wedge shaped countermeasures that are commonly used at transition zones in 640 several countries around the world.

641 Stark and Wynn [155] presented a report on the use of geosynthetic reinforcement systems in the 642 railway transition zones to mitigate the differential settlement at these locations. They concluded from 643 this ongoing research that ballast reinforcement in transition approaches with a geoweb underlay 644 helps to mitigate transition problems by providing enhanced ballast confinement and improved load 645 distribution. They also showed there is a large reduction in cost and installation time when geoweb 
underlay is used; in fact this research shows that geosynthetic reinforcement will help to reduce differential settlement because it can increase (when used at approaches) and decrease (when used under the bridge abutment) the stiffness values.

Coelho et al. [26] presented the results of field measurements for a track crossing with a concrete culvert by showing that the design for the transition was not optimal. The box culvert is almost $1.5 \mathrm{~m}$ deep from the track and is made from a sand embankment over soft soils. There are $4 \mathrm{~m}$ long by $300 \mathrm{~mm}$ thick approach slabs on both sides of the culvert above which sand is placed up to the ballast under the actual track. The vertical displacement, axle load, and average track stiffness are measured by geophones (mounted on top of wooden sleepers), uniaxial accelerometers (within ballast), triaxial accelerometers (within soil below track), strain gauges and a high-speed camera. The hanging sleepers in the transition zone that are the result of long term track differential settlements are the main sources of the track displacement that caused increased impact loading and accelerated track degradation.

A summary of the most recent field investigations of the transition zones in terms of the project description, transition types, countermeasure used and the outcome of the overall research, is given in Table 2.

\section{Recommendations for improved track design}

Despite the effort that has gone into studying the performance of tracks at transition zones using advanced modelling techniques, an optimal solution to transition related problems is still not fully understood [79, 137], hence the need to find an effective and low cost solution (to eradicate/minimise the problems), with minimum disruption to traffic and a longer life [64]. The main aim of designing these transition zones is to maintain track quality while reducing the maintenance cycles and costs [137]. In order to use computational models properly for predicting the true dynamic track performance, the model parameters require realistic calibration either using large-scale laboratory simulations or instrumented field trials.

Vertical track stiffness at transition zones is mainly influenced by the type of materials used in the embankment, and its slope and height in the transition zone. Natural ground beneath an embankment also affects the stiffness of track depending on the material used in the embankment, so it should be replaced if it is highly compressible [49-51]. Therefore, to design a transition zone efficiently, a proper selection of materials along with the shape and height of the embankment should be considered, as should a proper consideration of natural ground characteristics.

While the inconsistent dynamic response of ballast particles with respect to the point of load application indicates its particulate nature [107], and while finite element modelling (FEM) cannot 
model discrete particles due to continuum based solutions, discrete element modelling (DEM) can model irregular-shaped particles, the angularity of granular material, and particle breakage; therefore particle to particle contact for wheel load interactions can be considered properly in dynamic track modelling using DEM. In particular, the DEM application may be most appropriate where particle degradation is exacerbated due to impact, and while these track sections can be modelled separately using DEM, most part of the track can generally be modelled as a continuum using FEM. A FEMDEM coupled model could be the best approach to investigate the ballasted rail track dynamic as suggested by Nishiura et al. [121] who developed a sleeper model by DEM for viscoelastic multibody dynamics and coupled it with rail model (FEM) providing greater insight into the dynamic response of ballasted railway tracks under impact loading.

Ideally, ballast assemblies should be tested in a prototype scale to determine how enhanced dynamic loadings at transition zones will affect the deformation and degradation of ballast; this is because testing smaller particles with small equipment will affect the internal angle of friction (shearing resistance) of the granular assembly, and hence the rate of volumetric strain during the shearing process. A large-scale triaxial testing rig (300 $\mathrm{mm}$ diameter by $600 \mathrm{~mm}$ high) has been designed and built at the University of Wollongong (Figure 16a); it is custom made to minimise boundary effects, so it has been widely used to evaluate the deformation and degradation of ballast with reference to the origin, size, and shape of aggregates used in Australian tracks. Key factors affecting ballast degradation were found to be as loading characteristics (i.e. monotonic, cyclic), frequency and confining pressure. Details of the components of this apparatus and its measuring techniques can be found elsewhere [67, 74, 77, 87, 151]. A similar apparatus can also be found in [27] that can be used to investigate the resilient behavior of track ballast with particle size up to $63 \mathrm{~mm}$.

A large-scale process simulation testing apparatus (PSTA) has been used to study the response of ballast track components under realistic cyclic loading (Figure 16b). This PSTA can accommodate specimens $800 \mathrm{~mm}$ long by $600 \mathrm{~mm}$ wide by $600 \mathrm{~mm}$ high, these dimensions will mimic a typical unit cell section of Australian standard gauge tracks $[13,68,80,115]$. The PSTA can also apply a dynamic load up to $100 \mathrm{kN}$ with frequency up to $40 \mathrm{~Hz}$, simulating typical Australian passenger and heavy haul freight trains traveling up to $200 \mathrm{~km} / \mathrm{h}$. Large-scale constant normal stiffness (CNS) direct shear tests (Figure 16c) have been designed to study the interface between ballast-rubber mats/geosynthetics and to determine the internal friction angle of ballast. The recently funded National Facility for Cyclic Testing High-Speed Rail (FCTHSR; Figure 16d) is now being commissioned with double axle loading to mimic heavy haul operations. With axle loads up to 40tonnes and a frequency range from $5-40 \mathrm{~Hz}$ (i.e. speeds of $55-220 \mathrm{~km} / \mathrm{h}$ ), the FCTHSR will accommodate a range of cyclic loading patterns to evaluate the actual performance of ballast under different structural and geotechnical conditions especially for transition zones. 
A large-scale permeameter has been designed to measure the hydraulic conductivity of ballast contaminated with fouling materials such as coal and subgrade mud $[69,160]$. This chamber will accommodate ballast specimens of $500 \mathrm{~mm}$ in diameter by $300-500 \mathrm{~mm}$ high (Figure 16e). A full-scale model track (dimensions: $4.76 \mathrm{~m}$ by $3.48 \mathrm{~m}$ by $0.79 \mathrm{~m}$ ) has been built at UOW to study the behaviour of fouled ballast (Figure 16f). This model track is used to determine how ballast fouling can influence ground penetrating radar (GPR) data, while capturing the moisture content and loading frequency [157]. These unique and novel testing devices help us to examine and quantify the influence of induced train loading characteristics on the strength, deformation, and degradation of ballast, hence could be utilised for design optimization of transition zones.

Likewise, the CEDEX track box; a full-scale (1:1) testing facility for railway tracks in Spain [104], can be utilized to optimize various maintenance works at transition zones especially for slab track to ballast track transitions. This track box is $21 \mathrm{~m}$ long, $4 \mathrm{~m}$ deep and $5 \mathrm{~m}$ wide and has a capacity to model the full rail track section for various train loads and speeds up to $450 \mathrm{~km} / \mathrm{h}$ considering static and dynamic loading conditions. This facility has been used in the past to study various aspects of rail track performance such as track lateral stability, vertical stiffness, short and long-term settlements, and track dynamic response under high-speeds trains among others, the details of which can be found in [36-38].

The full-scale laboratory testing facility developed by the University of Nottingham [17] for railway track can also be utilized to investigate the performance of railway ballast under impact loading caused by differential settlement at transition zones. This facility involves three sleepers and the cyclic load of $94 \mathrm{kN}$ can be applied directly to the sleepers through hydraulic actuators. The permanent settlement as well as transient deflection can be measured in addition to the transient stresses and degree of particle degradation, the results of various tests performed on this apparatus can be found elsewhere [6, 18, 21]. Similarly, the Southampton railway testing facility [2] can also be utilized to study the track dynamic response especially the permanent (plastic) settlement of ballast particles that can cause the differential settlement as suggested by Abadi et al. [1].

To produce a decent design, the difference between the response of track before and after a transition zone is set as low as possible. Various factors found in the literature that affect the structural response of track transitions are summarised in Figure 17; these factors should receive enough attention to achieve the appropriate design of transition zones in terms of selecting different design techniques and approaches. To make a precise model, every individual component must be modelled separately by considering characteristics such as elastic/plastic, linear/non-linear, continuum/particulate (discrete), and their interaction with neighbouring components. These factors can be addressed selecting proper modelling techniques such as 1D, 2D or 3D and commercially available advanced modelling software packages. Note that each model and modelling software has some limitations that 
should be considered before designing track transitions.

\section{Conclusions}

751 This paper presents a detailed review of rail track transitions, various associated issues and their 752 solutions. After defining the importance of rail transitions, their related problems are discussed, 753 including their causes and effects on railway operations. Numerous mitigations measures to improve 754 the performance of ballasted tracks at transition zones are also discussed, with special reference to 755 their effectiveness. The ongoing research into designing transition zones to minimise the effect of 756 abrupt changes in the structural properties of track is critically reviewed by considering large-scale 757 laboratory testing, mathematical and computational modelling, and field investigations. 758 Recommendations for the performance of the ballasted track at transitions are also presented after 759 reviewing the various design approaches. Following are the conclusions that can be drawn from this 760 review of track transition zones:

- Differential settlement and enhanced dynamic loads are the main problems associated with track transition and are thus responsible for track degradation. The major cause of these problems is the abrupt change in stiffness, which can only be controlled by designing smooth and gradual transition zones.

- Most current design practices are based mainly on empiricism established through trial and error. These methods can be unreliable if the empirical parameters are calibrated only to local subgrade and ballast properties, and should not be extended to any track section without exercising caution for different soil characteristics and dynamic loading conditions. Transition zones should be designed to cope with the required variations in stiffness and possible initial settlement, which may vary depending on the case. If the variations in stiffness are known, the length of the transition zone and the type of materials can be established to provide a smooth and gradual variation in track stiffness at the junction.

- One of many reasons for not having a precise and economical design of transition zones is because the problem is complex due to the interaction of several structures and structural components. Since conventional rail track structure consists of various structural components, it is a composite structure, but in transition zones, this complexity is enhanced due to the sudden variations in the structural properties of track. This makes prediction of the dynamic performance of the overall structure a challenging task because every component behaves differently under various loading conditions. Furthermore, the interaction between these components (vehicle-track-structure) makes the model more complex.

- There is a lack of effective computational model to study the dynamic response of transition zones due to the complexity of the problem. Similarly, implementing semi-analytical 
approaches based on the transformation of time and frequency is difficult owing to the substructural inhomogeneity of track. Various mitigation measures have been utilised but without any theoretical reasoning, and therefore they are not overcoming the need for frequent maintenance.

- It is observed that deformation in most models is very small and is in the elastic range, whereas in actual field investigations, high deformation occurs more frequently with the passage of time. The main reason for these discrepancies could be the assumed linear and elastic nature of the structural components, but the ballast, sub-ballast and subgrade layers do not behave elastically or in a linear fashion under repeated train loads; this leads to plastic deformation and permanent settlement i.e. bumps/dips. This plastic deformation has been overlooked in most transition models, which is another source of error for predicting the dynamic response of track. 
797 This appendix provides the governing equations used by [166] to solve the linear mathematical model

798 for the response analysis of inhomogeneous foundation using two-layer mass spring-dashpot model.

799 The governing equation for $x<0$ is as:

800

$$
\left\{\begin{array}{l}
\frac{E_{1} I_{1} \partial^{4} u_{11}}{\partial x^{4}}+m_{1} \frac{\partial^{2} u_{11}}{\partial t^{2}}+c_{1}\left(\frac{\partial u_{11}}{\partial t}-\frac{\partial u_{21}}{\partial t}\right)+k_{11}\left(u_{11}-u_{21}\right)=-F \delta(x-v t) \\
\frac{E_{2} I_{2} \partial^{4} u_{21}}{\partial x^{4}}+m_{2} \frac{\partial^{2} u_{21}}{\partial t^{2}}+c_{1}\left(\frac{\partial u_{21}}{\partial t}-\frac{\partial u_{11}}{\partial t}\right)+k_{11}\left(u_{21}-u_{11}\right)+k_{21} u_{21}+c_{2} \frac{\partial u_{21}}{\partial t}=0
\end{array}\right.
$$

and for $x>0$ is as:

$$
\left\{\begin{array}{l}
\frac{E_{1} I_{1} \partial^{4} u_{12}}{\partial x^{4}}+m_{1} \frac{\partial^{2} u_{12}}{\partial t^{2}}+c_{1}\left(\frac{\partial u_{12}}{\partial t}-\frac{\partial u_{22}}{\partial t}\right)+k_{12}\left(u_{12}-u_{22}\right)=0 \\
\frac{E_{2} I_{2} \partial^{4} u_{22}}{\partial x^{4}}+m_{2} \frac{\partial^{2} u_{22}}{\partial t^{2}}+c_{1}\left(\frac{\partial u_{22}}{\partial t}-\frac{\partial u_{12}}{\partial t}\right)+k_{12}\left(u_{22}-u_{12}\right)+k_{22} u_{22}+c_{2} \frac{\partial u_{22}}{\partial t}=0
\end{array}\right.
$$

806 These equations for vertical displacement in each section are solved by considering the interface conditions at $x=0$. The solution for these equations of differential settlements is a complex process that involves many assumptions and the substitution of many variables, it can be found in $[163,166]$.

\section{Acknowledgements}

810 This research was carried out by the Australian Research Council Industrial Transformation Training 811 Centre for Advanced Technologies in Rail Track Infrastructure (IC170100006) and funded by the 812 Australian Government. The authors thank the Australian Rail Track Corporation (ARTC) for their 813 continuous support and cooperation. The authors also appreciate the insightful collaboration and 814 assistance of Australasian Centre for Rail Innovation (ACRI) and Snowy Mountains Engineering 815 Corporation (SMEC), in particular the comments and thoughtful advice provided for the current study. 
Table 1: Comparison of computational modelling approaches and summarised key research findings on track transition zones

\begin{tabular}{|c|c|c|c|c|c|c|c|c|c|c|c|c|c|c|c|c|c|}
\hline 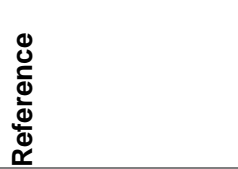 & $\frac{\searrow}{2}$ & 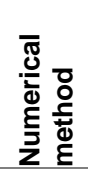 & 造 & 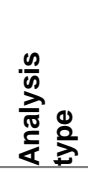 & 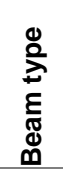 & 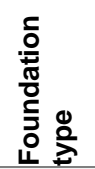 & 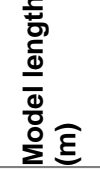 & 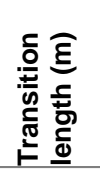 & 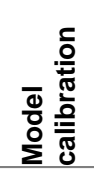 & 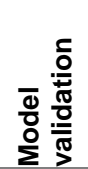 & 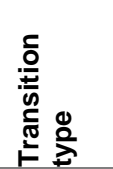 & 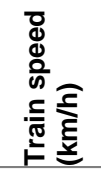 & $\begin{array}{l}\frac{\partial}{\sigma} \\
\frac{o}{0} \\
\frac{0}{x} \widehat{\frac{\xi}{x}}\end{array}$ & 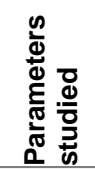 & 旡 & 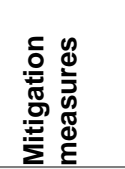 & Innovations / Findings \\
\hline $\begin{array}{l}\text { Aggestam and } \\
\text { Nielsen, 2019 } \\
\text { (Sweden) [4] }\end{array}$ & $2 \mathrm{D}$ & $\overline{F E M}$ & - & Dyn. & TS & LE & 60 & 23.4 & & Yes & $\begin{array}{l}\text { BTS } \\
\text { BTCd }\end{array}$ & $\begin{array}{l}250- \\
350\end{array}$ & 170 & $\begin{array}{l}\mathrm{CF} \\
\mathrm{BS}\end{array}$ & Both & SS, RP & $\begin{array}{l}\text { Considering certain responses of vehicle, especially } \\
\text { car body pitching motion, simplified (one bogie) } \\
\text { vehicle model is not appropriate. Train direction has } \\
\text { almost no effect on the dynamic response of track for } \\
\text { an optimised transition design }\end{array}$ \\
\hline $\begin{array}{l}\text { Hu et al., } 2019 \\
\text { (China)[59] }\end{array}$ & $3 D$ & FEM & ANSYS & Dyn. & TS & EP & 52.2 & 46.2 & No & Yes & $\begin{array}{l}\text { BsTR } \\
\tilde{\text { BTCc }}\end{array}$ & 350 & 140 & $\begin{array}{l}\text { VtD, } \\
\text { TV, } \\
\text { TA, } \\
\text { BS }\end{array}$ & Both & WSB & $\begin{array}{l}\text { Graded gravel with } 5 \% \text { cement is the best filling } \\
\text { material, followed by simple graded gravel, and then } \\
\text { well graded coarse grained soil }\end{array}$ \\
\hline $\begin{array}{l}\text { Esmaeili et al., } \\
2018 \\
\text { (Iran)[34] }\end{array}$ & $2 \mathrm{D}$ & FEM & ANSYS & Dyn. & EB & LE & 42.2 & 18 & No & Yes & $\begin{array}{l}\text { BTS } \\
\text { BTCC }\end{array}$ & $\begin{array}{l}120- \\
340\end{array}$ & $\begin{array}{l}160 \\
200\end{array}$ & $\begin{array}{l}\mathrm{RD} \\
\mathrm{TA} \\
\mathrm{RpF}\end{array}$ & SoTSt & AR & $\begin{array}{l}\text { Rail deflections and track acceleration decrease with } \\
\text { stiffer rail pads \& damping but increase with increased } \\
\text { train speed, auxiliary rails transition is smoother and } \\
\text { the dynamic performance improved }\end{array}$ \\
\hline $\begin{array}{l}\text { Koch et al., } 2018 \\
\text { (Hungary) [85] }\end{array}$ & $3 \mathrm{D}$ & FEM & PLAXIS & Dyn. & $\mathrm{RB}$ & LE & 96 & 18 & - & - & $\begin{array}{l}\text { BTS } \\
\text { BTCd }\end{array}$ & $\begin{array}{l}80 \\
250\end{array}$ & 125 & $\begin{array}{l}\text { VtD, } \\
\text { TV }\end{array}$ & SoTSt & $\mathrm{BCW}$ & $\begin{array}{l}\text { Vertical displacement and Velocity amplitudes } \\
\text { decrease with depth. Transition zone design is more } \\
\text { important for higher train speed than lower speeds }\end{array}$ \\
\hline $\begin{array}{l}\text { Labrado Palomo } \\
\text { et al., } 2018 \\
\text { (Spain) [86] }\end{array}$ & $3 D$ & FEM & ANSYS & Dyn. & SB & LE & 54 & 36 & Yes & Yes & $\begin{array}{l}\text { BTS } \\
\text { BTCd }\end{array}$ & $\begin{array}{l}50- \\
300\end{array}$ & 24 & $\begin{array}{l}\text { TV, } \\
\text { TA }\end{array}$ & SoTSt & $\begin{array}{l}\text { CW, } \\
\text { HMA, } \\
\text { SRG, } \\
\text { SRP }\end{array}$ & $\begin{array}{l}\text { Geogrids are not the right approach to modify the } \\
\text { vertical stiffness of track. Peak vibration increases } \\
\text { with an increase in train speeds. concrete wedge is } \\
\text { more effective technique, then HMA wedge and the } \\
\text { Piles }\end{array}$ \\
\hline $\begin{array}{l}\text { Paixão et al., } \\
2018 \\
\text { (Portugal) [126] }\end{array}$ & $3 \mathrm{D}$ & FEM & $\begin{array}{l}\text { Pegasus/ } \\
\text { MATLAB }\end{array}$ & Dyn. & $\mathrm{EB}$ & NLVE & 75 & 17.4 & Yes & Yes & $\begin{array}{l}\text { BTS } \\
\text { BTCv }\end{array}$ & 220 & 250 & $\begin{array}{l}\text { VtD, } \\
\text { CF, } \\
\text { BS }\end{array}$ & SoTSt & $\begin{array}{l}\text { WSB, } \\
\text { USPS }\end{array}$ & $\begin{array}{l}\text { USPs reduce the vibration transmitted to the ballast \& } \\
\text { sleeper-ballast contact forces so as the ballast } \\
\text { degradation \& diff. settlement in the long run }\end{array}$ \\
\hline $\begin{array}{l}\text { Wang and } \\
\text { Markine, 2018a } \\
\text { (Netherlands) } \\
\text { [171] }\end{array}$ & $3 \mathrm{D}$ & FEM & LS-DYNA & Dyn. & $\mathrm{HL}$ & NLE & 120 & Varies & - & Yes & $\begin{array}{l}\text { BTS } \\
\text { BTCd }\end{array}$ & 200 & 142 & $\begin{array}{l}\text { VtD, } \\
\text { WL, } \\
\text { BS }\end{array}$ & SoTSt & $\begin{array}{l}\text { WS, } \\
\text { LS, } \\
\text { WS+LS }\end{array}$ & $\begin{array}{l}\text { The dips in transition zones increase, expand \& } \\
\text { propagate farther away from bridges with loading } \\
\text { cycles. Number of iteration steps have strong effect } \\
\text { on settlement prediction }\end{array}$ \\
\hline $\begin{array}{l}\text { Wang and } \\
\text { Markine, 2018b } \\
\text { (Netherlands) } \\
\text { [174] }\end{array}$ & $3 D$ & FEM & LS-DYNA & Dyn. & $\mathrm{HL}$ & LE & 120 & Varies & - & Yes & $\begin{array}{l}\text { BTS } \\
\text { BTCd }\end{array}$ & $\begin{array}{l}72- \\
288\end{array}$ & 178 & $\begin{array}{l}\text { VtD, } \\
\text { WL, } \\
\text { BS }\end{array}$ & Both & $\begin{array}{l}\text { WS, } \\
\text { LS, } \\
\text { WS+LS }\end{array}$ & $\begin{array}{l}\text { Diff. settlement } \& \text { train speed, enhance the dynamic } \\
\text { effect (wheel loads, ballast stress), longer sleepers } \\
\text { are recommended for economy and longer \& wider for } \\
\text { performance, fasteners are effective but complex }\end{array}$ \\
\hline $\begin{array}{l}\text { Heydari-Noghabi } \\
\text { et al., 2017 } \\
\text { (Iran) [56] }\end{array}$ & $3 D$ & FEM & MATLAB & Dyn. & EB & & 52.2 & 18 & Yes & Yes & $\begin{array}{l}\text { BsTR } \\
\sim \\
\text { BTCc }\end{array}$ & $\begin{array}{l}120- \\
300\end{array}$ & $\begin{array}{l}180- \\
250\end{array}$ & $\begin{array}{l}\mathrm{RD} \\
\mathrm{CF}\end{array}$ & StTSo & AR & $\begin{array}{l}\text { Track deflection increases with an increase in train } \\
\text { speed and vehicle load. Auxiliary rails reduce rail } \\
\text { deflection, the optimum no. of additional rails is } 2\end{array}$ \\
\hline $\begin{array}{l}\text { Sañudo et al., } \\
2017 \\
\text { (Spain) [136] }\end{array}$ & $2 \mathrm{D}$ & FEM & ANSYS & Dyn. & - & LE & 200 & Varies & - & - & $\begin{array}{l}\text { BTS } \\
\text { BTCd }\end{array}$ & 300 & & $\begin{array}{l}\text { VtD, } \\
\text { BS, } \\
\text { TA }\end{array}$ & Both & SS & $\begin{array}{l}\text { The position \& separation of sleepers influences the } \\
\text { vertical acceleration and vibration, while slab to ballast } \\
\text { track train movement is more critical }\end{array}$ \\
\hline $\begin{array}{l}\text { Wang et al., } 2017 \\
\text { (Netherlands) } \\
\text { [175] }\end{array}$ & $3 \mathrm{D}$ & FEM & LS-DYNA & Dyn. & $\mathrm{HL}$ & LE & 120 & Varies & Yes & Yes & $\begin{array}{l}\text { BTS } \\
\text { BTCd }\end{array}$ & 144 & 142 & $\begin{array}{l}\text { VtD, } \\
\text { WL }\end{array}$ & Both & MCE & $\begin{array}{l}\text { Strong connection between track degradation } \& \text { the } \\
\text { high moisture condition causes increased dynamic } \\
\text { wheel loads and reduced stiffness at both sides of the } \\
\text { bridge }\end{array}$ \\
\hline $\begin{array}{l}\text { Paixão et al., } \\
2016 \text { (Portugal) } \\
\text { [125] }\end{array}$ & $2 \mathrm{D}$ & FEM & ANSYS & Dyn. & $\mathrm{RB}$ & NLE & 172.5 & & Yes & Yes & $\begin{array}{l}\text { BTS } \\
\text { BTCd }\end{array}$ & 220 & 132 & $\begin{array}{l}\text { VtD, } \\
\text { CF, } \\
\text { TA }\end{array}$ & Both & WSB, & $\begin{array}{l}\text { Soft to stiff train movements are more critical when } \\
\text { considering track degradation and wheel/rail contact } \\
\text { loss, wedge-shaped backfill is a good approach for } \\
\text { train-track system }\end{array}$ \\
\hline
\end{tabular}


Table 1 (continued)

\begin{tabular}{|c|c|c|c|c|c|c|c|c|c|c|c|c|c|c|c|c|c|}
\hline 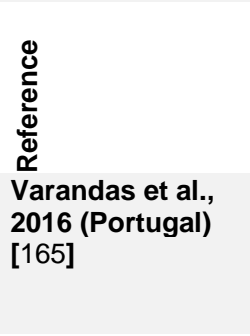 & 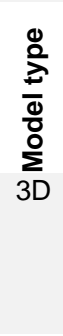 & 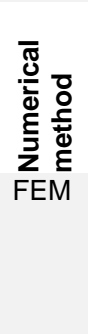 & 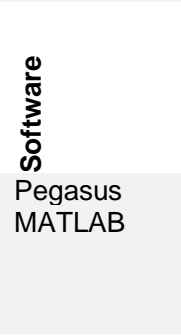 & $\begin{array}{l}\frac{\infty}{\infty} \\
\stackrel{\frac{\infty}{\pi}}{\frac{\pi}{\alpha}} \\
\text { Dyn. }\end{array}$ & 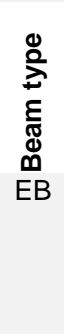 & 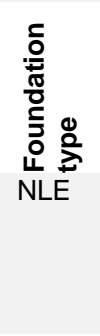 & 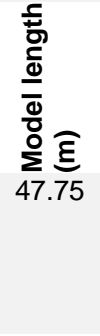 & 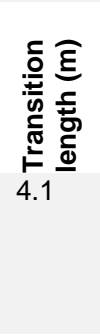 & 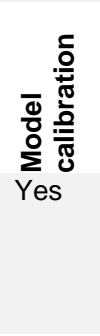 & 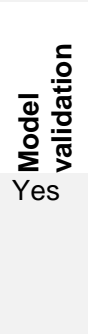 & 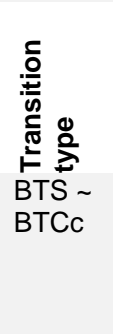 & 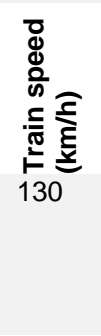 & 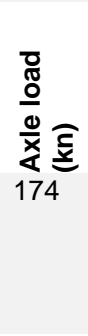 & 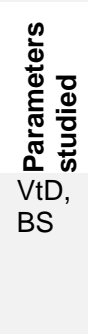 & 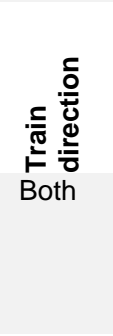 & 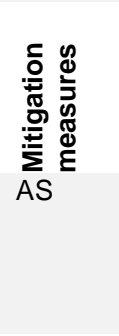 & $\begin{array}{l}\text { Ballast stresses are more than their strength and } \\
\text { create a tendency towards sliding/rolling. The flow } \\
\text { ability of ballast is due to high shear stresses. Ballast } \\
\text { settlement depends mainly on the movement and } \\
\text { inclination of the approach slab }\end{array}$ \\
\hline $\begin{array}{l}\text { Real et al., } 2016 \\
\text { (Spain) [134] }\end{array}$ & $3 D$ & FEM & ANSYS & $\begin{array}{l}\text { St. \& } \\
\text { Dyn. }\end{array}$ & SB & LE & 60 & 20 & Yes & Yes & $\begin{array}{l}\text { BTS } \\
\text { BsTAS } \\
\tilde{\text { BsTCd }}\end{array}$ & 35 & 90 & $\begin{array}{l}\text { TM, } \\
\text { TA }\end{array}$ & Both & $\mathrm{AR}, \mathrm{RP}$ & $\begin{array}{l}\text { Stiffness variation between concrete and asphalt slab } \\
\text { tracks can be smoothen by using rubber mats. No } \\
\text { contribution from the addition of auxialiary rail in } \\
\text { smoothening the transition. No significant effect on } \\
\text { track dynamic response }\end{array}$ \\
\hline $\begin{array}{l}\text { Shahraki et al., } \\
2015 \text { (Germany) } \\
\text { [147] }\end{array}$ & $3 D$ & FEM & ANSYS & Dyn. & $\mathrm{RB}$ & LE & 80 & 7.5 & - & - & $\begin{array}{l}\text { BTS } \\
\text { BsTCd }\end{array}$ & 300 & 180 & $\begin{array}{l}\text { VtD, } \\
\text { TA, } \\
\text { BS }\end{array}$ & SoTSt & $\begin{array}{l}\text { LS,AR, } \\
\text { WSB }\end{array}$ & $\begin{array}{l}\text { More improvement in the dynamic performance of } \\
\text { track with auxiliary rails, improved subgrade helps the } \\
\text { entire system to perform better. Larger sleepers are } \\
\text { the most effective way of reducing ballast stress }\end{array}$ \\
\hline $\begin{array}{l}\text { Mishra et al., } \\
2014 \text { (IIlinois) } \\
\text { [108] }\end{array}$ & $\begin{array}{l}2 \mathrm{D}, \\
3 \mathrm{D}\end{array}$ & $\begin{array}{l}\text { FEM, } \\
\text { DEM }\end{array}$ & $\begin{array}{l}\text { GEOTRACK } \\
\text { BLOKS3D }\end{array}$ & Dyn. & EB & LE & 2.22 & - & Yes & Yes & - & $\begin{array}{l}177- \\
241\end{array}$ & 270 & $\begin{array}{l}\text { BS, } \\
\text { BPA }\end{array}$ & - & $\mathrm{RP}$ & $\begin{array}{l}\text { Ballast is not a continuum medium therefore ballast } \\
\text { particles accelerate at different speeds depending on } \\
\text { its location with respect to load application }\end{array}$ \\
\hline $\begin{array}{l}\text { Chen, } 2013 \text { (UK) } \\
\text { [22] }\end{array}$ & $3 D$ & DEM & $\mathrm{PFC}^{3 \mathrm{D}}$ & Dyn. & - & LE & 2.1 & 1.9 & - & Yes & - & $\begin{array}{l}25- \\
380\end{array}$ & $\begin{array}{l}160- \\
320\end{array}$ & $\begin{array}{l}\text { VtD, } \\
\text { TA }\end{array}$ & Both & SRG & $\begin{array}{l}\text { Stiff to soft train movement causes larger settlement } \\
\text { than soft to stiff, multi-step stiffness is better at } \\
\text { reducing the differential settlement, while geogrid in } \\
\text { ballast over a soft subgrade is ineffective }\end{array}$ \\
\hline $\begin{array}{l}\text { Banimahd et al., } \\
2012 \text { (UK) [7, 9] }\end{array}$ & $3 \mathrm{D}$ & FEM & GEOTRACK & Dyn. & - & $\begin{array}{l}\text { LE, } \\
\text { NLE }\end{array}$ & 60 & $4 \sim 10$ & - & - & $\begin{array}{l}\text { BTS } \\
\text { BTCd }\end{array}$ & $\begin{array}{l}180- \\
250\end{array}$ & 170 & $\begin{array}{l}\text { VtD, } \\
\text { CF, } \\
\text { TA }\end{array}$ & SoTSt & - & $\begin{array}{l}\text { Soft subgrade, Voids and other faults at transition } \\
\text { zones produce increased interaction forces, while } \\
\text { increased train speed causes passenger discomfort. } \\
\text { Simple variations in stiffness is not the primary issue, } \\
\text { a } 4-10 \text { m long transition based on deflection is enough }\end{array}$ \\
\hline $\begin{array}{l}\text { Gallego et al., } \\
\text { 2011 (Spain) [49- } \\
\text { 51] }\end{array}$ & $3 D$ & FEM & ANSYS & St & SB & EP & 7.2 & 4.8 & - & Yes & $\begin{array}{l}\text { BTS } \\
\text { BTCd }\end{array}$ & 300 & 180 & $\begin{array}{l}\text { VtD, } \\
\text { TM }\end{array}$ & Both & WSB & $\begin{array}{l}\text { Effect of the type of material in natural ground and the } \\
\text { embankment, and the height of an embankment on } \\
\text { the vertical track stiffness. The vertical stiffness of } \\
\text { track should be important when designing a transition } \\
\text { zone }\end{array}$ \\
\hline $\begin{array}{l}\text { Coelho et al., } \\
2011 \\
\text { (Netherlands) } \\
{[25]}\end{array}$ & $3 D$ & FEM & - & Dyn. & $\mathrm{RB}$ & & 20 & 5.0 & - & Yes & $\begin{array}{l}\text { BTS } \\
\text { BTCC }\end{array}$ & $\begin{array}{l}96- \\
200\end{array}$ & $\begin{array}{l}124 \\
193\end{array}$ & $\begin{array}{l}\text { VtD, } \\
\text { BS }\end{array}$ & Both & $\begin{array}{l}\text { AS, } \\
\text { MCE }\end{array}$ & $\begin{array}{l}\text { Dynamic response found to be } 20 \% \text { higher than static, } \\
\text { Higher response for soft to stiff train movement, } \\
\text { development of hanging sleepers and their effect on } \\
\text { the long-term performance of track }\end{array}$ \\
\hline $\begin{array}{l}\text { Varandas et al., } \\
2011 \text { (Portugal) } \\
\text { [167] }\end{array}$ & $1 \mathrm{D}$ & - & - & Dyn. & EB & NLE & 60 & 5.0 & - & Yes & $\begin{array}{l}\text { BTS } \\
\text { BTCc }\end{array}$ & $\begin{array}{l}120- \\
130\end{array}$ & $\begin{array}{l}108- \\
174\end{array}$ & $\begin{array}{l}\mathrm{VtD} \\
\mathrm{CF}\end{array}$ & Both & AS & $\begin{array}{l}\text { Hanging sleepers were observed on both sides of the } \\
\text { culvert, ballast settlement above the approach slab is } \\
\text { caused by sleeper loading and ballast flow in a } \\
\text { horizontal direction }\end{array}$ \\
\hline $\begin{array}{l}\text { Galvín et al., } \\
\text { 2010 (Spain) [52, } \\
\text { 53] }\end{array}$ & $3 D$ & FEM & - & $\begin{array}{l}\text { QS } \\
\& \\
\text { Dyn }\end{array}$ & EB & NLE & 90 & 15.4 & - & Yes & $\begin{array}{l}\text { BTS } \\
\text { BsTCd }\end{array}$ & 298 & 152 & TV, & SoTSt & $\begin{array}{l}\text { RP, } \\
\text { HSb }\end{array}$ & $\begin{array}{l}\text { Rail pads used in ballast-less tracks play very } \\
\text { important role in the vibration induced under moving } \\
\text { train loads }\end{array}$ \\
\hline $\begin{array}{l}\text { Nicks, } 2009 \\
\text { (Texas) [120] }\end{array}$ & $3 D$ & FEM & LS-DYNA & Dyn. & EB & LE & 16 & $\begin{array}{l}1.6- \\
8.4\end{array}$ & No & Yes & $\begin{array}{l}\text { BTS } ~ \\
\text { BTCd, } \\
\text { BTS } \sim \\
\text { BsTCd }\end{array}$ & $\begin{array}{l}32- \\
161\end{array}$ & 292 & $\begin{array}{l}\text { CF, } \\
\text { TA, } \\
\text { VtD, } \\
\text { BS }\end{array}$ & Both & $\begin{array}{l}\text { CMS, } \\
\text { USPS, } \\
\text { SB, RP }\end{array}$ & $\begin{array}{l}\text { Going from soft to stiff structure causes higher impact } \\
\text { loads, increased velocity has more impact for bumps } \\
\text { than dips, track modulus is linearly proportional to soil } \\
\text { modulus, ballast deck bridge is better than the ballast- } \\
\text { less deck, steel bars of varying lengths will reduce } \\
\text { track deflection and subgrade pressure }\end{array}$ \\
\hline
\end{tabular}




\section{Table 1 (continued)}

\begin{tabular}{|c|c|c|c|c|c|c|c|c|c|c|c|c|c|c|c|c|c|}
\hline 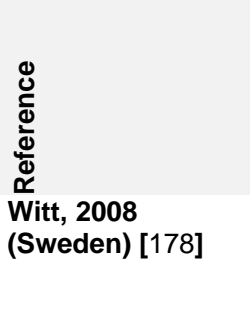 & $\begin{array}{l}\sum_{2}^{0} \\
\frac{0}{0} \\
\frac{0}{0} \\
3 D\end{array}$ & 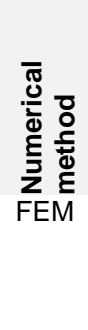 & 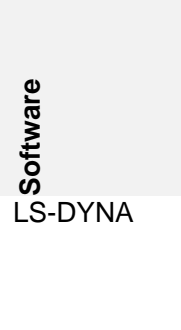 & $\begin{array}{l}\stackrel{0}{2} \\
\frac{0}{0} \\
\frac{0}{0} \\
\frac{2}{\pi} \\
\frac{2}{4} \\
\text { Dyn. }\end{array}$ & 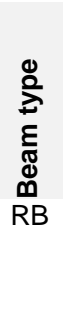 & 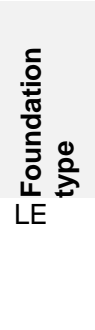 & 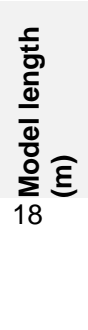 & 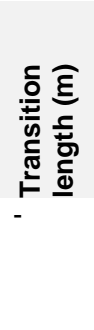 & 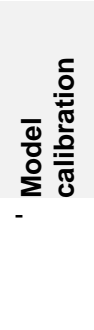 & 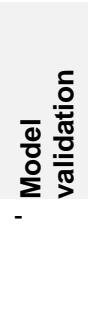 & 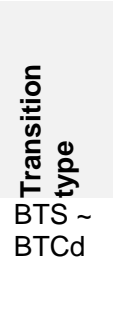 & 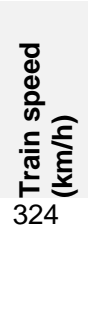 & 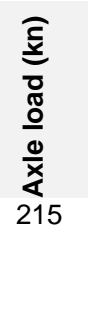 & 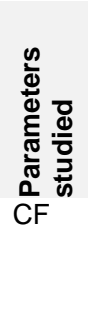 & 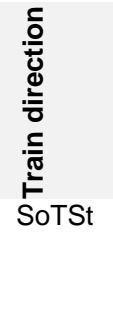 & 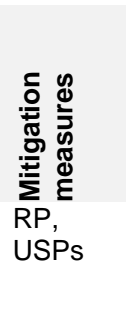 & $\begin{array}{l}\text { Medium strength USPs (with vertical stiffness of } \\
400 \mathrm{kn} / \mathrm{mm} \text { ) are better at reducing the wheel/rail } \\
\text { contact forces, Softer USPs help to reduce the } \\
\text { ballast contact forces }\end{array}$ \\
\hline $\begin{array}{l}\text { Namura and } \\
\text { Suzuki, 2007 } \\
\text { (Japan) [113] }\end{array}$ & $3 D$ & FEM & - & Dyn. & TB & LE & $\sim 5$ & - & - & Yes, & $\begin{array}{l}\text { BTS } \\
\text { BsTCd }\end{array}$ & $\begin{array}{l}100- \\
300\end{array}$ & $\sim 160$ & WL, & SoTSt & LS, RS & $\begin{array}{l}\text { Ballast settlement increased with the use of longer } \\
\text { sleepers (more) and the resilient sleepers (less), } \\
\text { length of approach track should be more than } 22 \mathrm{~m} \text {. } \\
\text { Resilient sleepers are best at reducing ballast } \\
\text { vibration }\end{array}$ \\
\hline $\begin{array}{l}\text { Read and Li, } \\
2006 \text { (Colorado) } \\
\text { [133] }\end{array}$ & $2 \mathrm{D}$ & FEM & GEOTRACK & QS & SB & LE & 115 & 0 & - & - & - & 80 & $\begin{array}{l}54 \\
67 \\
100\end{array}$ & $\begin{array}{l}\text { VtD, } \\
\text { BS, } \\
\text { TM }\end{array}$ & - & $\begin{array}{l}\text { CW, } \\
\text { AR, } \\
\text { HMA, } \\
\text { WS+LS }\end{array}$ & $\begin{array}{l}\text { Concrete slab is the best approach, followed by HMA, } \\
\text { and then additional rails. Longer and wider sleepers } \\
\text { at reduced spacing have an insignificant effect }\end{array}$ \\
\hline $\begin{array}{l}\text { Li and Davis, } \\
2005 \text { (Colorado) } \\
\text { [95] }\end{array}$ & $3 D$ & FEM & NUCARS & Dyn. & EB & LE & - & 30 & - & - & $\begin{array}{l}\text { BTS } \\
\text { BTCd }\end{array}$ & 160 & 178 & $\begin{array}{l}\text { WL, } \\
\mathrm{CF}\end{array}$ & - & - & $\begin{array}{l}\text { Variations in stiffness lead increase the variations in } \\
\text { dynamic load and wheel-rail interaction forces }\end{array}$ \\
\hline $\begin{array}{l}\text { Lei and Mao, } \\
2004 \text { (China) [91] }\end{array}$ & $2 \mathrm{D}$ & FEM & - & Dyn. & SB & LE & 231 & 20 & Yes & - & $\begin{array}{l}\text { BTS } \\
\text { BTCd }\end{array}$ & $\begin{array}{l}60- \\
300\end{array}$ & 170 & $\begin{array}{l}\text { CF, } \\
\text { TA }\end{array}$ & SoTSt & - & $\begin{array}{l}\text { Variations in vertical stiffness have no direct effect on } \\
\text { wheel/rail dynamic interaction forces. Permanent } \\
\text { settlement is the main cause of transition related } \\
\text { problems. Suggestions for irregularity angle and } \\
\text { length of transition zone }\end{array}$ \\
\hline $\begin{array}{l}\text { Hunt and } \\
\text { Winkler, } 1997 \\
\text { (UK) [62] }\end{array}$ & $2 \mathrm{D}$ & DEM & - & Dyn. & SB & LE & 10 & 2.0 & - & - & $\begin{array}{l}\text { BTS } \\
\text { BTCd }\end{array}$ & 150 & 110 & $\begin{array}{l}\text { VtD, } \\
\text { CF }\end{array}$ & SoTSt & USPs & $\begin{array}{l}\text { Rate of track settlement mainly depends on the Initial } \\
\text { settlement (voids under sleepers) owing to } \\
\text { accelerated settlement under impulsive loads }\end{array}$ \\
\hline
\end{tabular}

\section{Numerical Method (FEM: Finite Element Method, DEM: Discrete Element Method)}

Analysis Type (St.: Static, Dyn.: Dynamic, QS: Quasi-static),

Beam Type (TS: Timoshenko, EB: Euler-Bernoulli, HL: Hughes-Liu, SB: Simple Beam, RB: Rectangular Beam),

Foundation Type (LE: Linear Elastic, NLE: Non-linear Elastic, LVE: Linear Visco- elastic, NLVE: Non-linear Visco-elastic, EP: Elastoplastic)

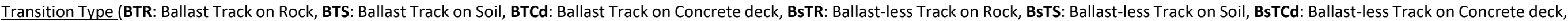
BTCc: Ballast Track on Concrete Culvert, BTCv: Ballast Track on Concrete Viaduct, BsTAS: Ballast-less Track on Asphalt Slab),

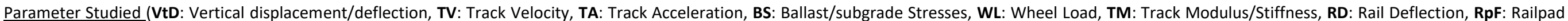
Force, CF: Contact Forces, BPA: Ballast Particles Acceleration),

Train Direction (SoTSt: Soft to Stiff, StTSo: Stiff to Soft),

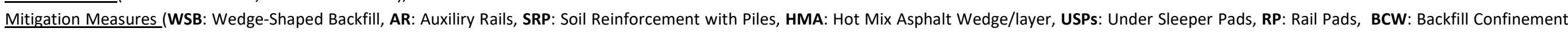

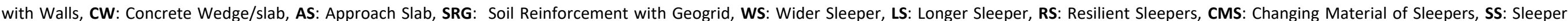
Spacing/Location, MCE: Moisture Contenet Effect, SB: Steel Bars, HSb: Hydraulic sub-base ) 
Table 2: Summarised outcomes of field mesurements on track transition zones

\begin{tabular}{|c|c|c|c|c|c|c|c|c|c|c|}
\hline Author & Description & 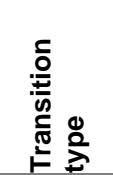 & 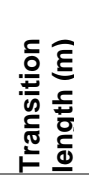 & 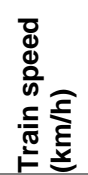 & 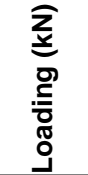 & 总 & 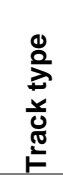 & 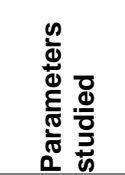 & 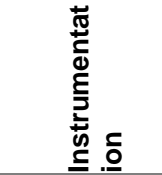 & Outcomes \\
\hline $\begin{array}{l}\text { Boler et al., } 2019 \\
\text { (USA) [15] }\end{array}$ & Stone blowing & $\begin{array}{l}\text { BTS } \\
\text { BTCd }\end{array}$ & & 177 & 150 & & PT & $\begin{array}{l}\mathrm{VtD}, \\
\mathrm{WL}, \mathrm{TA}, \\
\mathrm{BS}\end{array}$ & MDD, SG & $\begin{array}{l}60 \% \text { reduction in transient displacements, Reduction in vertical acceleration and in gaps at sleeper- } \\
\text { ballast interface, increased effectiveness and longevity }\end{array}$ \\
\hline $\begin{array}{l}\text { Paixão et al., } 2018 \\
\text { (Portugal) }[126]\end{array}$ & WSB+USPS & $\begin{array}{l}\text { BTS } \\
\text { BTC } v\end{array}$ & 20 & 220 & 250 & & MT & $\begin{array}{l}\text { RD, TA, } \\
\text { SD }\end{array}$ & $\begin{array}{l}\text { SG, LU, } \\
\text { PSD, Acm, } \\
\text { LVDT }\end{array}$ & $\begin{array}{l}\text { Variations in the vertical stiffness of various sections along the transition, USPs with } t=7 \mathrm{~mm} \\
\text { reduced the stiffness by } 30 \% \text { of embankment but increases by } 22 \% \text { for UGM, USPs with } \mathrm{t}=10 \mathrm{~mm} \\
\text { reduced the stiffness by } 27 \% \text { for CBM but remains same for CBM and concrete }\end{array}$ \\
\hline $\begin{array}{l}\text { Wang and } \\
\text { Markine, } 2018 \\
\text { (Netherlands) } \\
\text { [174] }\end{array}$ & $\begin{array}{l}\text { methodology for } \\
\text { comprehensive } \\
\text { analysis of railway } \\
\text { transition zones }\end{array}$ & $\begin{array}{l}\text { BTS } \\
\text { BTCd }\end{array}$ & 24 & 104 & 186 & Both & PT & VtD & VGS & $\begin{array}{l}\text { Maximum displacement close to bridge is higher than the far end, maximum displacement is larger } \\
\text { for embankment } \sim \text { bridge case than the bridge embankment case of train movement, Differential } \\
\text { settlement at transition zones causes hanging sleepers }\end{array}$ \\
\hline $\begin{array}{l}\text { Zuada Coelho et } \\
\text { al., } 2018 \\
\text { (Netherlands) [26] }\end{array}$ & Approach slab & $\begin{array}{l}\text { BTS } \\
\text { BTCc }\end{array}$ & 4 & $\begin{array}{l}65- \\
106\end{array}$ & $\begin{array}{l}76- \\
142\end{array}$ & Both & PT & $\begin{array}{l}\text { VtD, } \\
\text { WL, TS }\end{array}$ & $\begin{array}{l}\text { Gp, Acm, } \\
\text { VC, SG }\end{array}$ & $\begin{array}{l}\text { Large differences in displacement and increased wheel loads show the presence of hanging } \\
\text { sleepers. Non symmetric response and non-uniform distribution of track displacements indicates } \\
\text { inefficiency at the transition zone. Pivoting about the culvert generates enhanced impact loading }\end{array}$ \\
\hline $\begin{array}{l}\text { Stark and Wynn, } \\
2018 \\
\text { (USA) [155] }\end{array}$ & $\begin{array}{l}\text { Reinforcement } \\
\text { (Geoweb, HMA, } \\
\text { Grout) }\end{array}$ & $\begin{array}{l}\text { BTS } \\
\text { BTCd }\end{array}$ & 15 & & $\begin{array}{l}30 \\
\text { MGT }\end{array}$ & & FT & $\mathrm{VtD}, \mathrm{TA}$ & $\mathrm{VC}, \mathrm{Acm}$ & $\begin{array}{l}\text { Geosynthetic reinforced transitions are less expensive, perform well for freight loads and reduce } \\
\text { differential vertical displacements. Geoweb can be used as an alternative to HMA. With } \\
\text { Geosynthetic reinforcement stiffness increases (in approaches) and decreases (while used under } \\
\text { bridge abutments) }\end{array}$ \\
\hline $\begin{array}{l}\text { Wilk et al., } 2016 \\
\text { (USA) [177] }\end{array}$ & $\begin{array}{l}\text { Sleeper support } \\
\text { effect, BCW, HMA }\end{array}$ & $\begin{array}{l}\text { BTS } \\
\text { BsTCd }\end{array}$ & 8.2 & $\begin{array}{l}16 \\
40 \\
177\end{array}$ & 280 & Both & $\begin{array}{l}\text { PT, } \\
\text { FT, } \\
\text { MT }\end{array}$ & $\begin{array}{l}\text { VtD, } \\
\text { WL, TA, } \\
\text { VF }\end{array}$ & Acm & $\begin{array}{l}\text { For tracks with better sleeper support, peak acceleration remains below } 5 \mathrm{~g} \text { for various types of } \\
\text { trains, speeds, and loads, indicating smooth load transfer between track components, whereas } \\
\text { poor sleeper support means that acceleration varies from } 5 \mathrm{~g} \text { to } 10 \mathrm{~g} \text {. Accelerometer data indicates a } \\
\text { qualitative analysis of the track support and not quantitative }\end{array}$ \\
\hline $\begin{array}{l}\text { Mishra et al., } 2014 \\
\text { (IIlinois) [107] }\end{array}$ & Railpads, & $\begin{array}{l}\text { BTS } \\
\text { BTCd }\end{array}$ & & $\begin{array}{l}177- \\
241\end{array}$ & 135 & Both & MT & $\begin{array}{l}\text { VtD, } \\
\text { WL, TA }\end{array}$ & MDD, SG & $\begin{array}{l}\text { Data obtained for track deformation and corresponding loading through field instrumentation is } \\
\text { utilised to calibrate a } 3 D \text { track dynamic model }\end{array}$ \\
\hline $\begin{array}{l}\text { Fortunato et al., } \\
2013 \\
\text { (Portugal) [44] }\end{array}$ & $\begin{array}{l}\text { Wedge-shaped } \\
\text { approach }\end{array}$ & $\begin{array}{l}\text { BTS } \\
\text { BTCd }\end{array}$ & 20 & 220 & $\begin{array}{l}66- \\
125\end{array}$ & SoTSt & MT & VtD & $\begin{array}{l}\text { SG, LU, } \\
\text { PSD, Acm, } \\
\text { LVDT, IT }\end{array}$ & $\begin{array}{l}\text { Passenger trains at higher speed cause more acceleration amplitude at sleepers than heavy freight } \\
\text { at lower speeds. Using wedge-shaped approach leads to a gradual transition of vertical stiffness, } \\
\text { and settlement seems to stabilise after one year of construction }\end{array}$ \\
\hline $\begin{array}{l}\text { Namura and } \\
\text { Suzuki, 2007 } \\
\text { (Japan) [113] }\end{array}$ & $\begin{array}{l}\text { Railpads,subgrade } \\
\text { stabilization, Auxiliary } \\
\text { rails, Ggluing resin }\end{array}$ & $\begin{array}{l}\text { BTS } \\
\text { BTCd }\end{array}$ & 20 & $\begin{array}{l}100- \\
300\end{array}$ & & Both & PT & WL, TA & SG, TLV & $\begin{array}{l}\text { Variations in loads occur on ballast track at transition zone. Application of rail pads has no effect on } \\
\text { track irregularities. Axle load variation at track transition found which increased with increasing } \\
\text { speed. More variations in acceleration while travelling from a ballast track to a slab track }\end{array}$ \\
\hline $\begin{array}{l}\text { Li and Davis, } \\
2005 \text { (Colorado) } \\
{[95]}\end{array}$ & $\begin{array}{l}\text { HMA, geocell, Thick } \\
\text { ballast, cement } \\
\text { stabilised }\end{array}$ & $\begin{array}{l}\text { BTS } \\
\text { BTCd }\end{array}$ & 30 & 160 & 178 & Both & FT & $\begin{array}{l}\mathrm{RD}, \\
\mathrm{VtD}, \mathrm{TS}\end{array}$ & SE, TLV & $\begin{array}{l}\text { More track geometry degradation at bridge approaches, No improvement in track performance, a } \\
\text { very high initial settlement rate of } 100 \text { to } 180 \mathrm{~mm} \text { in just six months ( } 80 \mathrm{MGT} \text { ), Rubber mats reduce } \\
\text { track stiffness and increase track damping }\end{array}$ \\
\hline
\end{tabular}

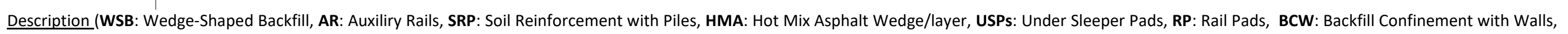

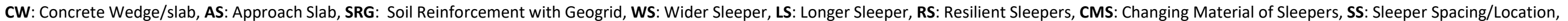
MCE: Moisture Contenet Effect, SB: Steel Bars, HSb: Hydraulic sub-base )

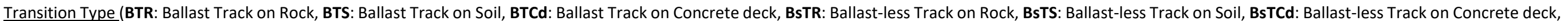

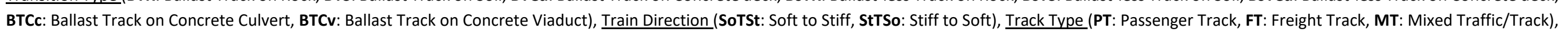

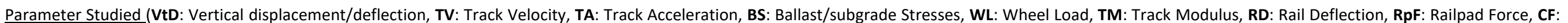
Contact Forces, BPA: Ballast Particles Acceleration),

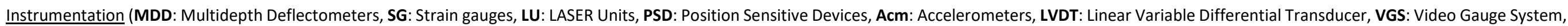
VC: Video Cameras, Gp: Geophones, IT: Inclinometer Tubes, SE: Survey Equipments, TLV: Track Loading Vehicle 


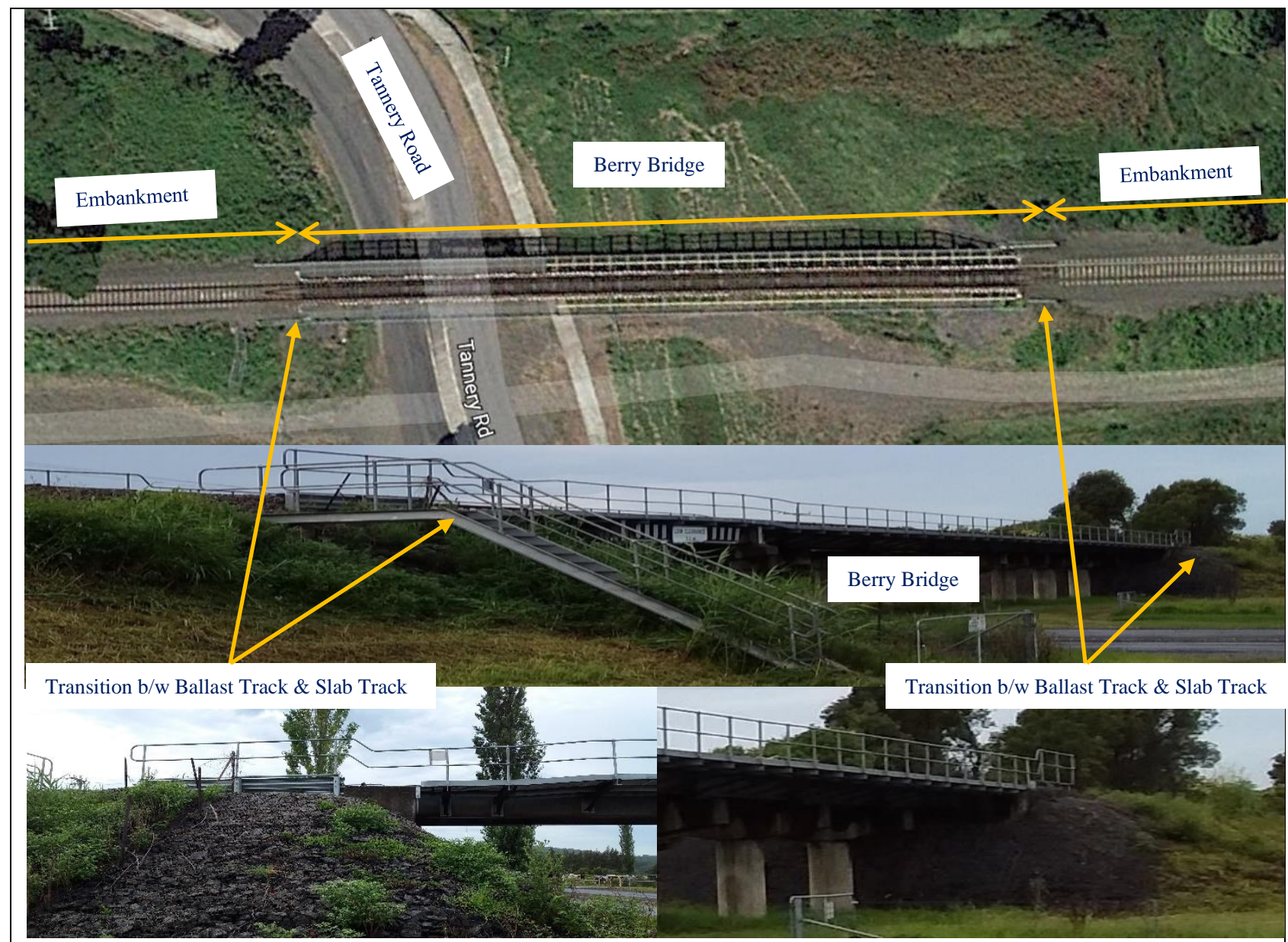

(a) Track transitions at Berry bridge crossing Tannery road, NSW, Australia

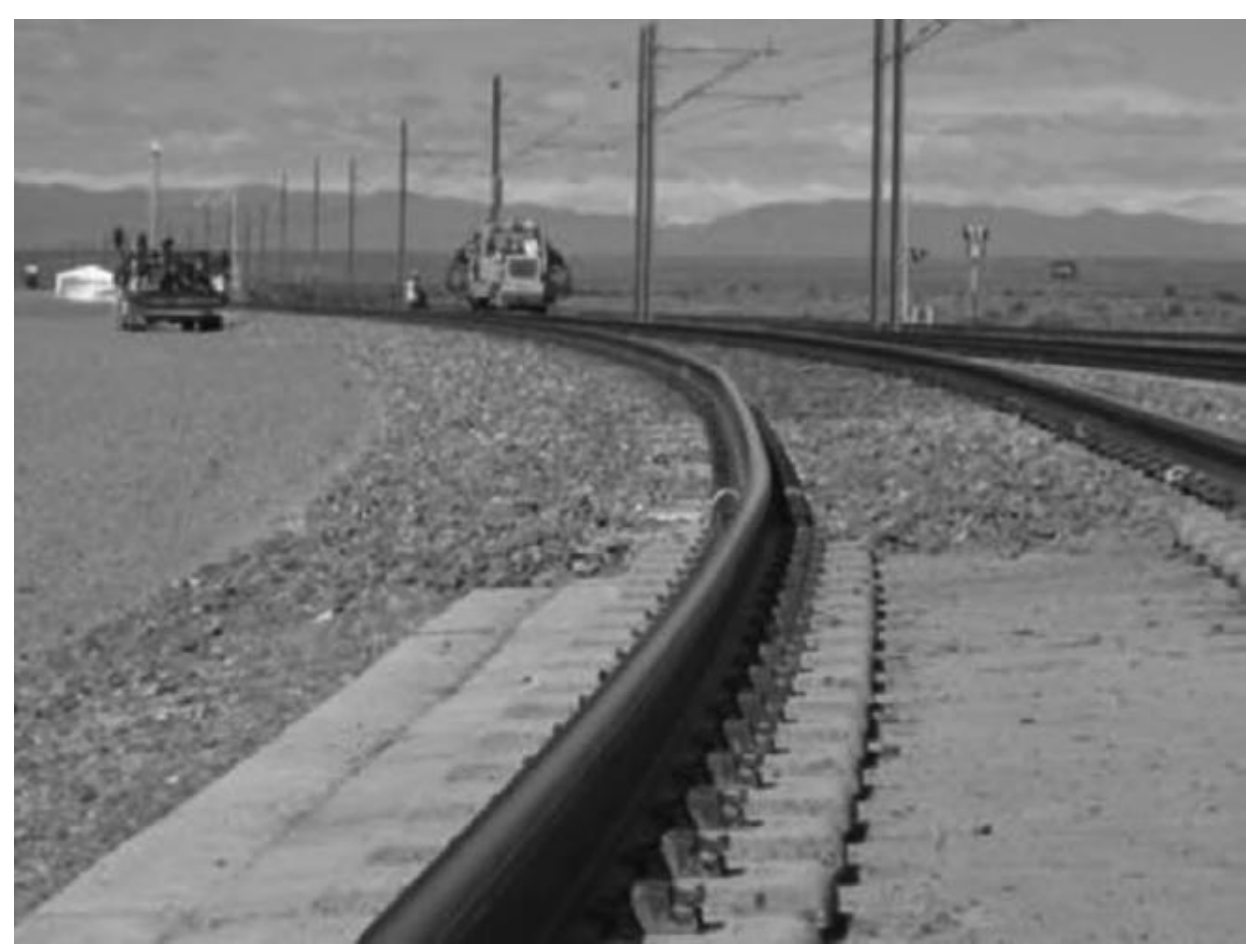

(b) Slab track to ballast track transitions indicating alignment error (adopted from [96])

Figure 1: Rail track transitions due to sudden change in substructural components 


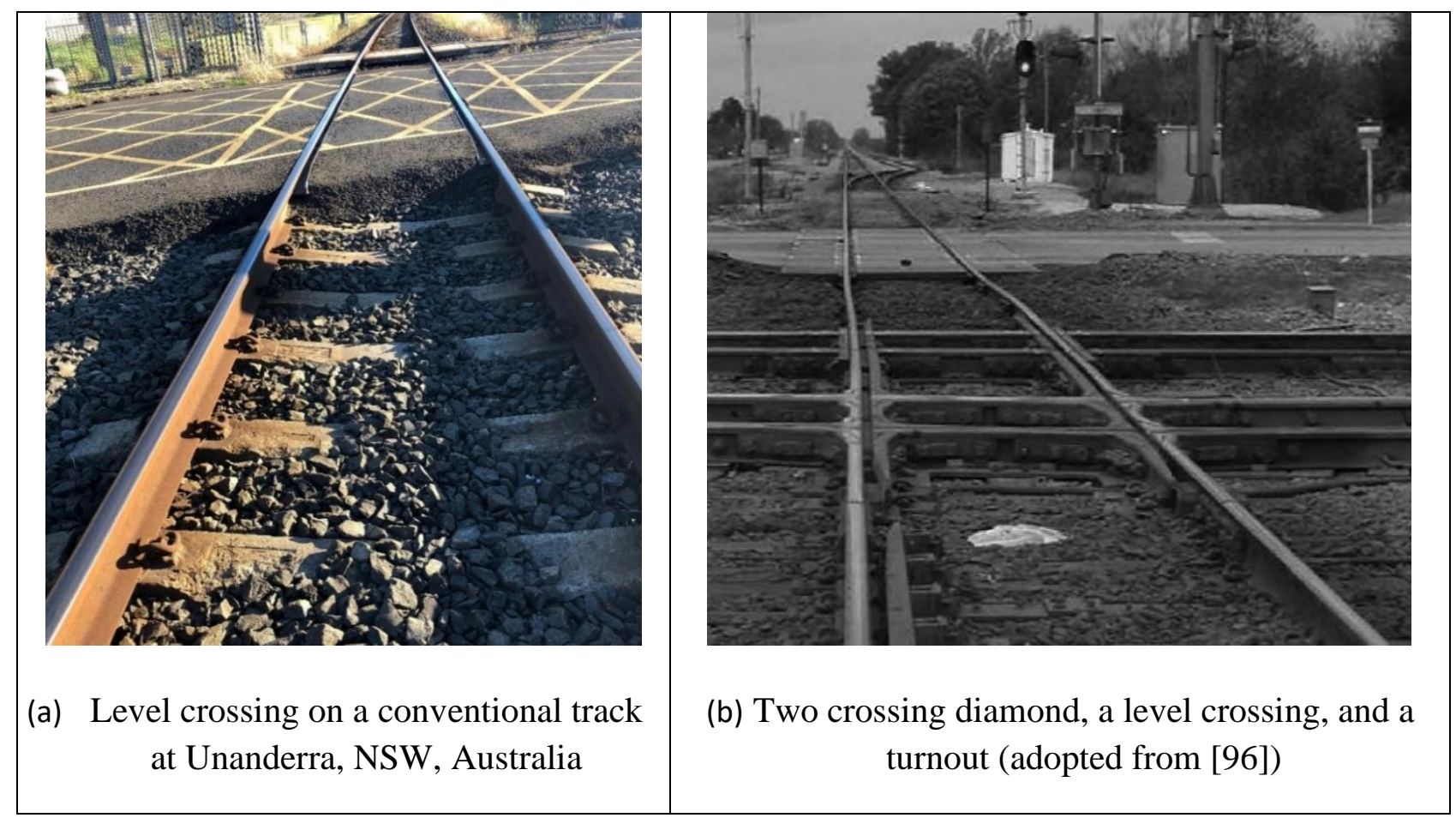

Figure 2: Rail track transitions due to the change of superstructural components 


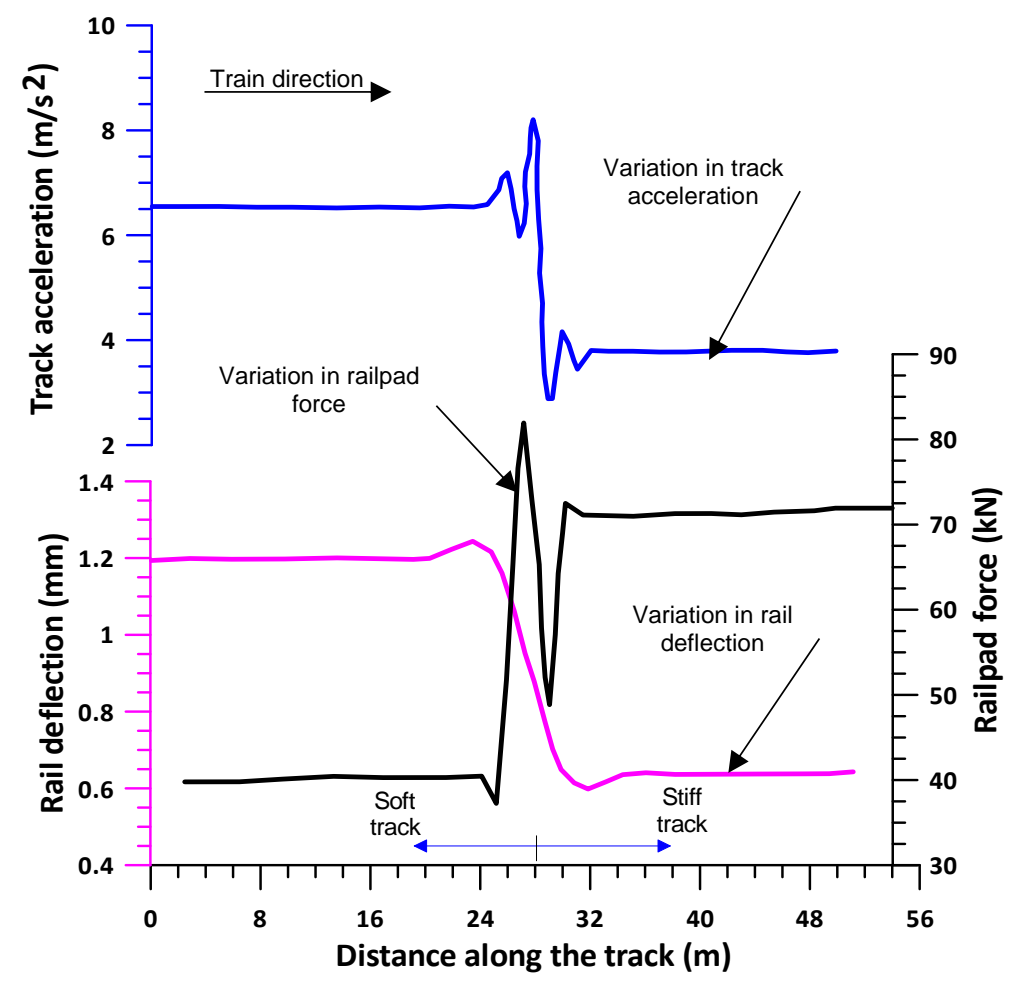

Figure 3: Variation in rail deflection, railpad force and track acceleration at track transition (data source: [34]) 


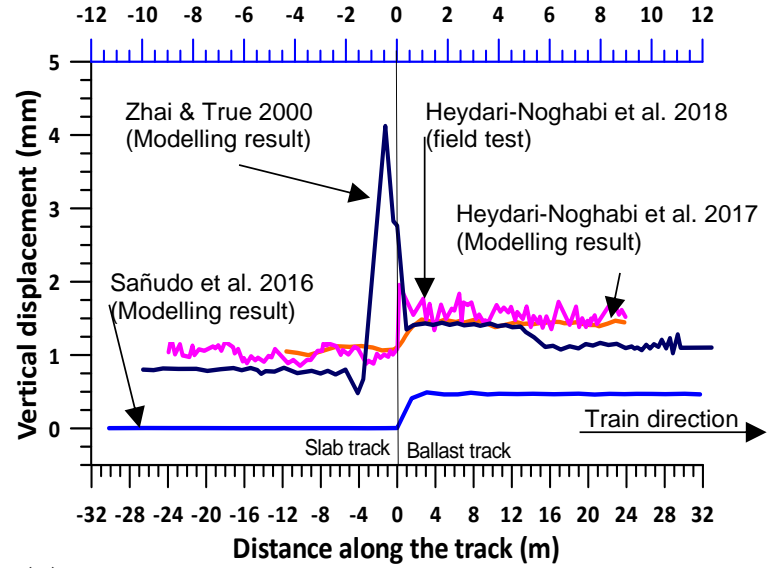

(a)

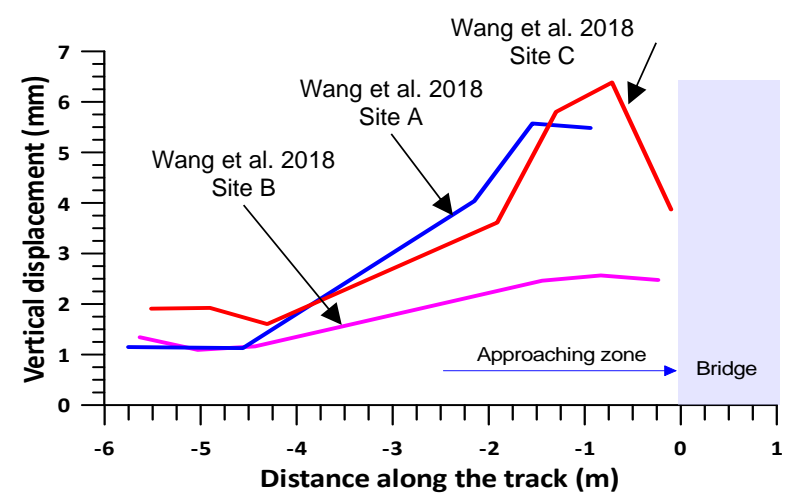

(c)

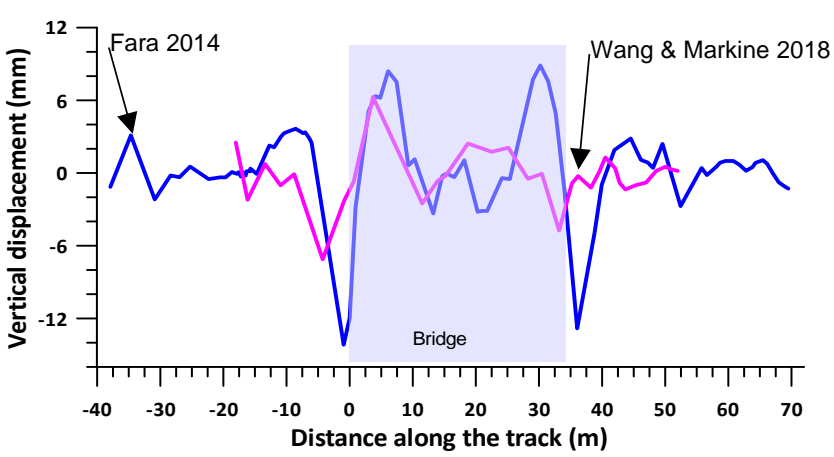

(b)

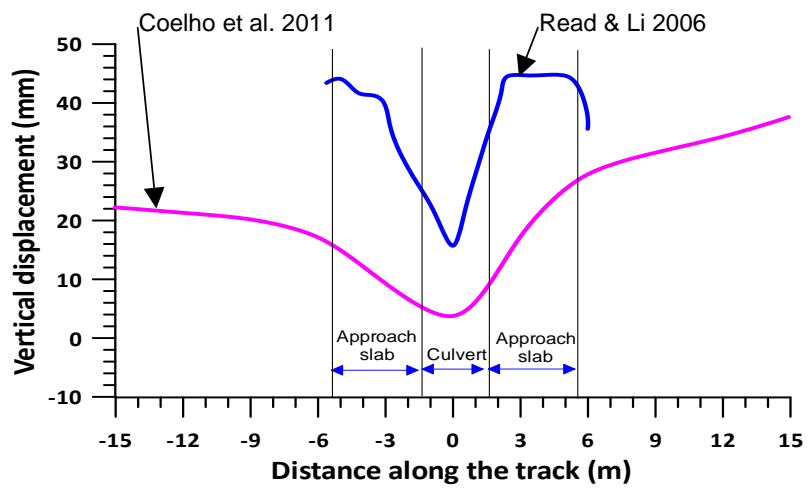

(d)

Figure 4: Comparison of differential settlements measured at various track transitions; (a) slab track to ballast track, (b) bridge crossing, (c) bridge approaches and (d) culvert crossing 


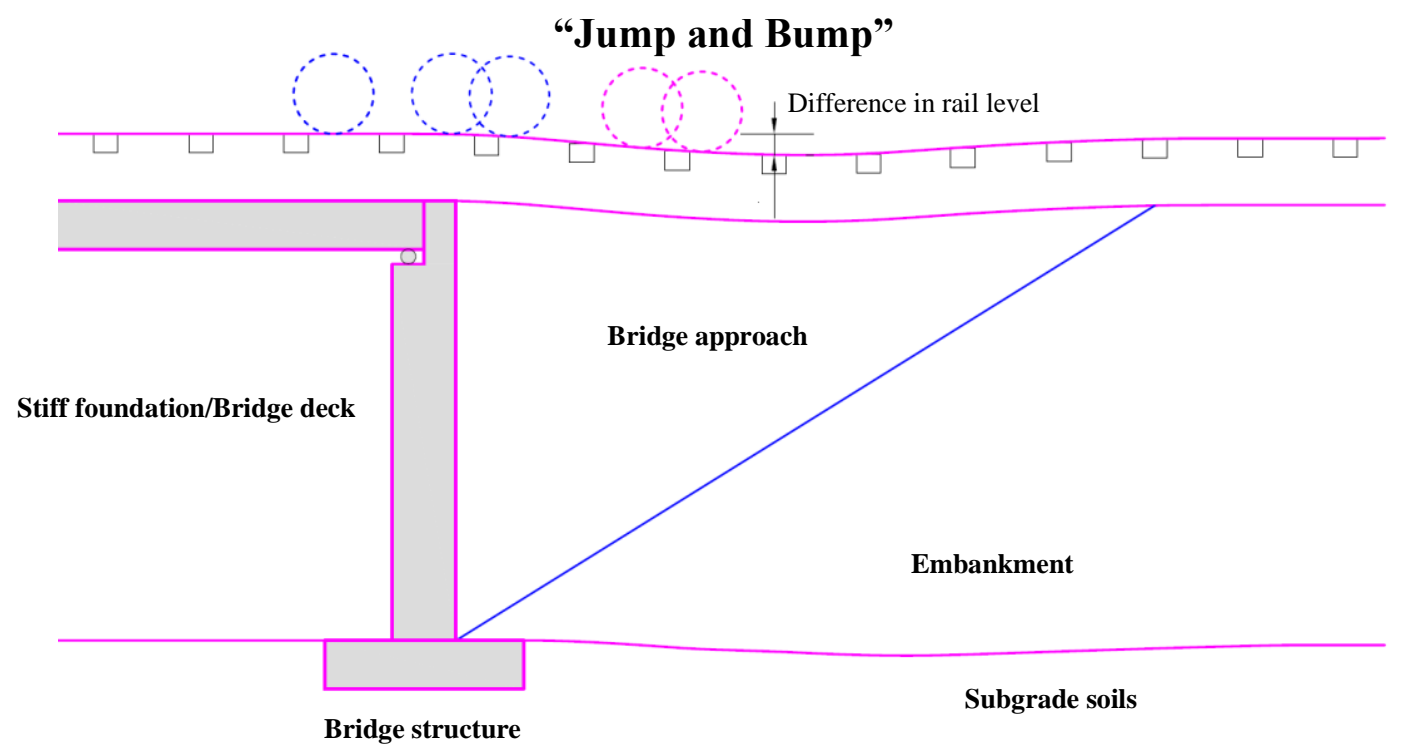

Figure 5: Schematic diagram of the development of bump/dip at bridge approaches (modified after [43]) 


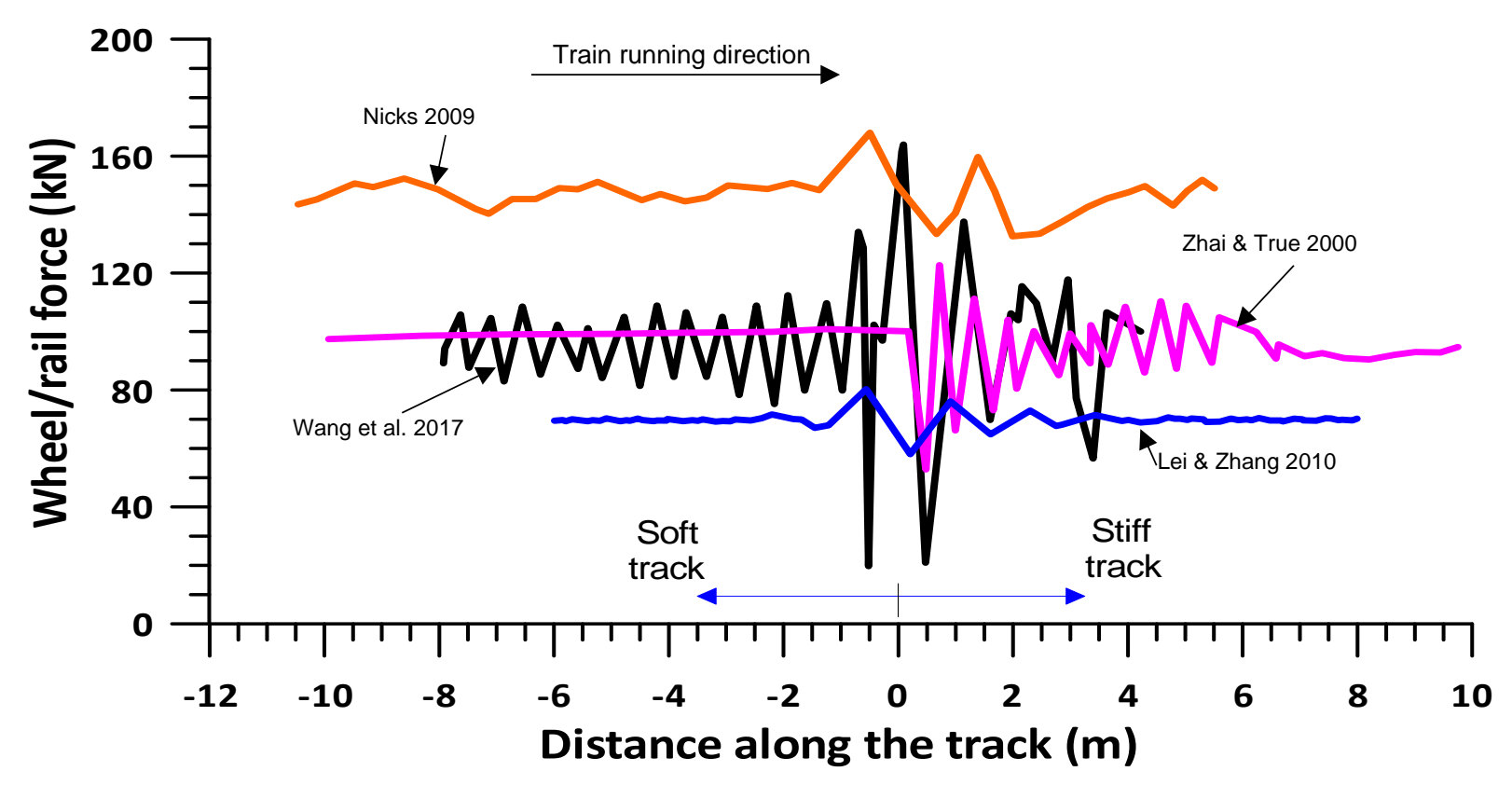

Figure 6: Variation in wheel rail interaction forces at track transition 


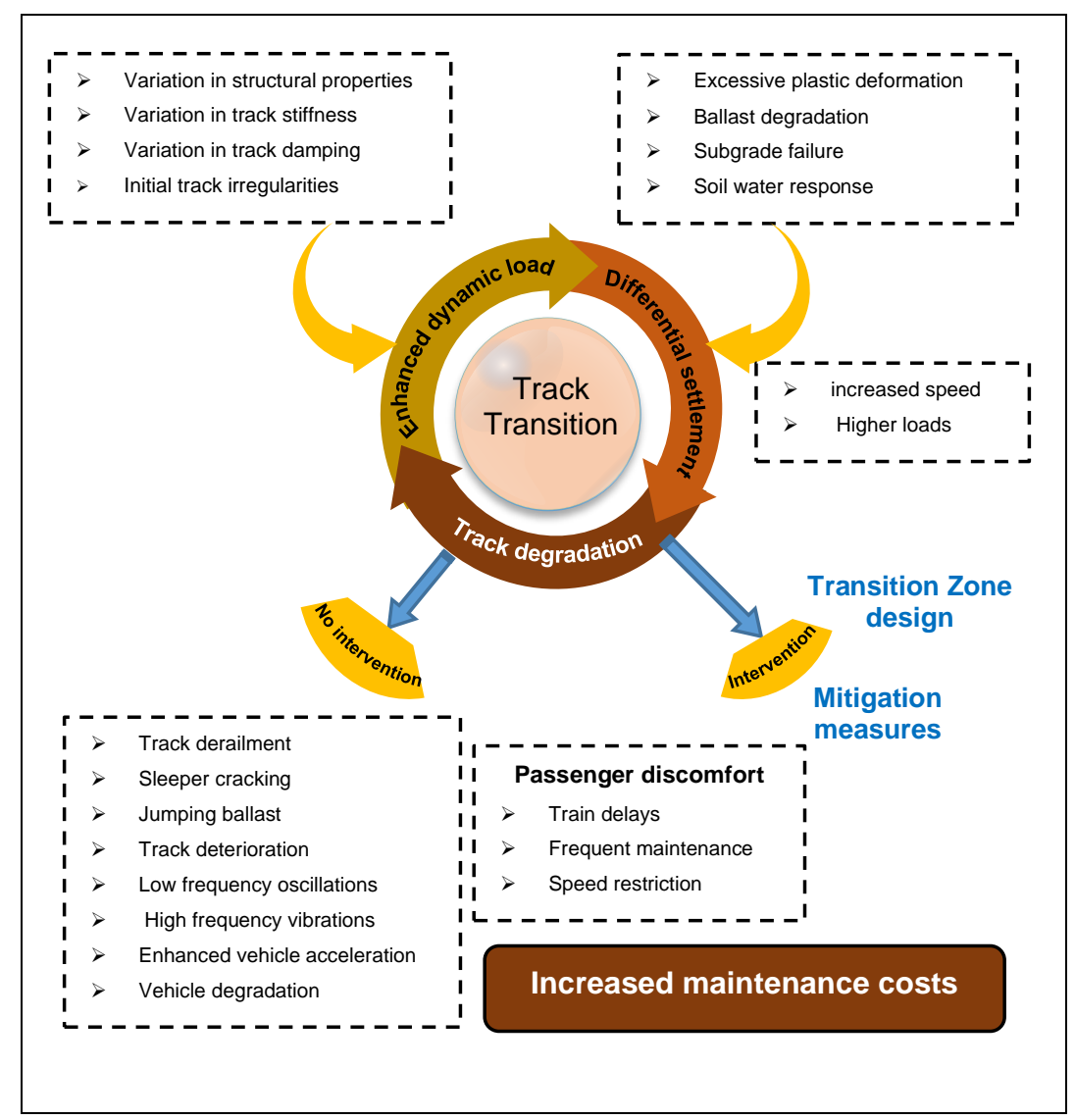

Figure 7: Summarised track transition problems: causes and effects (inspired by [122]) 


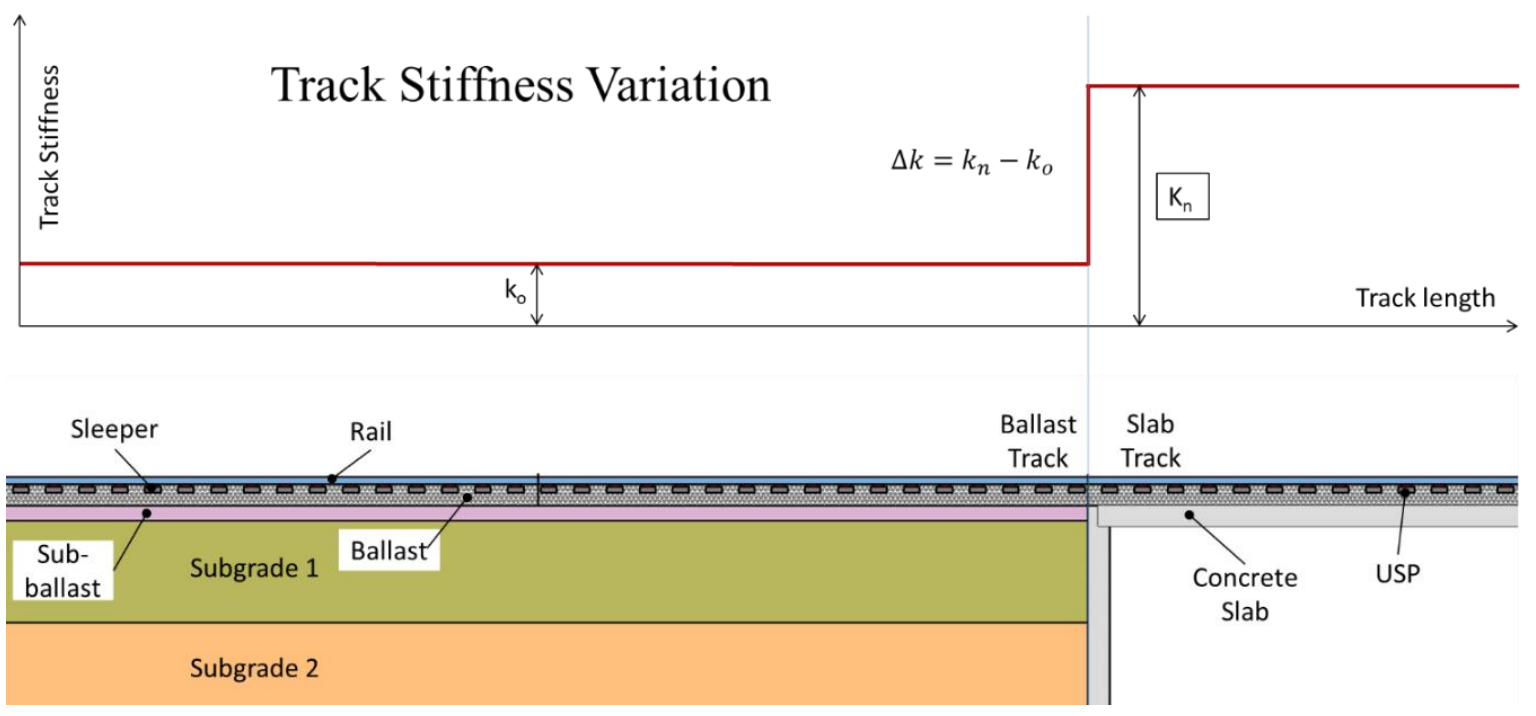

Figure 8: Track stiffness variation from a ballasted track to a slab track at transition zones 


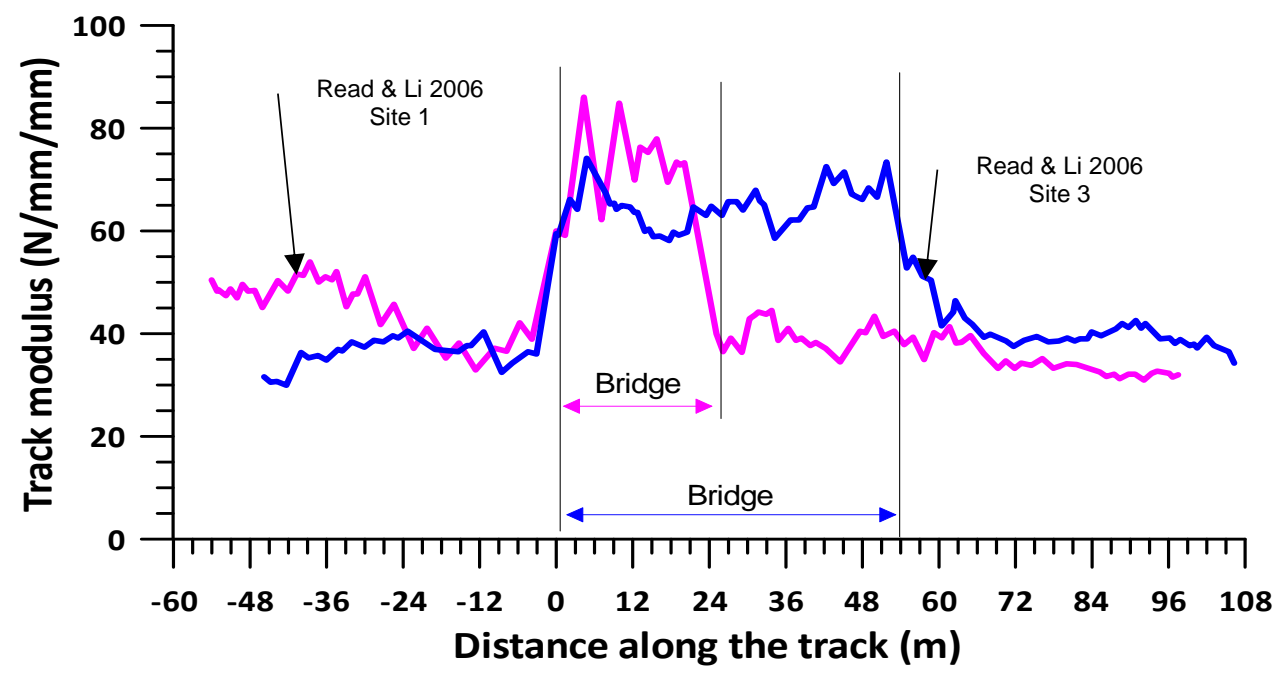

(a)

Distance along the track $(\mathrm{m})$

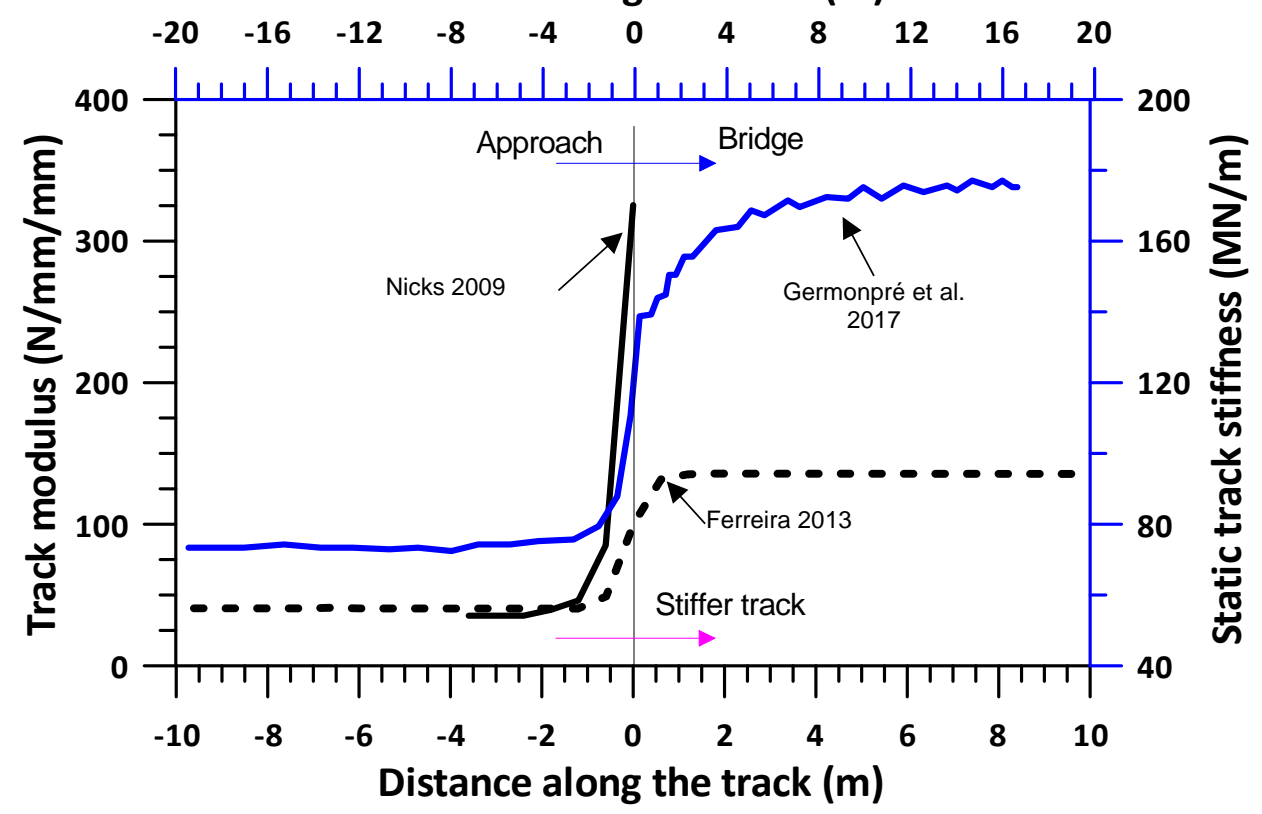

(b)

Figure 9: Abrupt variation in track modulus/stiffness at various track transitions; (a) at bridge crossings, (b) soft to stiff track transition 
Continuous stiffness measurements, West coast line in Sweden, east track w37 2001, $20 \mathrm{~km} / \mathrm{h} \mathrm{5,7} \mathrm{Hz}$

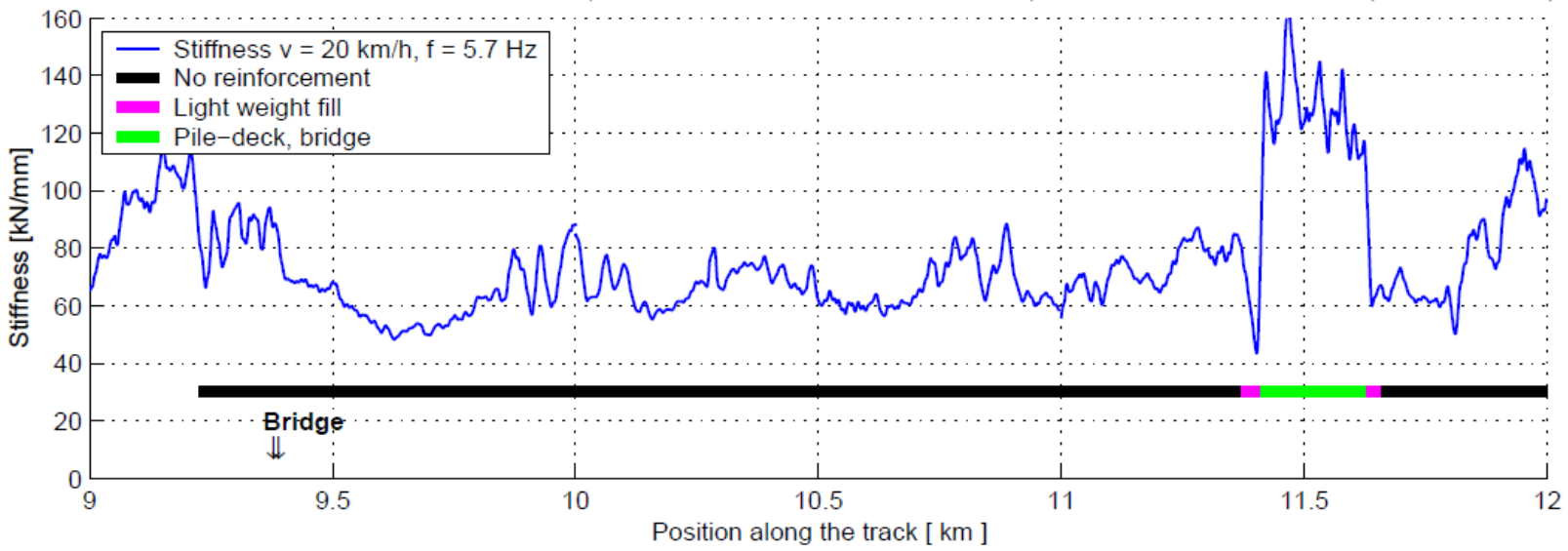

Figure 10: Variation in track stiffness for various track types along the railway track (adopted from [30]) 


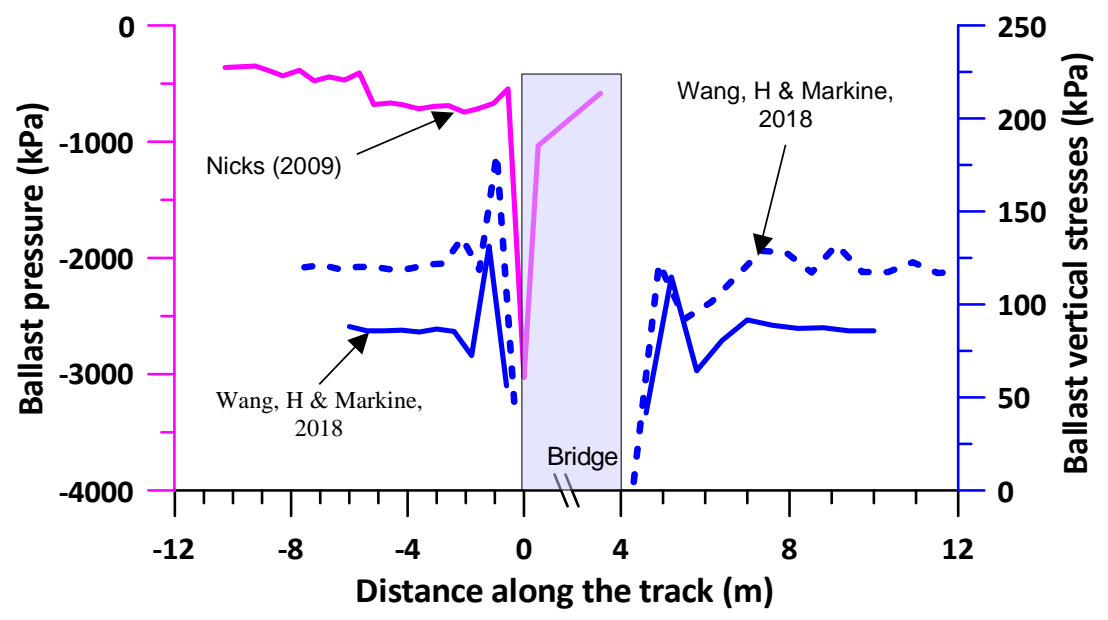

Figure 11: Variation in measured ballast stresses at various track transitions 

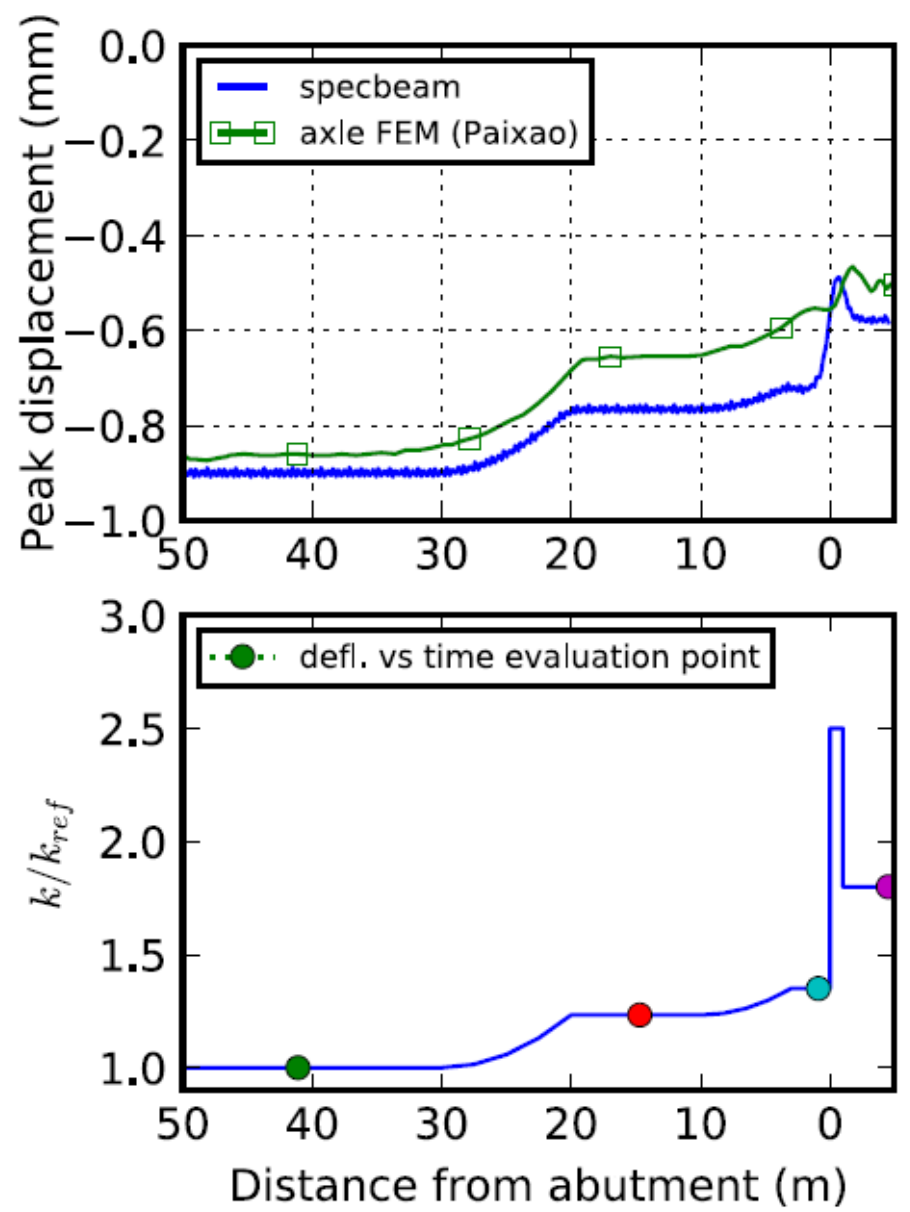

Figure 12: Peak displacement and stiffness distribution at transition zone (data source: [169]) 


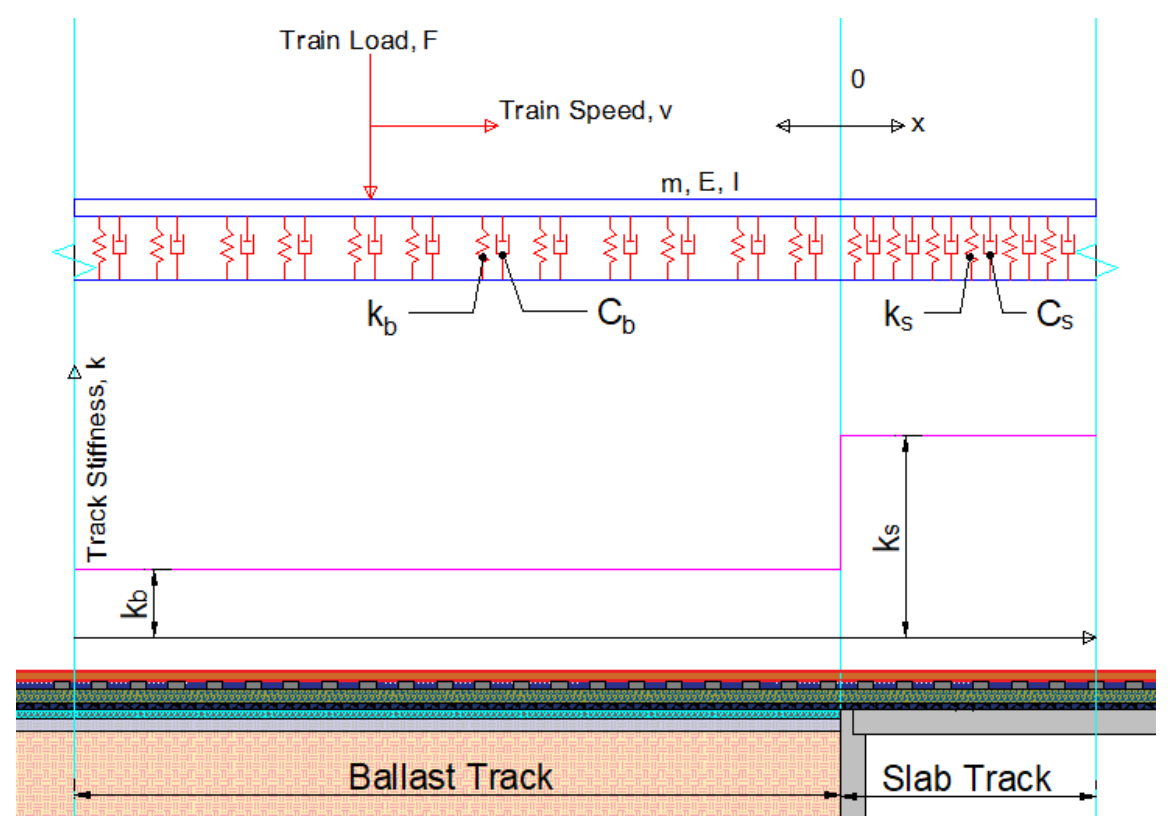

Figure 13: Mass and spring-dashpot models for ballast track to slab track transition 


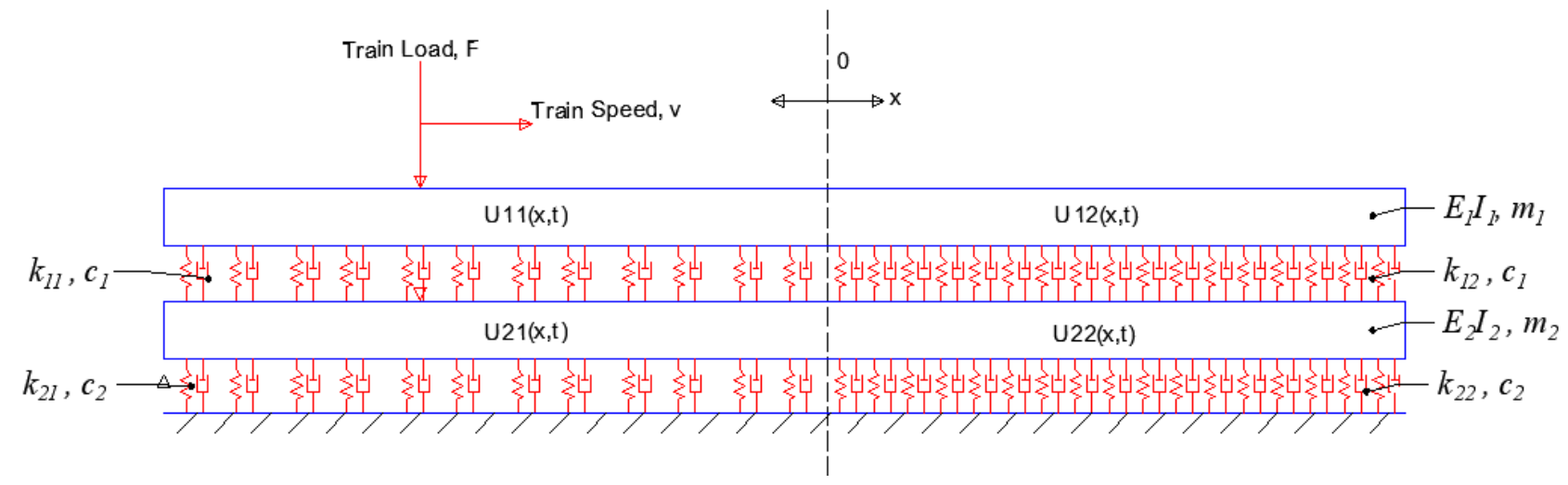

Figure 14: Two layers mass spring-dashpot model for track transition 


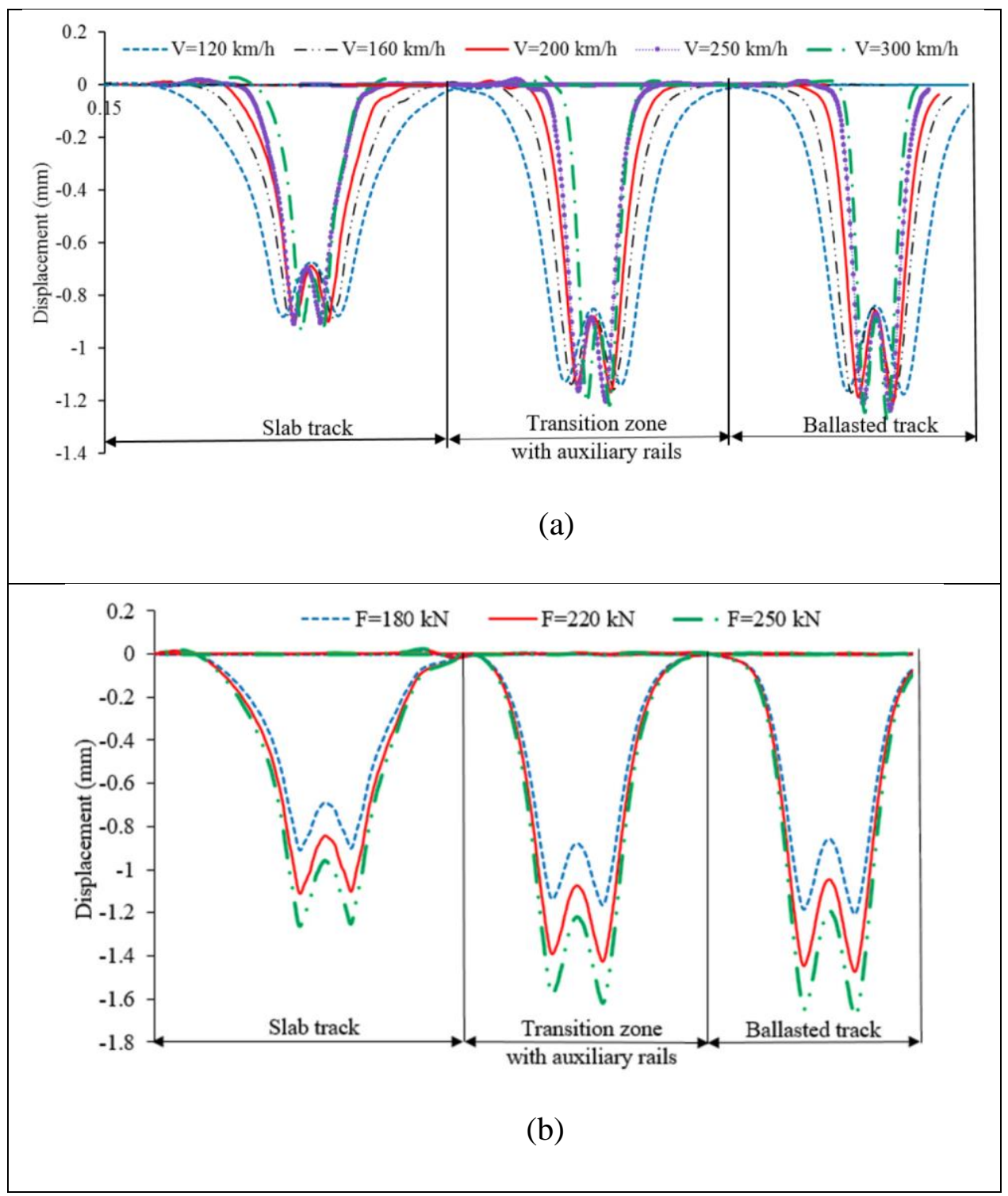

Figure 15: Rail deflection along the transition zone (a) for $180 \mathrm{kN}$ vehicle load and various speeds, (b) for $200 \mathrm{~km} / \mathrm{h}$ speed and various vehicle loads (adopted from [56]). 


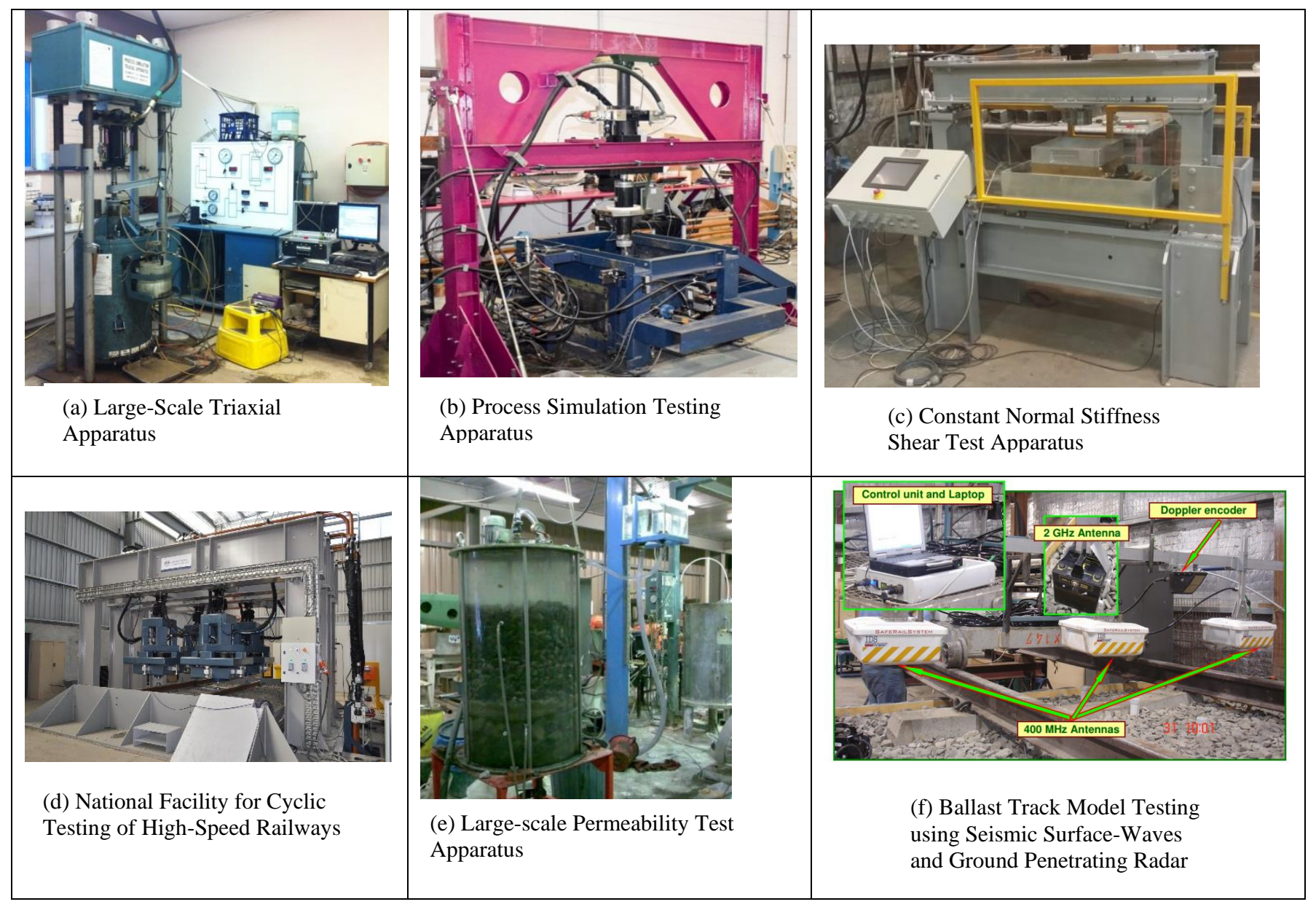

Figure 16: Selected large-scale ballast testing equipment at the University of Wollongong Australia 


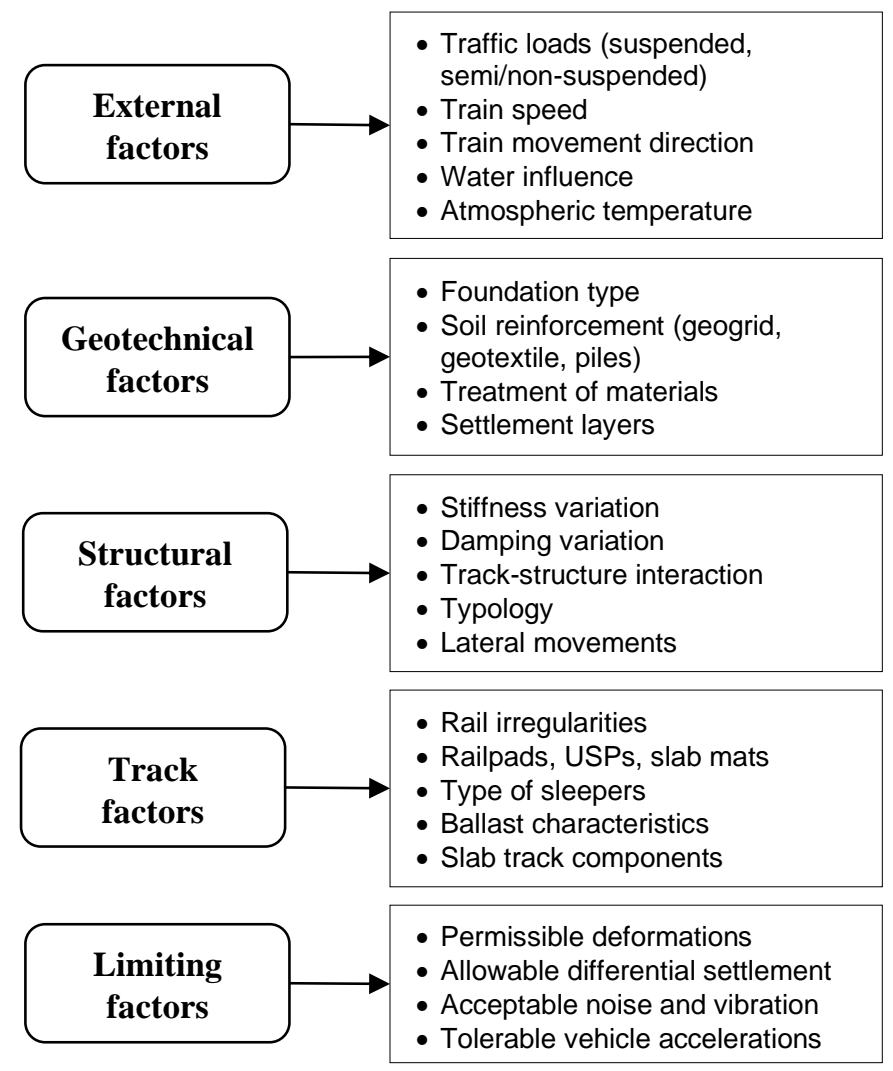

Figure 17: Summarised important factors for transition zone design considerations 


\section{References}

1. Abadi, T., L. Le Pen, A. Zervos and W. Powrie. A review and evaluation of ballast settlement models using results from the southampton railway testing facility (srtf). Proceedings of the 3rd International conference on transportation geotechnics. 2016; 143: 999-1006.

2. Abadi, T., L. L. Pen, A. Zervos and W. Powrie, Effect of sleeper interventions on railway track performance. Journal of Geotechnical and Geoenvironmental Engineering, 2019. 145(4): p. 04019009.

3. Admetlla Pérez, N., Transición vía en placa-vía con balasto mediante traviesas cuadro. Minor thesis. Universitat Politècnica de Catalunya · BarcelonaTech (UPC); 2010.

4. Aggestam, E. and J. C. Nielsen, Multi-objective optimisation of transition zones between slab track and ballasted track using a genetic algorithm. Journal of Sound and Vibration, 2019. 446: p. 91-112.

5. Alves Ribeiro, C., A. Paixão, E. Fortunato and R. Calçada, Under sleeper pads in transition zones at railway underpasses: Numerical modelling and experimental validation. Structure and Infrastructure Engineering, 2015. 11(11): p. 1432-1449.

6. Aursudkij, B., G. McDowell and A. Collop, Cyclic loading of railway ballast under triaxial conditions and in a railway test facility. Granular Matter, 2009. 11(6): p. 391.

7. Banimahd, M., Advanced finite element modelling of coupled train-track systems: A geotechnical perspective. PhD thesis. Heriot-Watt University; 2008.

8. Banimahd, M. and P. Woodward. 3-dimensional finite element modelling of railway transitions. Proceedings of the 9th international conference on railway engineering. 2007.

9. Banimahd, M., P. K. Woodward, J. Kennedy and G. M. Medero. Behaviour of train-track interaction in stiffness transitions. Proceedings of the Institution of Civil Engineers-Transport. 2012; 165: 205-214.

10. Berggren, E., Railway track stiffness: Dynamic measurements and evaluation for efficient maintenance. PhD thesis. Stockholm; Royal Institute of Technology (KTH); 2009.

11. Beskou, N. D. and D. D. Theodorakopoulos, Dynamic effects of moving loads on road pavements: A review. Soil Dynamics and Earthquake Engineering, 2011. 31(4): p. 547-567.

12. Biabani, M. M., B. Indraratna and N. T. Ngo, Modelling of geocell-reinforced subballast subjected to cyclic loading. Geotextiles and Geomembranes, 2016. 44(4): p. 489-503.

13. Biabani, M. M., N. T. Ngo and B. Indraratna, Performance evaluation of railway subballast stabilised with geocell based on pull-out testing. Geotextiles and Geomembranes, 2016. 44(4): p. 579-591.

14. Bian, X., W. Li, Y. Qian and E. Tutumluer, Micromechanical particle interactions in railway ballast through dem simulations of direct shear tests. International Journal of Geomechanics, 2019. 19(5): p. 04019031.

15. Boler, H., D. Mishra, E. Tutumluer, S. Chrismer and J. P. Hyslip, Stone blowing as a remedial measure to mitigate differential movement problems at railroad bridge approaches. Proceedings of the Institution of Mechanical Engineers, Part F: Journal of Rail and Rapid Transit, 2019. 233(1): p. 63-72.

16. Briaud, J.-L., Settlement of bridge approaches:(the bump at the end of the bridge). Vol. 234. 1997: Transportation Research Board.

17. Brown, S., B. Brodrick, N. Thom and G. McDowell. The nottingham railway test facility, uk. Proceedings of the Institution of Civil Engineers-Transport. 2007; 160: 59-65.

18. Brown, S., J. Kwan and N. Thom, Identifying the key parameters that influence geogrid reinforcement of railway ballast. geotextiles and geomembranes, 2007. 25(6): p. 326-335.

19. Cai, C., X. Shi, G. Voyiadjis and Z. J Zhang, Structural performance of bridge approach slabs under given embankment settlement. Vol. 10. 2005.

20. Carrascal, I., J. Casado, J. Polanco and F. Gutiérrez-Solana. Comportamiento dinámico de placas de asiento de sujeción de vía de ferrocarril. Proceedings of the Anales de mecánica de la fractura. 2005; 22: 372-377.

21. Čebašek, T. M., A. Esen, P. Woodward, O. Laghrouche and D. Connolly, Full scale laboratory testing of ballast and concrete slab tracks under phased cyclic loading. Transportation 
Geotechnics, 2018. 17: p. 33-40.

22. Chen, C., Discrete element modelling of geogrid-reinforced railway ballast and track transition zones. PhD thesis. University of Nottingham; 2013.

23. Chen, C. and G. R. McDowell, An investigation of the dynamic behaviour of track transition zones using discrete element modelling. Proceedings of the Institution of Mechanical Engineers, Part F: Journal of Rail and Rapid Transit, 2016. 230(1): p. 117-128.

24. Choi, J., Influence of track support stiffness of ballasted track on dynamic wheel-rail forces. Journal of transportation engineering, 2013. 139(7): p. 709-718.

25. Coelho, B., P. Hölscher, J. Priest, W. Powrie and F. Barends, An assessment of transition zone performance. Proceedings of the Institution of Mechanical Engineers, Part F: Journal of Rail and Rapid Transit, 2011. 225(2): p. 129-139.

26. Coelho, B., J. Priest and P. Hölscher, Dynamic behaviour of transition zones in soft soils during regular train traffic. Proceedings of the Institution of Mechanical Engineers, Part F: Journal of Rail and Rapid Transit, 2018. 232(3): p. 645-662.

27. Correia, A. G. and S. Gillett. A large triaxial apparatus for the study of granular materials under repeated loading used at lnec. Proceedings of the European Symposium Euroflex 1993. 1996: 45-51.

28. Czyczula, W., P. Koziol and D. Blaszkiewicz, On the equivalence between static and dynamic railway track response and on the euler-bernoulli and timoshenko beams analogy. Shock and Vibration, 2017. 2017: p. 13.

29. Dahlberg, T., Some railroad settlement models - a critical review. Proceedings of the Institution of Mechanical Engineers, Part F: Journal of Rail and Rapid Transit, 2001. 215(4): p. 289-300.

30. Dahlberg, T., Railway track settlements-a literature review, in Report for the EU project SUPERTRACK. Division of Solid Mechanics, IKP. Linköping University. Linköping. Sweden. 2003.

31. Dahlberg, T., Railway track stiffness variations - consequences and countermeasures. International Journal of Civil Engineering, 2010. 8(1): p. 1-12.

32. Dimitrovová, Z. and J. Varandas, Critical velocity of a load moving on a beam with a sudden change of foundation stiffness: Applications to high-speed trains. Computers \& Structures, 2009. 87(19-20): p. 1224-1232.

33. Ding, H., L.-Q. Chen and S.-P. Yang, Convergence of galerkin truncation for dynamic response of finite beams on nonlinear foundations under a moving load. Journal of Sound and Vibration, 2012. 331(10): p. 2426-2442.

34. Esmaeili, M., H. Heydari-Noghabi and M. Kamali. Numerical investigation of railway transition zones stiffened with auxiliary rails. Proceedings of the Institution of Civil EngineersTransport. 2018: 1-10.

35. Esmaeili, M., J. A. Zakeri and M. Babaei, Laboratory and field investigation of the effect of geogrid-reinforced ballast on railway track lateral resistance. Geotextiles and Geomembranes, 2017. 45(2): p. 23-33.

36. Estaire, J., V. Cuéllar and J. Cámara. Settlement laws of bed layers of a ballast track as determined in 1: 1 scale models performed in cedex track box. Proceedings of the Int. Conf. Transportation Geotechnics and Geoecology. 2017.

37. Estaire, J., V. Cuéllar and M. Santana, Testing railway tracks at 1: 1 scale at cedex track box. Proceedings of the Intern. Cong. on High-Speed Rail. Technologies and Long Term Impacts, 2017.

38. Estaire, J. and M. Santana, Large direct shear tests performed with fresh ballast, in Railroad ballast testing and properties. 2018, ASTM International.

39. Esveld, C., Modern railway track, 2nd editon. Delft university of technology. 2001.

40. Esveld, C., The significance of track resilience. Eur. Railway Rev. News, 2009. 10(1420): p. 28.

41. Esveld, C. Recent developments in high-speed track. Proceedings of the 1st Int. Conf. on Road and Rail Infrastructure. 2010.

42. Esveld, C., V. Markine and M. Duškov. Feasibility of eps as a lightweight sub-base material in railway track structures. Proceedings of the 3rd international conference on EPS Geofoam. 2001: 1-10. 
43. Fara, A., Transition zones for railway bridges: A study of the sikån bridge. Master`s thesis. Sweden; Luleå University of Technology; 2014.

44. Fortunato, E., A. Paixão and R. Calçada, Railway track transition zones: Design, construction, monitoring and numerical modelling. International Journal of Railway Technology, 2013. 2(4): p. 33-58.

45. Frohling, R., H. Scheffel and W. Ebersöhn, The vertical dynamic response of a rail vehicle caused by track stiffness variations along the track. Vehicle System Dynamics, 1996. 25(S1): p. $175-187$.

46. Frohling, R. D., Deterioration of railway track due to dynamic vehicle loading and spatially varying track stiffness. PhD thesis. University of Pretoria, South Africa; 1997.

47. Froio, D., E. Rizzi, F. M. Simões and A. P. Da Costa, Universal analytical solution of the steadystate response of an infinite beam on a pasternak elastic foundation under moving load. International Journal of Solids and Structures, 2018. 132: p. 245-263.

48. Gallage, C., B. Dareeju and M. Dhanasekar. State-of-the-art: Track degradation at bridge transitions. Proceedings of the 4th international conference on structural engineering and construction management 2013. 2013: 40-52.

49. Gallego Giner, I. and A. López Pita, Numerical simulation of embankment-structure transition design. Proceedings of the Institution of Mechanical Engineers, Part F: Journal of Rail and Rapid Transit, 2009. 223(4): p. 331-343.

50. Gallego Giner, I., A. López Pita, E. W. Vieira Chaves and A. M. Rivas Álvarez. Design of embankment-structure transitions for railway infrastructure. Proceedings of the Institution of Civil Engineers-Transport. 2012; 165: 27-37.

51. Gallego, I., J. Muñoz, A. Rivas and S. Sanchez-Cambronero, Vertical track stiffness as a new parameter involved in designing high-speed railway infrastructure. Journal of transportation engineering, 2011. 137(12): p. 971-979.

52. Galvín, P., A. Romero and J. Dominguez, Vibrations induced by hst passage on ballast and nonballast tracks. Soil Dynamics and Earthquake Engineering, 2010. 30(9): p. 862-873.

53. Galvín, P., A. Romero and J. Domínguez, Fully three-dimensional analysis of high-speed traintrack-soil-structure dynamic interaction. Journal of Sound and Vibration, 2010. 329(24): p. 5147-5163.

54. Germonpré, M., G. Degrande and G. Lombaert. A track model for the prediction of groundborne vibrations due to parametric excitation. Proceedings of the 10th International Conference on Structural Dynamics. 2017; 199: 2663-2668.

55. Gundavaram, D. and S. K. K. Hussaini, Polyurethane-based stabilization of railroad ballast-a critical review. International Journal of Rail Transportation, 2019: p. 1-22.

56. Heydari-Noghabi, H., J. N. Varandas, M. Esmaeili and J. Zakeri, Investigating the influence of auxiliary rails on dynamic behavior of railway transition zone by a $3 \mathrm{~d}$ train-track interaction model. Latin American Journal of Solids and Structures, 2017. 14: p. 2000-2018.

57. Heydari-Noghabi, H., J. Zakeri, M. Esmaeili and J. Varandas, Field study using additional rails and an approach slab as a transition zone from slab track to the ballasted track. Proceedings of the Institution of Mechanical Engineers, Part F: Journal of Rail and Rapid Transit, 2018. 232(4): p. $970-978$.

58. Hölscher, P. and P. Meijers, Literature study of knowledge and experience of transition zones. Delft: report, 2007(415990-0011).

59. $\mathrm{Hu}, \mathrm{P}$., C. Zhang, S. Wen and Y. Wang, Dynamic responses of high-speed railway transition zone with various subgrade fillings. Computers and Geotechnics, 2019. 108: p. 17-26.

60. Huang, H. and B. Brennecke, Track stiffness transition zone studied with three-dimensional sandwich track model. Transportation Research Record: Journal of the Transportation Research Board, 2013(2374): p. 136-142.

61. Huang, H., E. Tutumluer, Y. M. Hashash and J. Ghaboussi. Discrete element modeling of aggregate behavior in fouled railroad ballast. Proceedings of the $2009 \mathrm{GeoHunan}$ International Conference-Recent Advancement in Soil Behavior, In Situ Test Methods, Pile Foundations, and Tunneling. 2009: 33-41.

62. Hunt, H. and Winkler. Settlement of railway track near bridge abutments.(third paper in young railway engineer of the year (1996) award). Proceedings of the Institution of Civil Engineers- 
Transport. 1997; 123: 68-73.

63. Hussaini, S. K. K., B. Indraratna and J. S. Vinod, A laboratory investigation to assess the functioning of railway ballast with and without geogrids. Transportation Geotechnics, 2016. 6: p. 45-54.

64. Hyslip, J. P., D. Li and C. McDaniel. Railway bridge transition case study. Proceedings of the 8th International Conference (BCR2A'09) University of Illinois, Urbana-Champaign. 2009.

65. Indraratna, B. and D. Ionescu. State of the art large scale testing of ballast. Proceedings of the Conference on Railway Engineering, Adelaide, Australia. 2000; 24: 24.1-24.13.

66. Indraratna, B., H. Khabbaz, W. Salim and D. Christie, Geotechnical properties of ballast and the role of geosynthetics. Proceedings of the ICE: Ground Improvement, 2006. 10(3): p. 91101.

67. Indraratna, B., J. Lackenby and D. Christie, Effect of confining pressure on the degradation of ballast under cyclic loading. Institution of Civil Engineers: Geotechnique, 2005. 55(4): p. 325328.

68. Indraratna, B., N. T. Ngo and C. Rujikiatkamjorn, Deformation of coal fouled ballast stabilized with geogrid under cyclic load. Journal of Geotechnical and Geoenvironmental Engineering, 2013. 139(8): p. 1275-1289.

69. Indraratna, B. and T. Ngo, Ballast railroad design: SMART-UOW Approach. Vol. First edition. 2018, Boca Raton: CRC Press.

70. Indraratna, B., S. Nimbalkar, D. Christie, C. Rujikiatkamjorn and J. Vinod, Field assessment of the performance of a ballasted rail track with and without geosynthetics. Journal of Geotechnical and Geoenvironmental Engineering, 2010. 136(7): p. 907-917.

71. Indraratna, B., S. Nimbalkar and T. Neville, Performance assessment of reinforced ballasted rail track. Proceedings of the ICE: Ground Improvement, 2014. 167(1): p. 24-34.

72. Indraratna, B., Y. Qi, T. N. Ngo, C. Rujikiatkamjorn, T. Neville, F. B. Ferreira and A. Shahkolahi, Use of geogrids and recycled rubber in railroad infrastructure for enhanced performance. Geosciences, 2019. 9(1): p. 30.

73. Indraratna, B., Q. Sun and J. Grant, Behaviour of subballast reinforced with used tyre and potential application in rail tracks. Transportation Geotechnics, 2017. 12: p. 26-36.

74. Indraratna, B., Q. Sun, N. T. Ngo and C. Rujikiatkamjorn, Current research into ballasted rail tracks: Model tests and their practical implications. Australian Journal of Structural Engineering, 2017. 18(3): p. 204-220.

75. Indraratna, B., Y. Sun and S. Nimbalkar, Laboratory assessment of the role of particle size distribution on the deformation and degradation of ballast under cyclic loading. Journal of geotechnical and geoenvironmental engineering, 2016. 142(7): p. 04016016.

76. Insa, R., P. Salvador, J. Inarejos and A. Roda, Analysis of the influence of under sleeper pads on the railway vehicle/track dynamic interaction in transition zones. Proceedings of the Institution of Mechanical Engineers, Part F: Journal of Rail and Rapid Transit, 2012. 226(4): p. 409-420.

77. Ionescu, D., Evaluation of the engineering behaviour of railway ballast. 2004.

78. Iwnicki, S., S. Grassie and W. Kik, Track settlement prediction using computer simulation tools. Project report. Manchester Metropolitan University; 2000.

79. J. Pires, H.T.M. Phuong, A.G. Dumont, M. Vajdić, S. Lenart and I. S. Oslaković, Smartrail del 3.2 rehabilitation of open tracks and transition zones. Project report. 7th Framework Programme; 2014.

80. Jayasuriya, C., B. Indraratna and T. N. Ngo, Experimental study to examine the role of under sleeper pads for improved performance of ballast under cyclic loading. Transportation Geotechnics, 2019. 19: p. 61-73.

81. Kang, Y., S. Yang, H. Lee, Y. Kim, S. Jang and E. Kim, A study of track and train dynamic behavior of transition zone between concrete slab track and ballasted track. Report. Korea Railroad Research Institute, Uiwang, South Korea; 2008.

82. Kennedy, J., P. Woodward, G. Medero and M. Banimahd, Reducing railway track settlement using three-dimensional polyurethane polymer reinforcement of the ballast. Construction and Building Materials, 2013. 44: p. 615-625.

83. Kerr, A. D. and L. A. Bathurst, A method for upgrading the performance at track transitions for 
high-speed service. Report. U.S. Department of Transportation; 2001.

84. Kerr, A. D. and B. E. Moroney, Track transition problems and remedies. Bulletin American Railway Engineering Association, 1993(742): p. 267-298.

85. Koch, E., P. Hudacsek, R. Szepesházi and O. Kegyes - Brassai, 3d modelling of train - track interaction at bridge transition, in XVI Danube - European Conference on Geotechnical Engineering. 2018. p. 695-700.

86. Labrado Palomo, M., F. Roca Barceló, F. Ribes Llario and J. Real Herráiz, Effect of vehicle speed on the dynamics of track transitions. Journal of Vibration and Control, 2018. 24(21): p. 5118-5128.

87. Lackenby, J., B. Indraratna, G. McDowell and D. Christie, Effect of confining pressure on ballast degradation and deformation under cyclic triaxial loading. Institution of Civil Engineers: Geotechnique, 2007. 57(6): p. 527-536.

88. Lazorenko, G., A. Kasprzhitskii, Z. Khakiev and V. Yavna, Dynamic behavior and stability of soil foundation in heavy haul railway tracks: A review. Construction and Building Materials, 2019. 205: p. 111-136.

89. Le Pen, L. and W. Powrie, Contribution of base, crib, and shoulder ballast to the lateral sliding resistance of railway track: A geotechnical perspective. Proceedings of the Institution of Mechanical Engineers, Part F: Journal of Rail and Rapid Transit, 2011. 225(2): p. 113-128.

90. Lei, X., High speed railway track dynamics. 2017: Springer.

91. Lei, X. and L. Mao, Dynamic response analyses of vehicle and track coupled system on track transition of conventional high speed railway. Journal of Sound Vibration, 2004. 271: p. 11331146.

92. Lei, X. and B. Zhang, Influence of track stiffness distribution on vehicle and track interactions in track transition. Proceedings of the Institution of Mechanical Engineers, Part F: Journal of Rail and Rapid Transit, 2010. 224(6): p. 592-604.

93. Lei, X. and B. Zhang, Analyses of dynamic behavior of track transition with finite elements. Journal of Vibration and Control, 2011. 17(11): p. 1733-1747.

94. Li, D., Deformations and remedies for soft railroad subgrades subjected to heavy axle loads, in Advances in transportation and geoenvironmental systems using geosynthetics. 2000. p. 307321.

95. Li, D. and D. Davis, Transition of railroad bridge approaches. Journal of Geotechnical and Geoenvironmental Engineering, 2005. 131(11): p. 1392-1398.

96. Li, D., J. Hyslip, T. Sussmann and S. Chrismer, Railway geotechnics. 2016: CRC Press.

97. Li, D., D. Otter and G. Carr, Railway bridge approaches under heavy axle load traffic: Problems, causes, and remedies. Proceedings of the Institution of Mechanical Engineers, Part F: Journal of Rail and Rapid Transit, 2010. 224(5): p. 383-390.

98. $\mathrm{Li}, \mathrm{Z}$. and T. Wu, Vehicle/track impact due to passing the transition between a floating slab and ballasted track, in Noise and vibration mitigation for rail transportation systems. 2008, Springer. p. $94-100$.

99. Lima, A. d. O., M. Dersch, Y. Qian, E. Tutumluer and J. Edwards. Laboratory evaluation of under-ballast mat effectiveness to mitigate differential movement problem in railway transition zones. Proceedings of the 10th International Conference on Bearing Capacity of Roads, Railways and Airfields. 2017.

100. Long, J. H., S. M. Olson, T. D. Stark and E. A. Samara, Differential movement at embankmentbridge structure interface in illinois. Transportation Research Record, 1998. 1633(1): p. 53-60.

101. Luna, R., Evaluation of bridge approach slabs, performance and design. 2004.

102. Lundqvist, A. and T. Dahlberg, Load impact on railway track due to unsupported sleepers. Proceedings of the Institution of Mechanical Engineers, Part F: Journal of Rail and Rapid Transit, 2005. 219(2): p. 67-77.

103. Lundqvist, A., R. Larsson and T. Dahlberg, Influence of railway track stiffness variations on wheel/rail contact force. Track for High-Speed Railways, Porto, Portugal, 2006.

104. Manzanas, J., J. Moreno, V. Cuellar, M. Andreu and F. Navarro. Cedex's experimental facility for testing railway tracks. Proceedings of the 14th European Conference on Soil Mechanics and Geotechnical Engineering, Madrid, Spain. 2007: 2037-2055.

105. McDowell, G. R. and H. Li, Discrete element modelling of scaled railway ballast under triaxial 
conditions. Granular matter, 2016. 18(3): p. 66.

106. Mishra, D., H. Boler, E. Tutumluer, W. Hou and J. P. Hyslip, Deformation and dynamic load amplification trends at railroad bridge approaches: Effects caused by high-speed passenger trains. Transportation research record, 2017. 2607(1): p. 43-53.

107. Mishra, D., Y. Qian, H. Huang and E. Tutumluer, An integrated approach to dynamic analysis of railroad track transitions behavior. Transportation Geotechnics, 2014. 1(4): p. 188-200.

108. Mishra, D., E. Tutumluer, H. Boler, J. Hyslip and T. Sussmann, Railroad track transitions with multidepth deflectometers and strain gauges. Transportation Research Record: Journal of the Transportation Research Board, 2014(2448): p. 105-114.

109. Mishra, D., E. Tutumluer, T. D. Stark, J. P. Hyslip, S. M. Chrismer and M. Tomas, Investigation of differential movement at railroad bridge approaches through geotechnical instrumentation. Journal of Zhejiang University SCIENCE A, 2012. 13(11): p. 814-824.

110. Momoya, Y., E. Sekine and F. Tatsuoka, Deformation characteristics of railway roadbed and subgrade under moving-wheel load. Soils and Foundations, 2005. 45(4): p. 99-118.

111. Momoya, Y., T. Takahashi and T. Nakamura, A study on the deformation characteristics of ballasted track at structural transition zone by multi-actuator moving loading test apparatus. Transportation Geotechnics, 2016. 6: p. 123-134.

112. Namura, A., Y. Kohata and S. Miura, Effect of sleeper size on ballasted track settlement. Quarterly Report of RTRI, 2004. 45(3): p. 156-161.

113. Namura, A. and T. Suzuki, Evaluation of countermeasures against differential settlement at track transitions, in Quarterly Report of RTRI. 2007. p. 176-182.

114. Nassif, H., N. Vittilo and T. Abu Amra. Analysis and design of bridge approach and transition slabs in new jersey. Proceedings of the TRB 2003 Annual Meeting. 2003.

115. Navaratnarajah, S. K., B. Indraratna and N. T. Ngo, Influence of under sleeper pads on ballast behavior under cyclic loading: Experimental and numerical studies. Journal of Geotechnical and Geoenvironmental Engineering, 2018. 144(9): p. 04018068.

116. Ngo, N. T., B. Indraratna and C. Rujikiatkamjorn, Micromechanics-based investigation of fouled ballast using large-scale triaxial tests and discrete element modeling. Journal of Geotechnical and Geoenvironmental Engineering, 2016. 143(2): p. 04016089.

117. Ngo, N. T., B. Indraratna and C. Rujikiatkamjorn, Simulation ballasted track behavior: Numerical treatment and field application. International Journal of Geomechanics, 2016. 17(6): p. 04016130.

118. Ngo, N. T., B. Indraratna and C. Rujikiatkamjorn. A study of the geogrid-subballast interface via experimental evaluation and discrete element modelling. Granular Matter. 2017. 19(3): p.54.

119. Ngo, T. N., B. Indraratna and C. Rujikiatkamjorn, Improved performance of ballasted tracks under impact loading by recycled rubber mats. Transportation Geotechnics, 2019. 20: p. 100239.

120. Nicks, J. E., The bump at the end of the railway bridge. $\mathrm{PhD}$ thesis. Texas A\&M University; 2009.

121. Nishiura, D., H. Sakai, A. Aikawa, S. Tsuzuki and H. Sakaguchi, Novel discrete element modeling coupled with finite element method for investigating ballasted railway track dynamics. Computers and Geotechnics, 2018. 96: p. 40-54.

122. Paixão, A., Transition zones in railway tracks: An experimental and numerical study on the structural behaviour. PhD Thesis. Porto: University of Porto, Faculty of Engineering; 2014.

123. Paixao, A., E. Fortunato and R. Calçada, Design and construction of backfills for railway track transition zones. Proceedings of the Institution of Mechanical Engineers, Part F: Journal of Rail and Rapid Transit, 2015. 229(1): p. 58-70.

124. Paixão, A., E. Fortunato and R. Calçada, Transition zones to railway bridges: Track measurements and numerical modelling. Engineering structures, 2014. 80: p. 435-443.

125. Paixão, A., E. Fortunato and R. Calçada, A numerical study on the influence of backfill settlements in the train/track interaction at transition zones to railway bridges. Proceedings of the Institution of Mechanical Engineers, Part F: Journal of Rail and Rapid Transit, 2016. 230(3): p. 866-878.

126. Paixão, A., J. N. Varandas, E. Fortunato and R. Calçada, Numerical simulations to improve the 
use of under sleeper pads at transition zones to railway bridges. Engineering Structures, 2018. 164: p. 169-182.

127. Pita, A. L., P. F. Teixeira and F. Robuste, High speed and track deterioration: The role of vertical stiffness of the track. Proceedings of the Institution of Mechanical Engineers, Part F: Journal of Rail and Rapid Transit, 2004. 218(1): p. 31-40.

128. Plotkin, D. and D. Davis, Bridge approaches and track stiffness. Project report. U.S. Department of Transportation; 2008.

129. Puppala, A. J., E. Archeewa, S. Saride, S. Nazarian and L. Hoyos, Recommendations for design, construction, and maintenance of bridge approach slabs. Technical report. The University of Texas at Arlington; 2012.

130. Puppala, A. J., S. Saride, E. Archeewa, L. R. Hoyos and S. Nazarian, Recommendations for design, construction, and maintenance of bridge approach slabs: Technical report. The University of Texas at Arlington; 2009.

131. Puzavac, L., Z. Popović and L. Lazarević, Influence of track stiffness on track behaviour under vertical load. PROMET-Traffic \& Transportation, 2012. 24(5): p. 405-412.

132. Qian, Y., E. Tutumluer, D. Mishra and H. Kazmee, Triaxial testing and discrete-element modelling of geogrid-stabilised rail ballast. Proceedings of the Institution of Civil EngineersGround Improvement, 2018. 171(4): p. 223-231.

133. Read, D. and D. Li, Design of track transitions, in TCRP Research Results Digest. 2006.

134. Real, T., C. Zamorano, C. Hernández, J. García and J. Real, Static and dynamic behavior of transitions between different railway track typologies. KSCE Journal of Civil Engineering, 2016. 20(4): p. 1356-1364.

135. Rose, J., L. Walker and D. Li. Heavy-haul asphalt (hma) underlayment trackbeds: Pressures/deflections/materials properties measurements. Proceedings of the Proceedings of the international conference railway engineering 2002, held London, UK, July 2002-cd rom. 2002.

136. Sañudo, R., M. Cerrada, B. Alonso and L. dell'Olio, Analysis of the influence of support positions in transition zones. A numerical analysis. Construction and Building Materials, 2017. 145: p. 207-217.

137. Sañudo, R., L. Dell'Olio, J. Casado, I. Carrascal and S. Diego, Track transitions in railways: A review. Construction and Building Materials, 2016. 112: p. 140-157.

138. Sañudo, R., M. Miranda and V. Markine. The influence of train running direction and track supports position on the behaviour of transition zones. Proceedings of the 12th Conference on Transport Engineering. 2016; 18: 281-288.

139. Sasaoka, C. D. and D. Davis. Implementing track transition solutions for heavy axle load service. Proceedings of the AREMA 2005 Annual Conference, Chicago, IL. 2005.

140. Sato, Y., Japanese studies on deterioration of ballasted track. Vehicle system dynamics, 1995. 24(sup1): p. 197-208.

141. Sayeed, M. A. and M. A. Shahin, Design of ballasted railway track foundations using numerical modelling part i: Development. Canadian Geotechnical Journal, 2017(ja).

142. Seara, I. and A. G. Correia, Zonas de transição de vias-férreas. A importância de uma solução geoestrutural. 2008.

143. Selig, E. T. and D. Li, Track modulus: Its meaning and factors influencing it. Transportation Research Record, 1994(1470).

144. Selig, E. T. and J. M. Waters, Track geotechnology and substructure management. 1994: Thomas Telford.

145. Senalp, A. D., A. Arikoglu, I. Ozkol and V. Z. Dogan, Dynamic response of a finite length euler-bernoulli beam on linear and nonlinear viscoelastic foundations to a concentrated moving force. Journal of Mechanical Science and Technology, 2010. 24(10): p. 1957-1961.

146. Sew, I. D. G. S. and I. T. Y. Chin. Geotechnical solutions for high speed track embankment-a brief overview. Proceedings of the Technical Seminar Talk-PWI Annual Convention. 2001.

147. Shahraki, M., C. Warnakulasooriya and K. J. Witt, Numerical study of transition zone between ballasted and ballastless railway track. Transportation Geotechnics, 2015. 3: p. 58-67.

148. Shan, Y., B. Albers and S. A. Savidis, Influence of different transition zones on the dynamic response of track-subgrade systems. Computers and Geotechnics, 2013. 48: p. 21-28.

149. Shan, Y., Y. Shu and S. Zhou, Finite-infinite element coupled analysis on the influence of 
material parameters on the dynamic properties of transition zones. Construction and Building Materials, 2017. 148: p. 548-558.

150. Shan, Y., S. Zhou and Y. Shu, Differential settlement and soil dynamic stress of a culvertembankment transition zone due to an adjacent shield tunnel construction. KSCE Journal of Civil Engineering, 2018. 22(7): p. 2325-2333.

151. Siahaan, F., B. Indraratna, N. Ngo, C. Rujikiatkamjorn and A. Heitor, Influence of particle gradation and shape on the performance of stone columns in soft clay. Geotechnical Testing Journal, 2018. 41(6): p. 1076-1091.

152. Sol-Sánchez, M., F. Moreno-Navarro and M. C. Rubio-Gámez, The use of elastic elements in railway tracks: A state of the art review. Construction and building materials, 2015. 75: p. 293305.

153. Stanislav, L., F. B. Karmen, N.-C. Karin, M. K. Amir, K. Miha, V. Marko, C. Kangle and C. Julie, Guidelines on the use of novel construction and maintenance techniques within the operational railway environment. 2018, DESTination RAIL - Decision Support Tool for Rail Infrastructure Managers.

154. Stark, T. D. and S. T. Wilk, Root cause of differential movement at bridge transition zones. Proceedings of the Institution of Mechanical Engineers, Part F: Journal of Rail and Rapid Transit, 2016. 230(4): p. 1257-1269.

155. Stark, T. D. and L. Wynn, Reinforced railway transitions to mitigate differential displacements. American Association of Railroads, Technology Digest, TD-18-0XX, Transportation Tech. Center, Inc., Pueblo, CO, 2018.

156. Steffens, D. M., Identification and development of a model of railway track dynamic behaviour. Master`s thesis. Queensland University of Technology; 2005.

157. Su, L.-J., C. Rujikiatkamjorn and B. Indraratna, An evaluation of fouled ballast in a laboratory model track using ground penetrating radar. Geotechnical Testing Journal, 2010. 33(5): p. 343350.

158. Suiker, A. S. and R. de Borst, A numerical model for the cyclic deterioration of railway tracks. International journal for numerical methods in engineering, 2003. 57(4): p. 441-470.

159. Teixeira, P. F., C. Casas-Esplugas, A. López-Pita and L. Ubalde, Deterioration in geometric track quality on high speed lines: The experience of the madrid-seville high speed line (19922002). 2006.

160. Tennakoon, N., B. Indraratna, C. Rujikiatkamjorn, S. Nimbalkar and T. Neville, The role of ballast-fouling characteristics on the drainage capacity of rail substructure. Geotechnical Testing Journal, 2012. 35(4): p. 629-640.

161. Tutumluer, E., Y. Qian, Y. M. Hashash, J. Ghaboussi and D. D. Davis, Discrete element modelling of ballasted track deformation behaviour. International Journal of Rail Transportation, 2013. 1(1-2): p. 57-73.

162. Tutumluer, E., T. D. Stark, D. Mishra and J. P. Hyslip. Investigation and mitigation of differential movement at railway transitions for us high speed passenger rail and joint passenger/freight corridors. Proceedings of the Joint Rail Conference. 2012: 75-84.

163. Van Dalen, K., Ground vibration induced by a high-speed train running over inhomogeneous subsoil, transition radiation in two-dimensional inhomogeneous elastic systems. Master`s thesis. Department of Structural Engineering, TUDelft; 2006.

164. Varandas, J.N., P. Hölscher and M. Silva. A settlement model for ballast at transition zones. Proceedings of the 10th international conference on computational structures technology. 2010.

165. Varandas, J., P. Hölscher and M. Silva, Three-dimensional track-ballast interaction model for the study of a culvert transition. Soil Dynamics and Earthquake Engineering, 2016. 89: p. 116127.

166. Varandas, J. N., Long-term behaviour of railway transitions under dynamic loading application to soft soil sites. PhD thesis. Lisboa: Faculdade de Ciências e Tecnologia da Universidade Nova de Lisboa; 2013.

167. Varandas, J. N., P. Hölscher and M. A. Silva, Dynamic behaviour of railway tracks on transitions zones. Computers \& structures, 2011. 89(13-14): p. 1468-1479.

168. Wahls, H. E., Design and construction of bridge approaches. Vol. 159. 1990: Transportation Research Board. 
169. Walker, R. T. and B. Indraratna, Moving loads on a viscoelastic foundation with special reference to railway transition zones. International Journal of Geomechanics, 2018. 18(11): p. 04018145.

170. Wang, H., L. Chang and V. Markine, Structural health monitoring of railway transition zones using satellite radar data. Sensors, 2018. 18(2): p. 413.

171. Wang, H. and V. Markine, Modelling of the long-term behaviour of transition zones: Prediction of track settlement. Engineering Structures, 2018. 156: p. 294-304.

172. Wang, H., V. Markine and X. Liu, Experimental analysis of railway track settlement in transition zones. Proceedings of the Institution of Mechanical Engineers, Part F: Journal of rail and rapid transit, 2018. 232(6): p. 1774-1789.

173. Wang, H., V. Markine, I. Shevtsov and R. Dollevoet. Analysis of the dynamic behaviour of a railway track in transition zones with differential settlement. Proceedings of the joint rail conference. 2015: V001T01A024-V001T01A024.

174. Wang, H. and V. L. Markine, Methodology for the comprehensive analysis of railway transition zones. Computers and Geotechnics, 2018. 99: p. 64-79.

175. Wang, H., M. Silvast, V. Markine and B. Wiljanen, Analysis of the dynamic wheel loads in railway transition zones considering the moisture condition of the ballast and subballast. Applied Sciences, 2017. 7(12): p. 1208.

176. Wei, K., Z.-x. Liu, Y.-c. Liang and P. Wang, An investigation into the effect of temperaturedependent stiffness of rail pads on vehicle-track coupled vibrations. Proceedings of the Institution of Mechanical Engineers, Part F: Journal of Rail and Rapid Transit, 2017. 231(4): p. 444-454.

177. Wilk, S. T., T. D. Stark and J. G. Rose, Evaluating tie support at railway bridge transitions. Proceedings of the Institution of Mechanical Engineers, Part F: Journal of Rail and Rapid Transit, 2016. 230(4): p. 1336-1350.

178. Witt, S., The influence of under sleeper pads on railway track dynamics. Master`s Thesis. Dept. of Management and Engineering, Linkoping Univ. Institute of Technology; 2008.

179. Woldringh, R. and B. New. Embankment design for high speed trains on soft soils. Proceedings of the 12th European Conference on Soil Mechanics and Geotechnical Engineering, Holland Railconsult. 1999.

180. Woodward, P., J. Kennedy and G. Medero, Three-dimensional track reinforcement using polymer geocomposites. Proceedings of the American Railway Engineering and Maintenance of Way Association (AREMA), Chicago, USA, 2009.

181. Woodward, P., J. Kennedy and G. Medero. Improving the safety of the railway track infrastructure using insitu polyurethane geocomposites. Proceedings of the AREMA Annual Meeting, Number AREMA, Orlando, FL. 2010.

182. Woodward, P., J. Kennedy, G. Medero and M. Banimahd, Application of in situ polyurethane geocomposite beams to improve the passive shoulder resistance of railway track. Proceedings of the Institution of Mechanical Engineers, Part F: Journal of Rail and Rapid Transit, 2012. 226(3): p. 294-304.

183. Woodward, P., J. Kennedy, G. Medero and M. Banimahd, Maintaining absolute clearances in ballasted railway tracks using in situ three-dimensional polyurethane geocomposites. Proceedings of the Institution of Mechanical Engineers, Part F: Journal of Rail and Rapid Transit, 2012. 226(3): p. 257-271.

184. Wu, Q., M. Spiryagin, C. Cole and T. McSweeney, Parallel computing in railway research. International Journal of Rail Transportation, 2018: p. 1-24.

185. Yu, H., Z. Zhang, J. Chen, A. Bobet, M. Zhao and Y. Yuan, Analytical solution for longitudinal seismic response of tunnel liners with sharp stiffness transition. Tunnelling and Underground Space Technology, 2018. 77: p. 103-114.

186. Zakeri, J.-A. and V. Ghorbani, Investigation on dynamic behavior of railway track in transition zone. Journal of Mechanical Science and Technology, 2011. 25(2): p. 287-292.

187. Zaman, M., A. Gopalasingam and J. G. Laguros, Consolidation settlement of bridge approach foundation. Journal of Geotechnical Engineering, 1991. 117(2): p. 219-240.

188. Zarembski, A. and J. Palese, Transitions eliminate impact at crossings. Railway track and structures, 2003. 99(8). 
189. Zhai, W. and H. True, Vehicle-track dynamics on a ramp and on the bridge: Simulation and measurements. Vehicle System Dynamics, 2000. 33: p. 604-615.

190. Zhai, W., K. Wang and C. Cai, Fundamentals of vehicle-track coupled dynamics. Vehicle System Dynamics, 2009. 47(11): p. 1349-1376.

191. Zhang, S., X. Xiao, Z. Wen and X. Jin, Effect of unsupported sleepers on wheel/rail normal load. Soil Dynamics and Earthquake Engineering, 2008. 28(8): p. 662-673.

192. Zhang, X., C. Zhao and W. Zhai, Dynamic behavior analysis of high-speed railway ballast under moving vehicle loads using discrete element method. International Journal of Geomechanics, 2016. 17(7): p. 04016157.

193. Zhu, J., D. Thompson and C. Jones, On the effect of unsupported sleepers on the dynamic behaviour of a railway track. Vehicle system dynamics, 2011. 49(9): p. 1389-1408.

194. Zuada Coelho, B., Dynamics of railway transition zones in soft soils. PhD thesis. Delft University of Technology; 2011. 